Portland State University

PDXScholar

$1-1-2011$

\title{
The Effects of Multiple Thematic Layers on Web Map Use by Middle School Students
}

Andrew Percy Freed

Portland State University

Follow this and additional works at: https://pdxscholar.library.pdx.edu/open_access_etds Let us know how access to this document benefits you.

\section{Recommended Citation}

Freed, Andrew Percy, "The Effects of Multiple Thematic Layers on Web Map Use by Middle School Students" (2011). Dissertations and Theses. Paper 306.

https://doi.org/10.15760/etd.306

This Thesis is brought to you for free and open access. It has been accepted for inclusion in Dissertations and Theses by an authorized administrator of PDXScholar. Please contact us if we can make this document more accessible: pdxscholar@pdx.edu. 
The Effects of Multiple Thematic Layers on Web Map Use

by Middle School Students

by

Andrew Percy Freed

A thesis submitted in partial fulfillment of the

Requirements for the degree of

Master of Science
in
Geography

Thesis Committee:

Joseph Poracsky, Chair

Teresa Bulman

David Banis

Portland State University

2011 


\begin{abstract}
Access to the to the Internet and to a variety of interactive mapping tools has increased interest among middle school teachers to use interactive maps in conjunction with learning activities. There is very little research in the area of interactive mapping in educational situations, specifically with regards to layer maps that combine multiple thematic layers on a single map. This study evaluates the relationship between the number of layers present on a web-based map and middle-school students' accuracy and timeliness using the map to answer geographic questions. Additionally, this study examines the specific effect of a hill shade on student response time and accuracy when answering questions do not require any terrain information. Tests were conducted in five Portland, Oregon area middle school classrooms using Blackboard CE8 to present maps and collect responses. The results of this research indicate no significant relationship between the number of layers present on a web map and middle school students’ accuracy or response times while using the map to answer questions. The presence of a hillshade layers does not significantly impact the students' response times or accuracy while answering questions while using the map either.
\end{abstract}




\section{Acknowledgements}

I can now see the advantage to starting the program with a research agenda and a thesis topic in mind. However, I do not regret the ambling and circuitous route that I took. I enjoyed every moment of my coursework and every interaction with fellow students and the faculty. I'm indebted to them for sharing their interests, talents, and a sense of the community that should be a part of graduate school. Thanks especially to my committee members, especially Joe, for their patience and humor during the last few years.

My committee helped me succeed. Dr. Bulman provided crucial insight gearing my work towards students, interacting with and searching for potential teachers to work with, and in making my voice clear in my writing. David Banis helped inspire my final topic (as well as several other potential topics along the way), provided moral support, and provided guidance while my advisor was on sabbatical. Lastly, special thanks to Dr. Poracsky for sharing his excitement for cartography, his willingness to let me take my time, his understanding of the pressures of life, and his guidance through this process.

My wife and family have been incredibly supportive through this process. The birth of two beautiful daughters certainly slowed things down. However, I would like to thank them for sharing their time, especially this last year, while things came together.

Lastly, I want to thank Eric Marsh, Carissa Jangard Aimee Saddler, Brian Kelly, David Turnoy, Meghan Johnson, Megan Ciolli, and their respective students for volunteering their time to help me test these maps. Without them, I would be without data, no results, and no conclusion. Hopefully this document marks the conclusion. 
Table of Contents

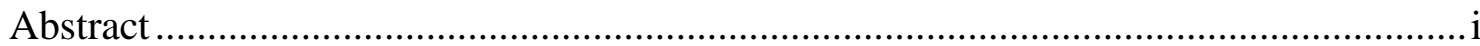

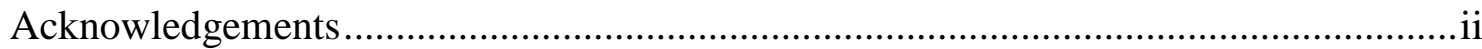

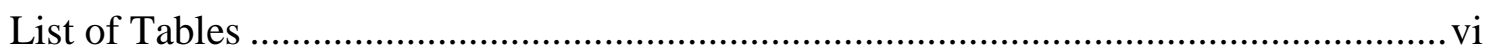

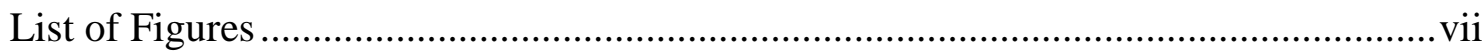

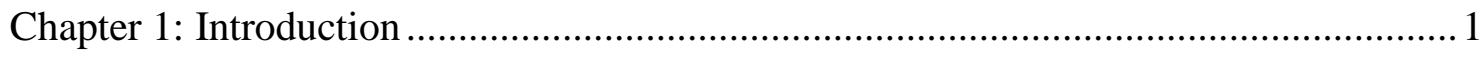

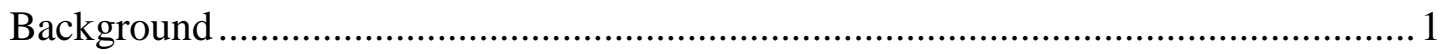

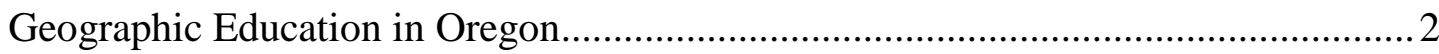

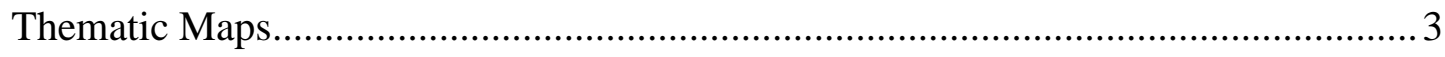

Chapter 2: Literature Review........................................................................ 7

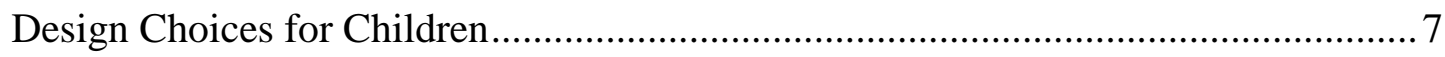

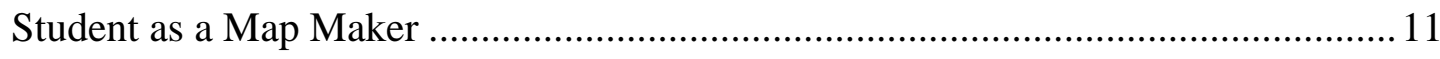

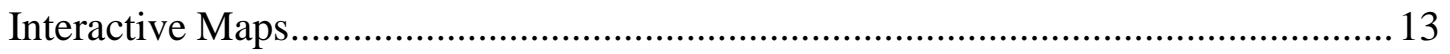

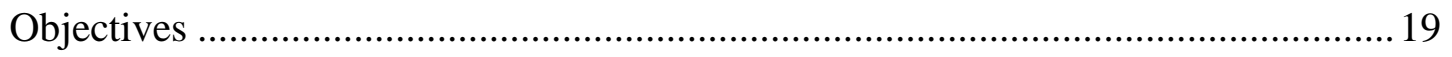

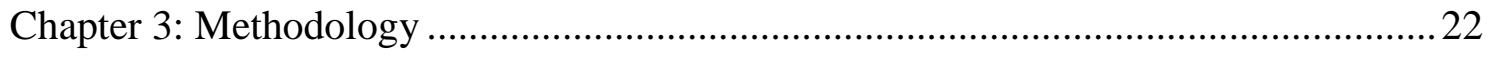

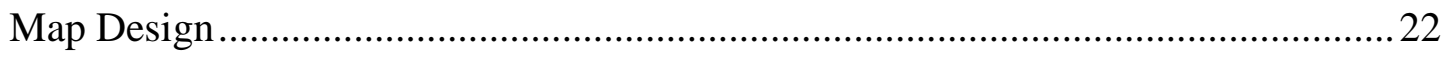

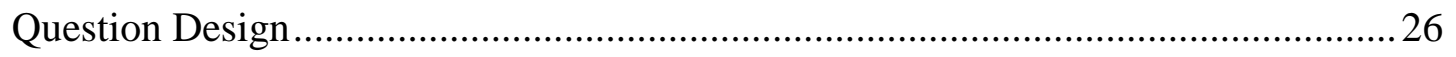

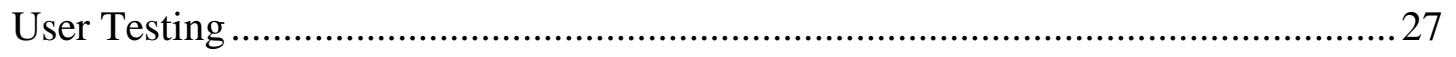

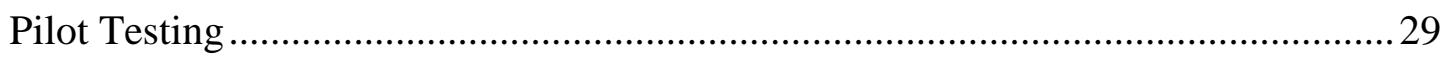

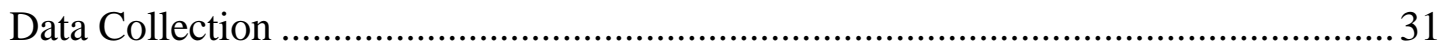


Data Analysis

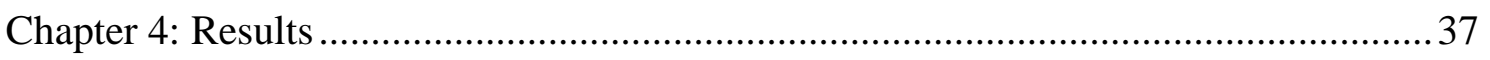

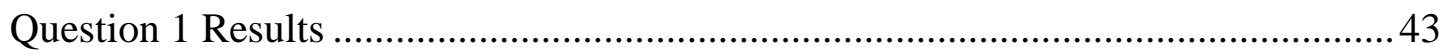

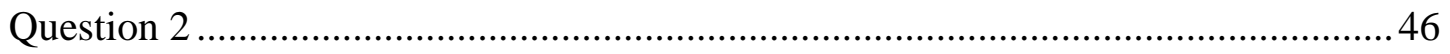

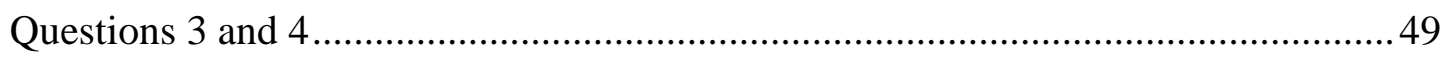

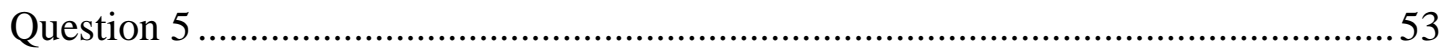

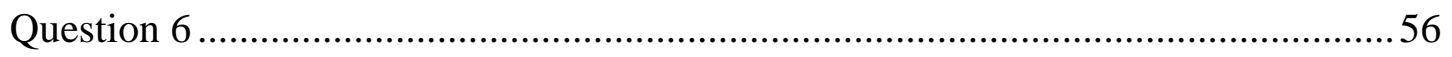

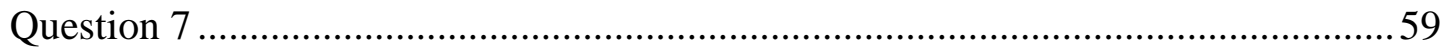

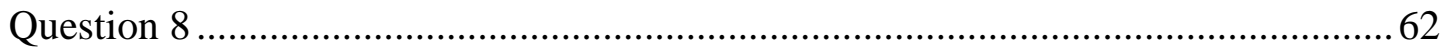

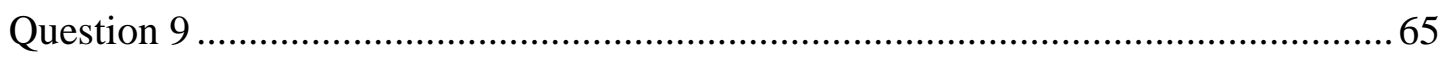

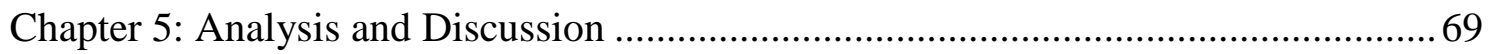

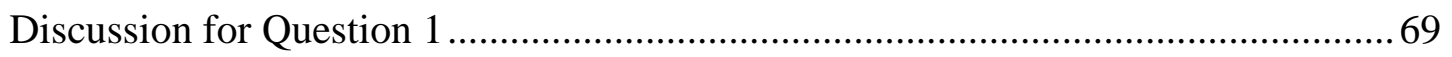

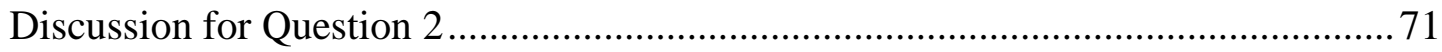

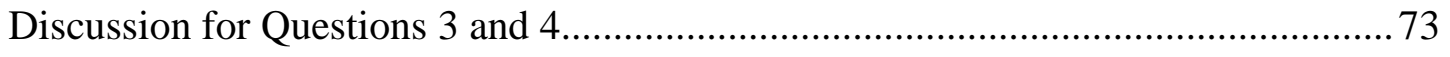

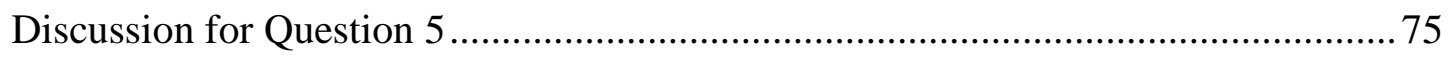

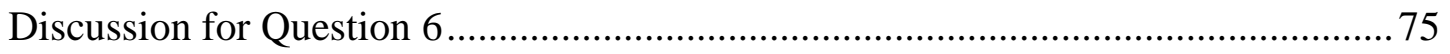

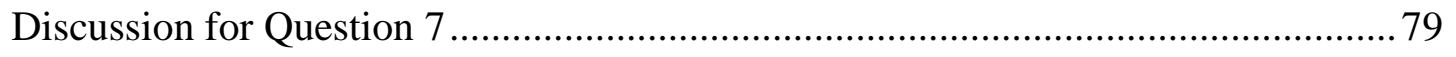

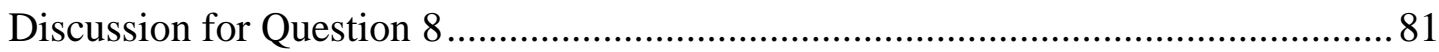

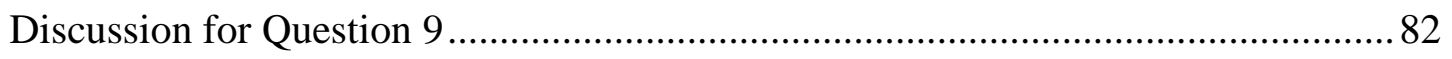

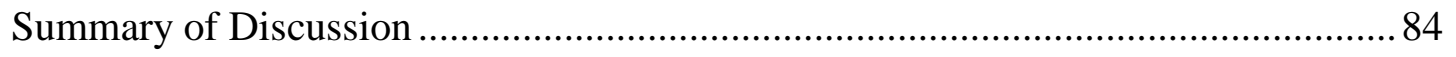

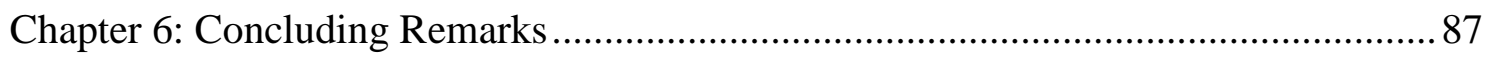

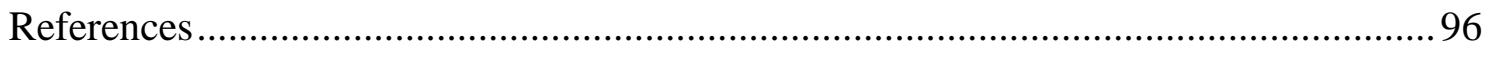


Appendix A: Design Considerations for Thematic Maps Based on Audience............... 99

Appendix B: Script for Map Introduction............................................................. 106

Appendix C: Informational Flyer.................................................................. 108

Appendix D: Sample of Map Interface and Question.............................................. 109

Appendix E: Human Subjects Research Review Committee Approval ........................ 113 


\section{List of Tables}

Table 1: Summary of Participants by School ......................................................... 32

Table 2: Analysis of Biographical Traits............................................................. 40

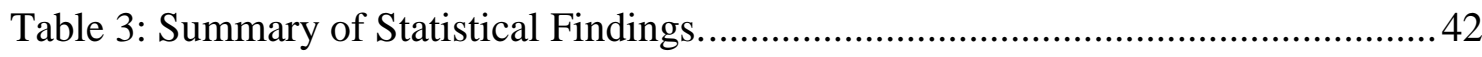

Table 4: Descriptive Statistics for Question 1, Layer Evaluation................................44

Table 5: Descriptive Statistics for Question 1, Hillshade Evaluation........................... 45

Table 6: Descriptive Statistics for Question 2, Layer Evaluation................................47

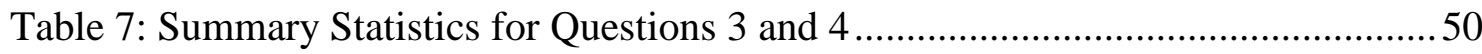

Table 8: Descriptive Statistics for Question 3, Hillshade Evaluation........................... 51

Table 9: Descriptive Statistics for Question 5, Layer Evaluation................................. 55

Table 10: Descriptive Statistics for Question 5, Hillshade Evaluation..........................55

Table 11: Descriptive Statistics for Question 6, Layer Evaluation................................57

Table 12: Descriptive Statistics for Question 7, Hillshade Evaluation.........................59

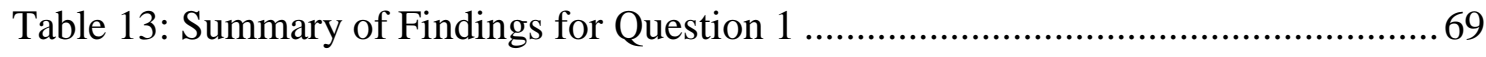

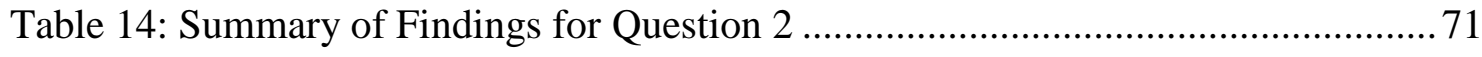

Table 15: Summary of Findings for Questions 3 \& 4............................................ 74 


\section{List of Figures}

Figure 1: A Qualitative Map.........................................................................................

Figure 2: A Quantitative Thematic Map …………………........................................ 4

Figure 3: Combining Layers to Create a Map. ……………………............................... 5

Figure 4: The Cartographic Process................................................................................. 16

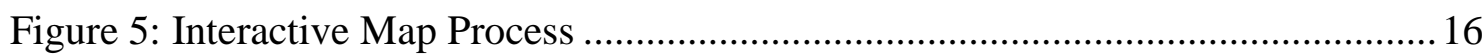

Figure 6: A Web Map Includes Many Competing Visual Elements ................................23

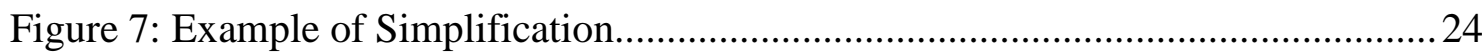

Figure 8: Example of Selection and Combination......................................................2 24

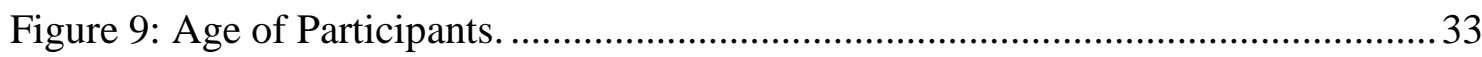

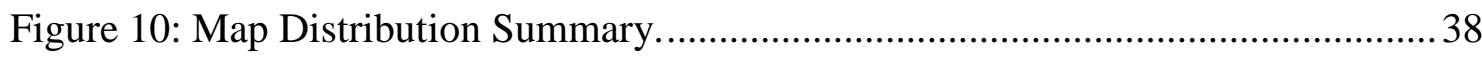

Figure 11: Map Distribution Summary Continued............................................................. 39

Figure 12: Question 1 and a Sample Map.................................................................... 43

Figure 13: Response Times For Each Map in Question 1..............................................45

Figure 14: Response Times for the Maps with Hillshades for Question 1.....................46

Figure 15: Response Times for Different Maps in Question 2......................................48

Figure 16: Response Times for Maps with and without Hillshades in Question 2.........49

Figure 17: Sample Question and Map Used in Questions 3 and 4 ................................. 50

Figure 18: Response Times for Each Map in Questions 3 and 4..................................52

Figure 19: Response Times for Maps with a Hillshade in Questions 3 and 4................53

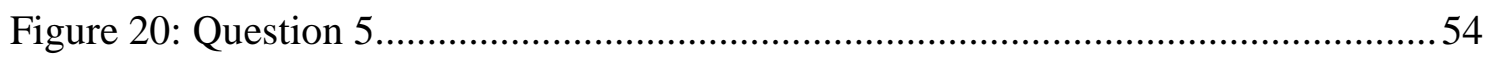

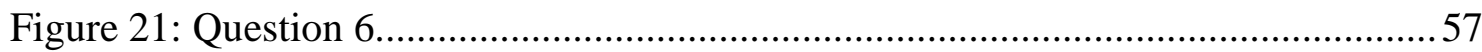


Figure 22: Question 6 Response Times per Map.............................................................. 58

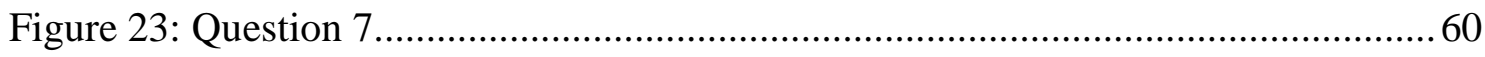

Figure 24: Response Times for Question 7................................................................. 61

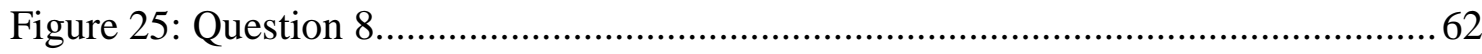

Figure 26: Map Preference Among Students in Question 8 .............................................63

Figure 27: Reason Given for Picking the Hillshade in Question 8..................................64

Figure 28: Reason Given for Picking Map without Hillshade in Question 8 ...................65

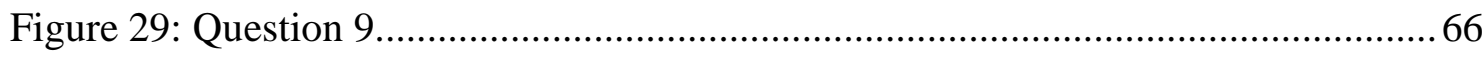

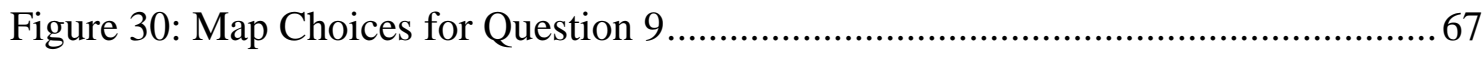

Figure 31: Reason Given for Choosing Map without the Hillshade..................................68

Figure 32: Reason Given for Choosing Map with Hillshade............................................. 68

Figure 33: Response Times for Question 2............................................................... 72

Figure 34: Response times for each map in Question 6..................................................76

Figure 35: Beef Cattle Distribution......................................................................... 77

Figure 36: Response Times for Maps in Question 7....................................................79 


\section{Chapter 1: Introduction}

The field of on-line mapping is evolving at a rapid pace and changes in the techniques, underlying technology, sources of data, and usage of maps make for a myriad of options for both the casual user and professional user alike. Access to the Internet and to a variety of interactive mapping tools has increased interest among school teachers in using interactive and on-line maps in conjunction with learning activities. However, there has been little research in the area of interactive and on-line map use in educational situations, specifically with regard to maps that combine multiple thematic layers on a single map.

This study evaluates the relationship between the number of layers present on a web-based map and middle-school students’ accuracy and response time using the map to answer geographic questions. Additionally, this study examines the specific effect of a hillshade on student response time and accuracy when answering questions that do not require any terrain information.

\section{Background}

Between 2006 and 2008, the Oregon Geographic Alliance collaborated with middle school instructors and students from Portland State University to create the Student Atlas of Oregon. The student atlas is a collection of thematic maps and illustrated geographic concepts that complement the curriculum taught to upper elementary and middle school students in Oregon. Map topics for the student atlas were selected based on examples taken from other child-oriented atlases and from current 
curricula, then further reduced to a collection that best met the needs of the widest group of students.

The Atlas was static; the maps were either print or electronic documents in Portable Document Format (PDF). When polled about features for an on-line version of the atlas, collaborators expressed interest in an interactive atlas, specifically one that would allow students to turn data layers on and off (Banis 2008). The ability to add data to interactive maps in the form of layers has become a popular feature among on-line mapping tools that both students and their instructors encounter outside the classroom.

\section{Geographic Education in Oregon}

Before developing a map, it is important to understand what content is identified as appropriate for upper elementary and middle school students, and what map skills they are expected to have. Educational content standards guided this research in the selection of maps and content.

In Oregon, the state's Department of Education (ODE) establishes curriculum guidelines and learning benchmarks for standardized content (ODE 2003a). These guidelines are not mandatory, and final decisions about instruction are left to local school districts (Morgan 2008). However, since the student atlas is available statewide, ODE's content standards and curriculum goals are reasonable criteria to follow for the purpose of this study. Content standards and curriculum goals establish, for example, that 5th graders are expected to "examine and understand how to prepare maps, charts, and other visual representations to locate places and interpret geographic information" 
(ODE 2005, 55). This standard is exemplified in the grade level learning targets by using "maps to determine population trends, precipitation, temperature and ethnic distribution" (ODE 2003, 15).

\section{Thematic Maps}

Thematic maps and general reference maps are the two major categories of maps widely used today. Reference maps focus on identifying a variety of geographic features, both natural and anthropogenic, with the primary focus on location (Dent 1996). As adults, we may frequently encounter a reference map in the form of a topographic map, such as a USGS Quad sheet.

In contrast, thematic maps focus on a single topic or "theme” and display either quantitative or qualitative information. Qualitative thematic maps are used to display the distribution of some phenomenon, such as downhill ski areas (Figure 1).

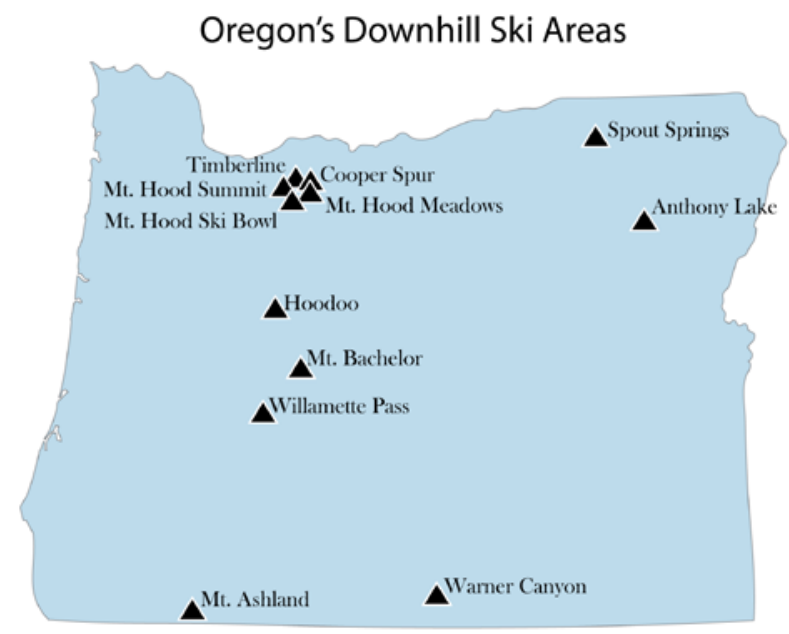

Figure 1: A Qualitative Map. This type of map is often used to show where a certain phenomenon occurs, such as downhill ski areas in this example. 
Quantitative thematic maps are used to communicate information about how much of an activity or phenomenon exists at a location. Quantitative thematic maps exist to give geographic meaning to tabular data (Dent 1996) such as the amount of rainfall at certain locations (Figure 2).

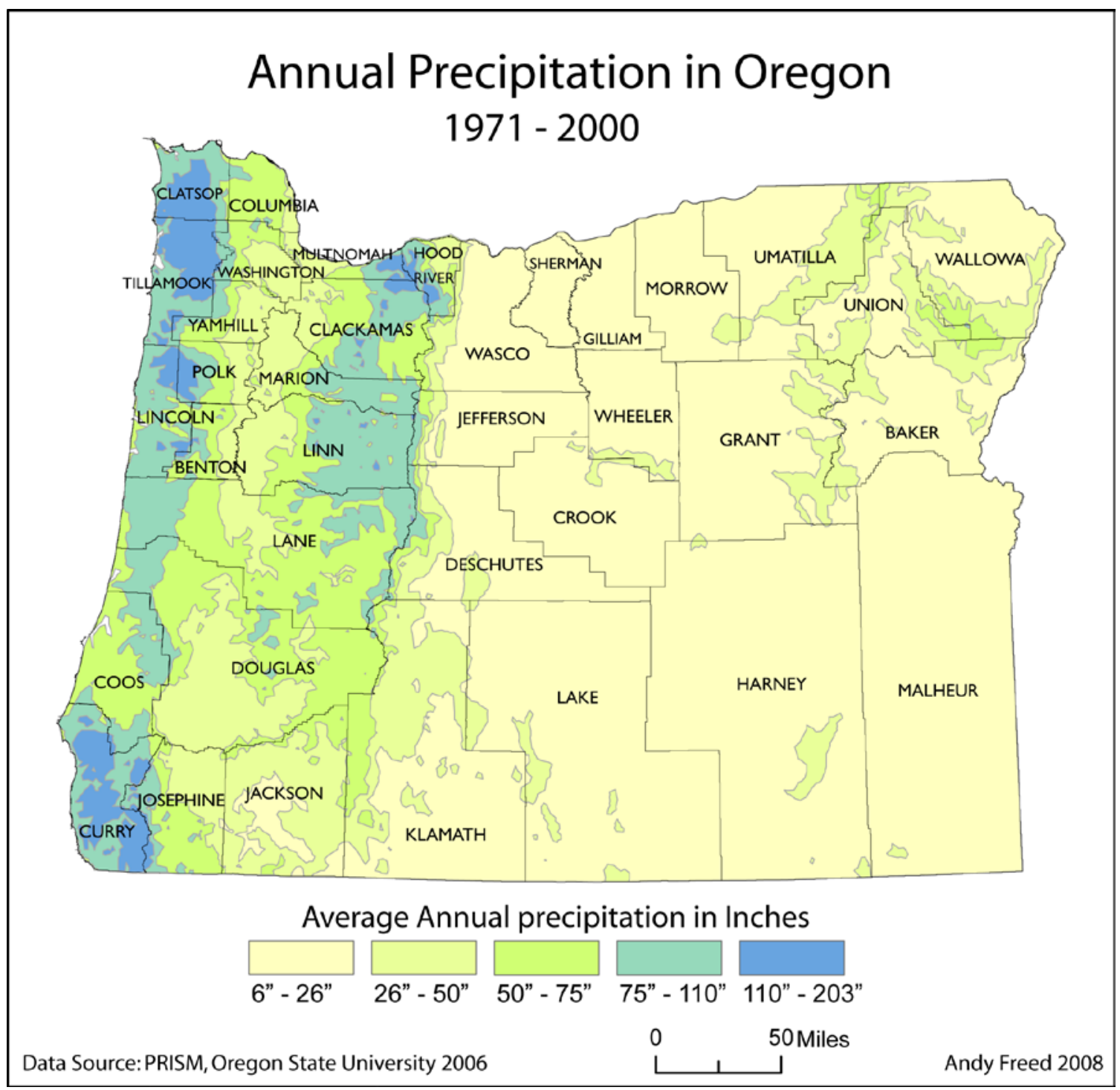

Figure 2: A Quantitative Thematic Map. This map uses area symbols to represent the amount of precipitation that parts of the state receive each year. 
The Student Atlas is largely comprised of thematic maps, so it is important to discuss this type of map and the potential for making thematic maps interactive. Constructing a thematic map involves overlaying a base map with a thematic subject, or layer. The base map should include as little geographic information as needed for the map user to understand the location and context of the thematic layer (Dent 1996). Since the advent of computer-based cartography, the information for base layers and thematic layers can be selected and combined quickly by the map maker. When a map reader uses an interactive layer map, he experiences much of the same power wielded by map makers when creating thematic maps. Figure 3 illustrates the concept of combining multiple data sources, or layers, into a single map.

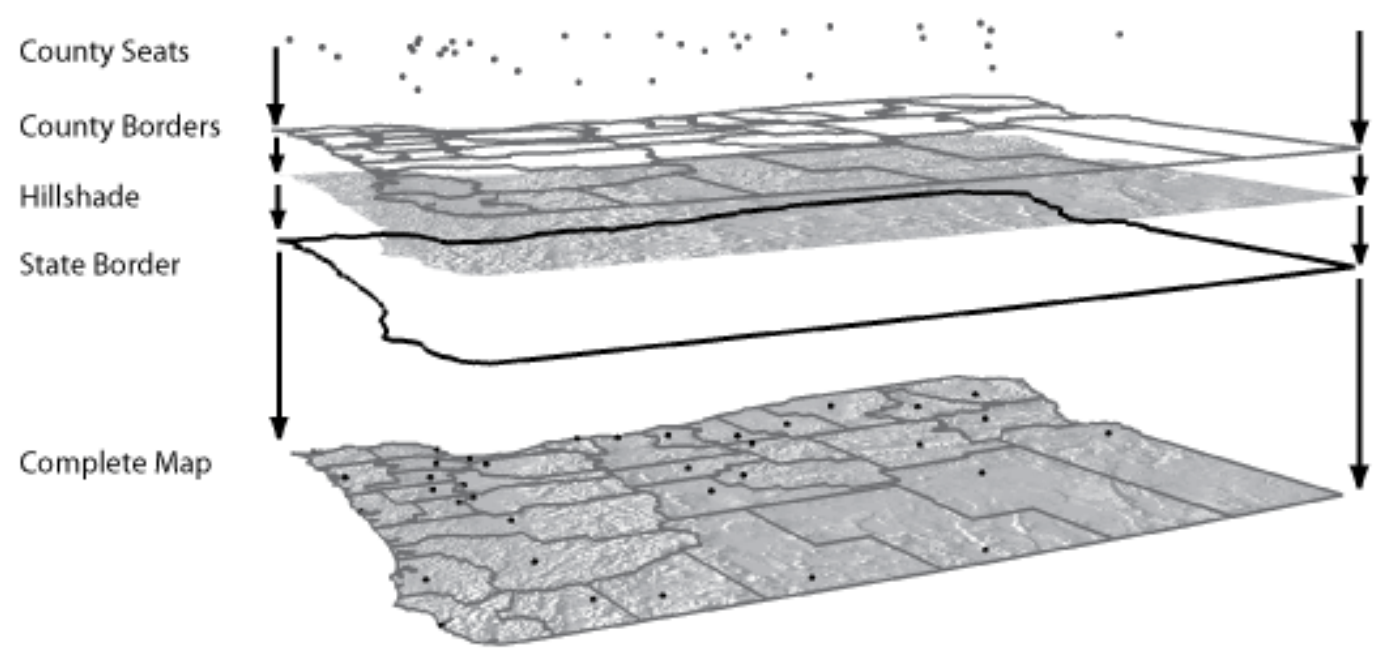

Figure 3: Combining Layers to Create a Map. Multiple data layers are combined by the map maker for a single map. With interactive maps, the map user can choose which layers comprise the final map. 
Symbology refers to how marks or symbols are used to display information on a map. Map makers must carefully choose the symbology they use to represent information on a map. The nature of the information and the scale of the map dictate appropriate symbology. When viewing a map of a state at a small scale, points are used to symbolize discrete phenomenon that exist at specific locations, such as cities. Lines are used to symbolize linear phenomena, such as roads and rivers. Area symbols are two-dimensional symbols that show areal phenomenon, such as lakes, or at a larger scale, cities (Dent 1996). There is a modest amount of research regarding the appropriate selection of symbols, including appropriate symbols for children (Miller 1982, Wiegand 2006, Michaelidou 2004, Gaspers 2007). Appendix A includes a summary of symbology guidelines. 


\section{Chapter 2: Literature Review}

When creating a map, it is important to understand who the intended users are and what media they will be using to view the map. That allows for the application of the best cartographic techniques and practices for communicating with that user in that media. Because the intended users of maps discussed in this thesis are children, and because the media to be discussed is a computer screen, the literature review is split into two sections: literature relevant to map use by children and literature relevant to the creation and use of web-based and interactive maps.

\section{Design Choices for Children}

A body of scholarly work exists investigating the use of maps by children. In the 1960s and 70s, inquiry focused on the developmental stages of children and their ability to understand symbolic representation of geographic features. Much of the work from the last 20 years involves including children in the map making process, as well as collaborative work among students. Some of the most recent work focuses on specific applications for student learning. First, I examined inquiries into the use of maps and atlases by children.

In order to improve geographic learning, we must improve our communication about geographic relationships with appropriate maps. Most of the research on designing thematic maps for children focuses on either selecting appropriate symbology or on map complexity. 
In 1965, Barbara Bartz studied a group of over 200 4th through 9th graders (ages 9 - 14) to examine how they interacted with maps and how they interpreted symbology. Bartz had students use several differently styled maps to see which symbology worked best based on their response to a series of questions. Her results led to a number of recommendations on what have become best design practices for children (Bartz 1965). Some examples of her recommendations discussed how the key should be labeled, and what should be included. She suggested that symbols in the key be the same size as those used on the map, and that some seemingly obvious items, such as water, be included as well. She also made recommendations about type and labeling, such as placing labels so they reinforce geographic location (i.e., if a city is on one side of a river, make sure that the label for that city is also on the same side of the river), and that when using font size to classify types of features, exaggerate the size even more than normal since children may not recognize the size difference. More of her recommendations have been summarized in Appendix A.

Jack Miller similarly created a set of guidelines for classroom maps based on his work with middle school students (Miller 1982). In his study, Miller gave students one of four different maps, each utilizing a different set of design choices to see which maps helped students answer questions best. Unfortunately, neither Bartz nor Miller created a map using their guidelines to retest students, and their recommendations tend to follow mapping conventions for adult audiences. For example, Dent stresses the importance of type placement being used to reinforce the location of a geographic feature (1996), and Bartz emphasizes this practice as being especially important for children (1965). 
Elementary and middle school students are already exposed to a number of thematic maps (Gaspers 2007) and research has shown that children are able to understand geographic relationships by using thematic maps (Trifonoff 1995, Gaspers 2007). Karen Trifonoff had 2nd grade students use a series of computer-based thematic maps to answer questions about differences in quantity and distribution of map objects. Responses to the questions were timed, then students were asked discussion questions for insight into their comprehension. Stephanie Gaspers used three different types of thematic maps to see which type of map best helped students understand and answer questions about population amounts and distributions. Trifonoff and Gaspers both concluded that younger students are capable of using both qualitative and quantitative thematic maps to successfully process geographic information.

Michaelidou et al. (2004) examined how students in elementary school use several types of textbook maps and analyzed students' ability to answer questions based on varying the complexity of the maps. While their research focused on grades 3-6, many of the questions used, answers found, and concepts discovered may be applied to this research. The maps used varied in scale, background complexity, number of thematic layers and methods of terrain representation. Standard practice in many textbooks is to reduce maps to the fewest number of thematic layers, a practice that Michaelidou et al. argue makes maps too simplistic and abstract to be useful. Their study measured students' ability to extract four types of geographic relationship: locations, types of geographic attributes, distribution of attributes, and relationships between locations with similar attributes. 
In their study, several nearly identical maps were used, with the exception of one map having fewer thematic layers, such as eliminating certain types of buildings. Performance differences between schools and genders were not significantly different, though there was some difference in performance between grade levels. Performance of students with maps that had multiple thematic layers was better than those with a reduced number of layers, except by fourth graders, who scored best on maps with the fewest number of layers. However, the maps with fewer layers "had a negative influence on older students (Grades 5 and 6) in extracting spatial relationships" (Michaelidou et al. 2004, 75). Student performance was better on political maps than physical maps, likely due to the simplicity of the background information. The political maps lacked topographical and landform information, which removed a competing visual element from those maps. From their results, Michaelidou et al. concluded "the practice of simplifying maps in elementary textbooks by eliminating thematic layers should be reconsidered" (Michaelidou et al. 2004, 81).

Landform representation provides an additional challenge, though it is essential for geographical context in some situations. As Peter Collier points out, "terrain portrayal is often a source of criticism for both its failure to create an impression of relief in the mind of the map user but also for its interference with the legibility of the other map information" (Collier 2003, 17). Michaelidou et al. (2004) found that shaded relief was the most useful in all cases in conveying slope and elevation for middle school aged students, but some other studies suggest that hillshades impair map readers in extracting non-landform information. Alan DeLucia's research (1972) in terrain 
portrayal used general reference maps instead of thematic maps and had participants try to locate symbols on maps. The research excluded consideration of the relationship between the terrain and other mapped phenomena. Sharon Muir (1985) found that many elementary students mistook colors used in hypsometric relief shading for vegetation instead of elevation. Patrick Wiegand (2006) sees promise in pseudo-3D displays of terrain using Digital Elevation Models (DEMs), though the efficacy is often affected by students' own experience with hills and slopes.

\section{Student as a Map Maker}

Interactive maps allow users to function to some degree as map makers. Several studies have included students in some form of map making as part of their geographic education. Leinhardt, Stainton, and Bausmith (1998) promote the benefit of having $7^{\text {th }}$ grade students construct maps because it helps them to "form a deeper appreciation of actual content of a map and the decisions, tacit ones, that are present in any map” (p. 29).

In a separate study, Bausmith and Leinhardt discuss the National Geography Standards for education and how the concept of layers is represented on maps. In this study, students worked alone or in groups to redraw maps at a different scale. Observation of students working and of the output showed that "students' success at the map enlargement task was also influenced by the extent to which they were able to recognize the interconnections between map elements" $(1998,105)$. Additionally, "as more and more layers were added to the map, more relationships between elements 
occurred, and more chances for inaccuracies to arise developed. With each added layer, it became more difficult to consider the many interconnections between elements" $(1998,105)$.

Bausmith and Leinhardt further argue that if the intention with maps is to improve student understanding of the relationships among geographic phenomena, we should not be giving them simplified maps with few layers, but instead "students should be provided with maps that have multiple layers that promote interconnections, and simplify the maps by putting less information in each layer" so that students are not flooded with information but still see enough layers to "consider the interrelationships between the layers" (Bausmith and Leinhardt 1998, 106).

What is the appropriate number of layers? Is this number always appropriate? One benefit of an interactive map is that the map user can add and subtract layers to create a map that helps the user answer a given question. As previous studies have shown, the number of layers appropriate for 3rd graders negatively affects 5th and 6th graders (Bausmith and Leinhardt 1998). Development of geographic understanding is fluid, and varies among children of the same age. An interactive map would allow students to add layers as necessary, and address the needs of students at different stages in development without neglecting or depriving students at a higher (or lower) level of understanding. By adding interactivity, maps are no longer just communication tools where a static and defined amount of information is provided to the map user, but a visualization tool (MacEachran 1995), which gives students the ability and information 
to explore geographic relationships beyond the static map at their own level of understanding.

\section{Interactive Maps}

Interactive maps and atlases have been discussed for over two decades, though a lack of guidelines and frequent changes in mapping technology suggests a comparison of building interactive maps with "trying to build the plane while it's flying” (Roth and Harrower 2008, 47). Early discussion focused on what types of activities computers can facilitate, including animation, data exploration, dynamic scale changes, 3D visualization, and content and design modifications (Waters and De Leeuw 1987, Egbert and Slocum 1992, Harrower 2004). With the advent of desktop Geographic Information System (GIS) software, some focus has been on utilizing these powerful applications in schools (Kraak 1996, Andrienko et al. 2002, Wiegand 2003, Dragićević 2004, Baker 2005) although there are many caveats regarding the complexity of the software and time requirements to learn and use the software (Audet and Paris 1997, Meyer and Butterick 1999, Baker 2005), which make Geographic Information Systems (GIS) less than ideal for providing interactivity to students in primary and secondary education.

Much of the early work on interactive maps focused on CD-ROM as a delivery method (Trifonoff 1994, Linn 1997), though the last decade has seen a shift from physical media to delivery over the Internet (Kraak 2001, Buckley 2003). Both delivery methods face the same design challenges as far as display and interaction are concerned, 
though the dynamic nature of the Internet allows for content to be updated seamlessly as new source data becomes available. This change adds the role of data custodian to the map maker (Kraak 2001) and changes maps from products to services (Buckley 2003).

Patrick Wiegand examined how students benefited from making choropleth maps with GIS software (Wiegand 2003) and found that while students held some misconceptions about choropleth maps, they were capable of showing a high level of understanding through group discussion. Wiegand also found that the mean number of data classes used by students slightly exceeded five, which was set as a default by the software.

Sophia Linn examined the effectiveness of interactive maps in the classroom in comparison to traditional maps and materials. Linn's intent was to see if interactive maps improved the students' ability to acquire and organize geographic information as required by National Geography Standards (1997). In Linn's study, $7^{\text {th }}$ grade students were introduced to a topic and given a pretest based on material from the introduction. Following the initial test, students were split into groups and assigned a project on the topic. Some students used an electronic atlas to research and present on their project, some used library materials, and some used materials prepared by the instructor. After one week working on the project, students were tested again, and then students exchanged material and took another test. While results from the first test found some improvement in performance, after the second test, there was ultimately no significant difference in performance between students who used an interactive atlas over students 
using traditional materials, though the results do suggest that students preferred using the computers.

Identifying an appropriate tool for interactive maps is a moving target. Internetbased applications and tools have changed frequently, so some tools discussed in the research, such as CommonGIS (Andrienko et al. 2002), are no longer available. Recent and current examples have included web mapping applications like MapServer, which is used for the Atlas of Canada (Williams et al. 2003) to provide a large collection of thematic maps on-line. Google Earth, a free commercial program that seamlessly combines data from the Internet, is another easy to use a tool that holds promise for student learning. Todd Patterson has even identified lesson plans that incorporate National Geography Standards for using the Google Earth software (Patterson 2005).

Jan McCoy examined the use of interactive and animated maps in teaching middle school geography. His research showed that students using animated maps learned course material better than students using static maps (McCoy 2003). McCoy also discussed the potential of interactive layer maps that allowed students or teachers to quickly add different layers to a map when exploring a theme such as demographics. 
The multiple layer technique can be used in many interactive map types, but it challenges some rules of traditional cartography. In the traditional cartographic

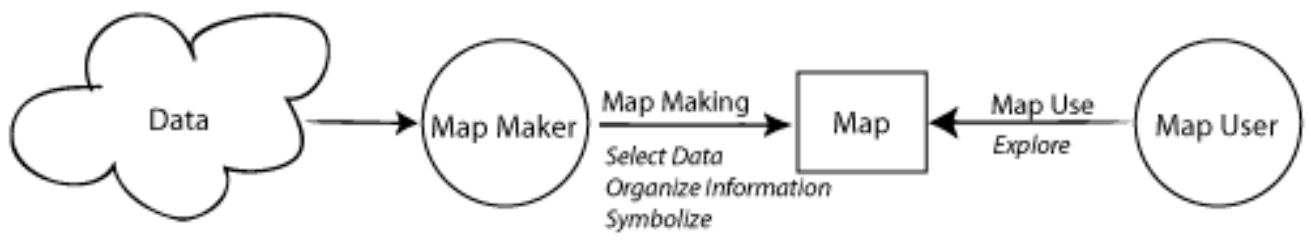

Figure 4: The Cartographic Process. Adapted from Dent (1996, 13)

process, illustrated in Figure 4, the map maker selects data, organizes and transforms the data, chooses symbolization, and creates a map for the end user with a fixed number of layers. The map maker has complete control over the final product (Dent 1996), and the map user is reliant on the map maker for portraying information.

With an interactive map, the map maker selects data that may be used, organizes, transforms and symbolizes data, and presents a map interface, but the map user selects the desired layers before deciding on a final map or maps (Kraak 2001), as illustrated in Figure 5.

This process may contradict the traditional view that base information should be

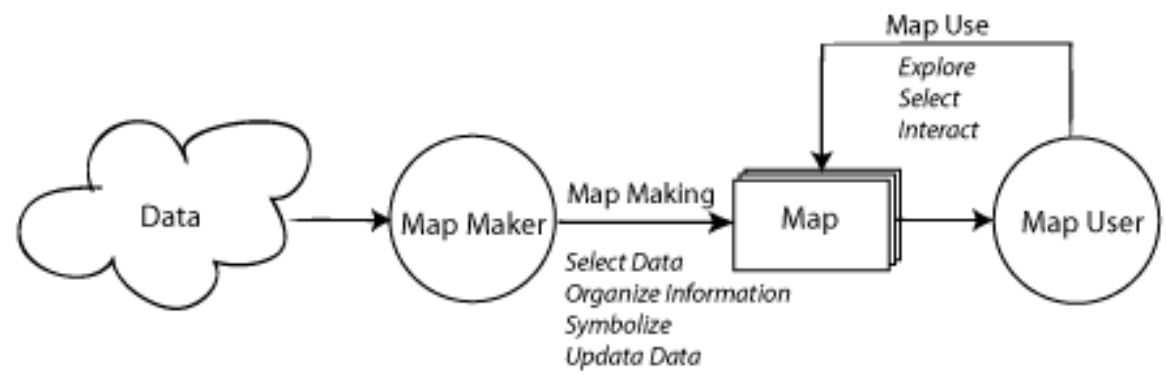

Figure 5: Interactive Map Process 
as generalized and simplified as possible, but it allows the map user to decide which base data give the thematic information the best context from the user's perspective. Additionally, one base layer may provide information that is helpful in understanding one dimension of a theme, but a separate base layer may better illustrate another aspect of the same theme. For example, on a thematic map depicting rainfall in the Pacific Northwest, a base layer showing roads or cities may give map readers a better understanding of where precipitation is greatest, but offers no information on why it might be greatest at certain locations. Adding a hillshade layer gives the map user a clue as to what types of terrain receive the highest precipitation.

Including multiple base layers on a static map may solve the problem in this example, but the resulting map may prove to be too visually cluttered and the map user must mentally remove the information that is extraneous for use. The advantage of the layer map is that the map reader can add or remove layers to investigate multiple dimensions of a theme, focusing only on the layers of interest. This creates a feedback loop in which an appropriate map can be created after considering multiple options before the user selects the layers he finds most useful.

Creating a dynamic layer map using existing atlas data is possible, but does the ability to add layers or remove layers from a map improve its usefulness or its effectiveness? Is there any benefit to having an interactive atlas when a traditional print version is available? Most importantly, does the number of layers presented on a map affect how useful a map is for a student trying to answer geographic questions? These are appropriate concerns for both cartographers and educators, but may be difficult to 
address. There have been several attempts to quantify the effectiveness of using electronic atlases and mapping applications (Trifonoff 1994, Linn 1997, Pedersen et al. 2005), which found that electronic maps may not improve learning, but they do not hinder it, and often have the benefit of engaging students more deeply in the learning process.

A few studies have found that student learning is improved if students are involved in making maps related to the subject being studied (Linn 1997, Bausmith and Leinhardt 1998, Leinhardt 1998). Some interactive maps involve students by allowing them to participate in the map making process. However, it is unclear whether students will be able to answer questions about geographic relationships when given the freedom to add and subtract layers on an interactive layer map. Fifth and sixth grade students are capable of answering geographic questions using static thematic maps (Michaelidou et al. 2004, Gaspers 2007) and using interactive maps (Trifonoff 1995, Linn 1997), but previous research did not consider maps where students could change the number of data layers on a map.

If students are able to answer questions that are posed to them, will the number of layers present correlate to how well they answer questions? The following question guides this research:

If a layer map has multiple base and thematic layers, will the resulting amount of information on the map interfere with a middle school student's ability to answer questions using the map? 


\section{Objectives}

The purpose of this research is to learn if the number of base and thematic layers, and therefore the amount of information on a map, determines how accurately and how quickly students answer questions about geographic relationships. The usefulness of an interactive layer map in the classroom depends on the outcomes of the following hypotheses:

1. The number of layers on a map will have a negative correlation with the accuracy of student responses to questions.

2. The number of layers on a map will have a negative correlation with the speed of students' response to questions.

3. Students will show a preference for maps with a hillshade over maps without.

4. Students will answer questions more accurately on maps without a hillshade layer.

5. Students will answer questions more quickly on maps without a hillshade layer. To investigate these hypotheses, I developed a series of on-line maps. The maps' subject area was Oregon, and combined several base and thematic data layers. The maps were placed inside an on-line assessment tool that is part of the Blackboard CE8 course management system. The assessment interface allowed students to view a map and answer questions using the map. The assessment tool also recorded and timed student responses automatically. Having the maps inside a web-based assessment tool allowed for many students to be tested simultaneously. For simplicity, I have referred to this testing application as "the map" from this point on. 
The intended users of the map were $5^{\text {th }}, 6^{\text {th }}$, and $7^{\text {th }}$ grade students and the intended media is a computer screen. The data for the map was collected from the Student Atlas of Oregon project, and was modified slightly to add additional layers for the purpose of this research. The map was built using guidelines suggested from other research in mapping for middle-school students (Miller 1982, Wiegand 2006, Michaelidou 2007) and for interactive web maps (Kraak 2004, Williams et al. 2003).

I did not use truly interactive maps because of technological limitations, and to reduce additional variables that could have affected results. Students did not make conscious decisions about how many layers are displayed, but were presented with maps having different numbers of layers representing the range of choices that might have been made by them and their responses to a series of map specific questions were evaluated. Students were also asked follow-up questions for insight in to their answer choices. The tabulated test results were then collected and prepared for analysis.

Analysis consisted of comparing individual students' test results and the time it took to answer each question. Since there were a minimum number of layers needed to answer each question, I expected that the students who answered the questions most accurately and quickly did so with the fewest number of layers necessary to answer each question. The time it took to answer questions was an indirect measurement of the complexity of the map. Complexity can be defined as the amount of clutter or the density of symbols and information on the map, and may have reduced how efficiently or accurately students were able to answer questions if they have trouble locating features or identifying the meaning of what is being symbolized. 
The results of these tests can help decide how effective an interactive layer map may be when used by students to answer questions about geographic relationships as expected of them by Oregon's grade level benchmarks. Specifically, the results will serve as a guideline for selecting the number and types of layers to make available to students in interactive maps. 


\section{Chapter 3: Methodology}

The purpose of this research is to identify how maps that combine thematic layers affect middle school students’ answers and response times to geographic questions. Using a web-based map interface facilitates working with a large group of students simultaneously, and simplifies data collection. The methodology is separated into map design, question design, user testing, pilot testing, data collection and data analysis.

\section{Map Design}

Cartographic design practices developed for static print maps vary insignificantly from those used in creating on-line maps (Kraak 2001), and those for creating maps intended for children (Miller 1984, Wiegand 2006). On-line maps follow many of the same design techniques used in print maps, with special attention being paid to situations where the output, a computer screen or projector, is beyond the control of the cartographer. The student atlas project consisted of print maps produced from digital data sources. This same data can be used in creation of an on-line map with little or no modification. Still, given the potential for a dynamic on-line map, design choices regarding complexity and resolution need to be addressed.

A map on the Internet naturally includes competing visual elements from menus, toolbars, and other web pages (Figure 6), which may affect the map user’s attention span or interfere with the ability to use the map. To simplify the interface, "graphic and information density should be low” (Kraak 2001), which is to suggest that both the map and the interface should provide proper white-space or padding between elements. 


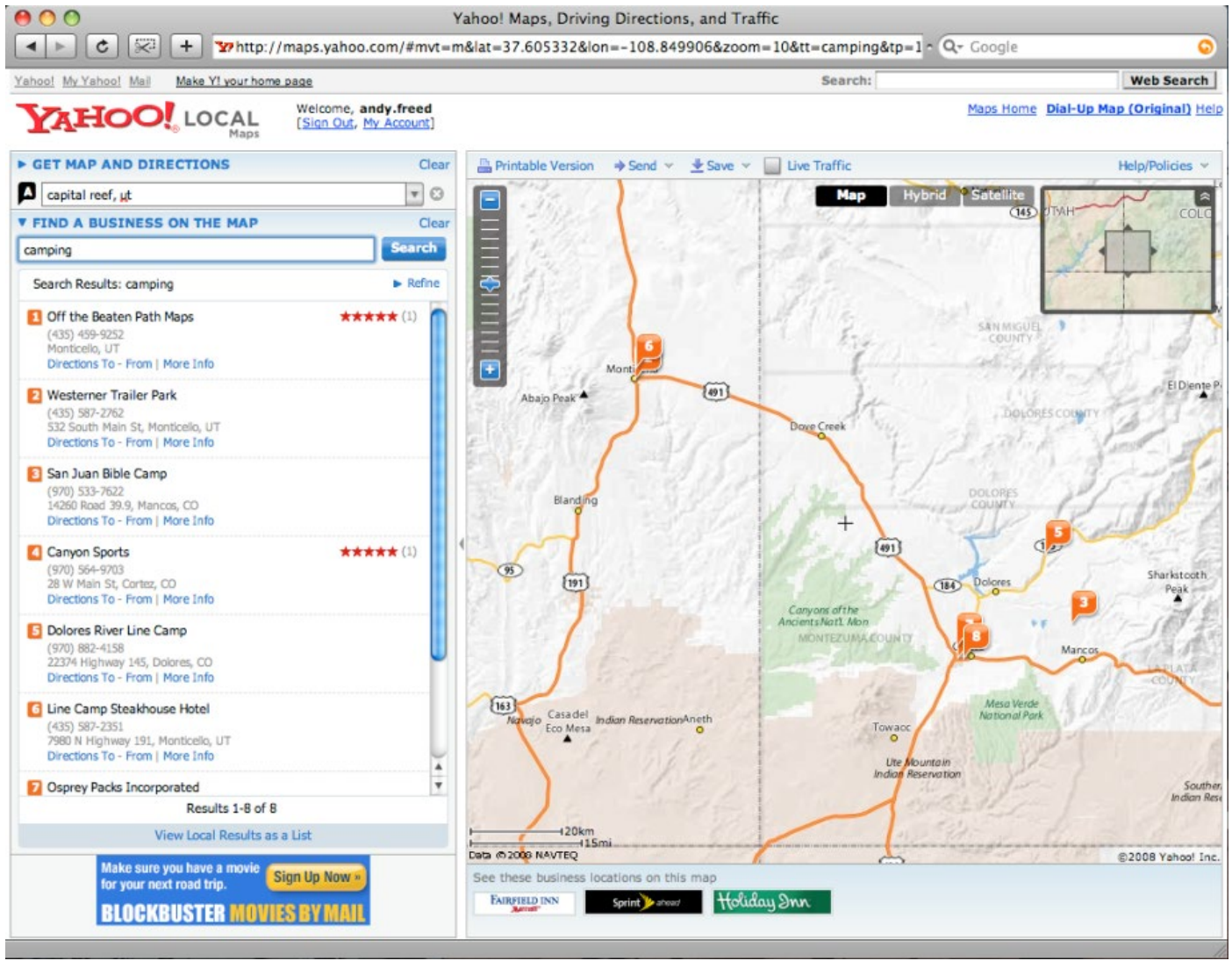

Figure 6: A web map includes many competing visual elements

This guideline complements Leinhardt and Bausmith's recommendation that maps for students should include more layers but less data in each layer (Bausmith and Leinhardt 1998). Based on these recommendations, data used for the print atlas were simplified for the resolution used in the on-line map. This includes smoothing the edges of some area features like counties (Figure 7) and removing smaller features like islands that were present in the original data. Figure 8 shows examples of selection and combination, two more forms of generalization that reduce the amount of information on the map without significantly affecting the accuracy at this scale. 


\section{Original Counties Layer}

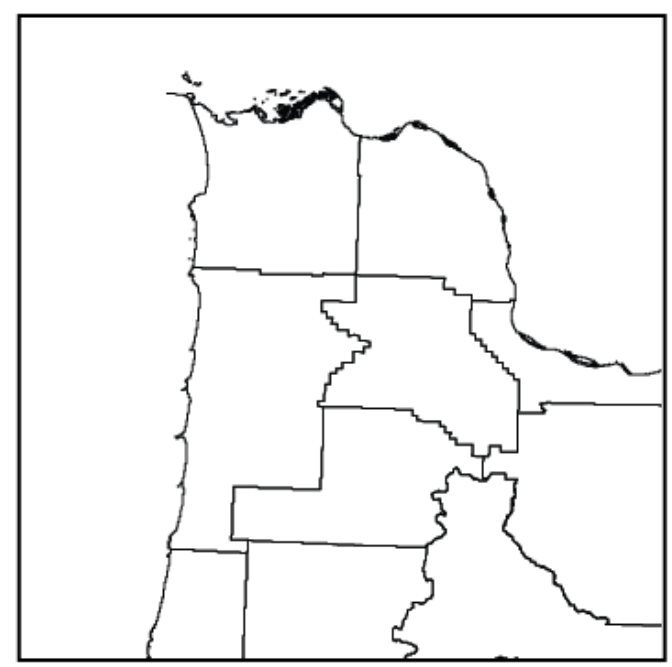

Simplified Counties Layer

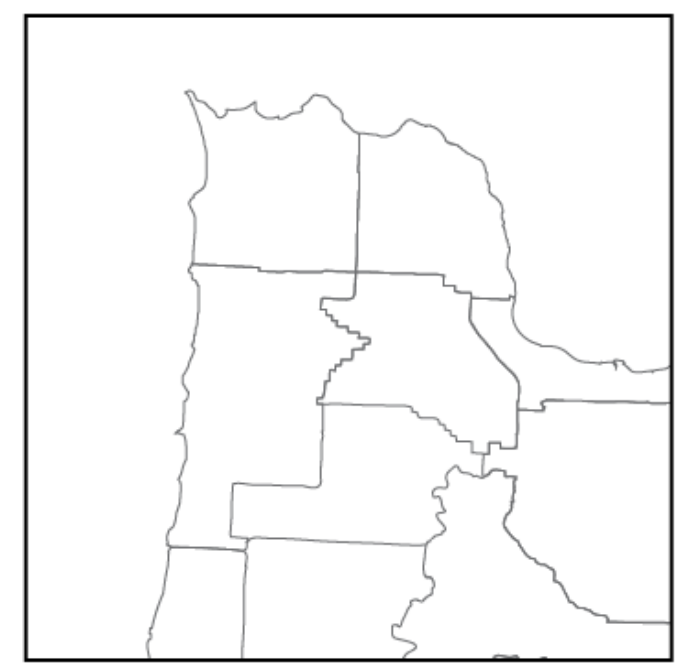

Figure 7: Example of simplification. Lines were smoothed by removing additional points from the vector file and islands were removed because they were unimportant at the scale being displayed

\section{Original Precipitation layer}

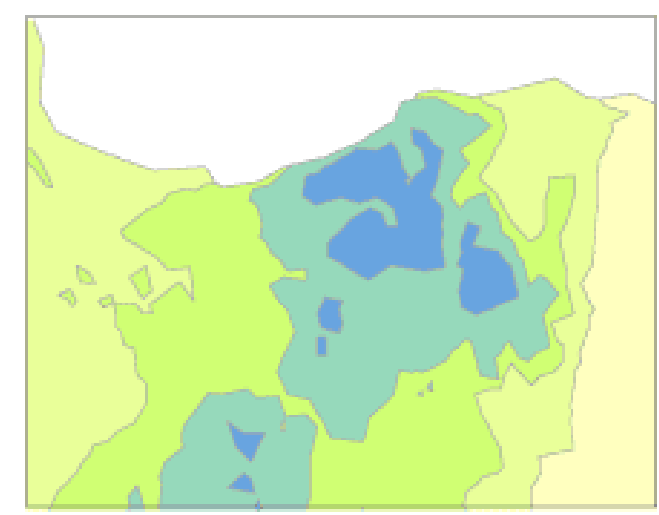

Same layer after selection and combination

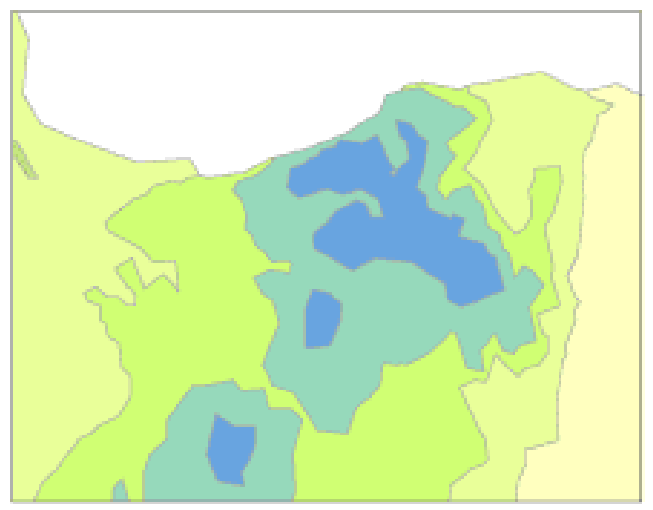

Figure 8: Example of selection and combination. Some small polygons were removed from the original (selection) and some were merged to reduce the number of smaller features (combination)

The output of the on-line map also creates a challenge that is different from that posed by print maps. The on-line map may be viewed on CRT monitors, TFT flat-panel displays, LCD overhead projectors and even output to print. Each media is unique, so 
conservative use of colors, such as a "web-safe” palate, or dedicated set of computer display friendly colors are recommended (Feringa 2001, Van der Worms 2001). While current web design trends downplay the usefulness or benefit of the web-safe palette (Weinman 2008), children often benefit from simple color schemes with high contrast (Miller 1982) and saturation (Buckingham and Harrower 2007). The map size has also been tailored to fit in a standard 1024 x 768 pixel display, which is a common standard in computer labs.

Many maps in the print version of the student atlas exclude neighboring states. The map includes outlines and labels for California, Washington, Idaho and the Pacific Ocean for appropriate context, as suggested by Patrick Wiegand (2006).

Conveying terrain information is challenging but important to include. While hillshades can interfere with map users ability to understand thematic information (DeLucia 1972), the technique seems best for middle school students for showing both elevation and for making comparisons about elevation (Michaelidou et al. 2004).

Due to time restrictions and technical limitations, I was unable to create an interface that presented fully interactive layer maps, presented questions to students, recorded layer choices and question responses. Instead I created a series of individual maps with varying layers to imitate a true interactive layer map. Taken individually, each map may exhibit design choices that defy mapping conventions, but were selected to function as if it were part of an interactive layer map. For example, label placement of county seat names may not seem appropriate when there are only two layers visible, but the labels were placed based on the interaction with labels from other layers that 
may not be visible. I decided to keep the design the same on each layer map for consistency between various layer maps.

\section{Question Design}

Creating appropriate questions for students requires identifying questions that are appropriate for middle school students according to state curriculum and National Geography Standards. The National Geography Standards state that students leaving $4^{\text {th }}$ grade should be able to use a "thematic map to answer questions about human distributions” (NGS 1994, 107), “use labels and symbols to locate and identify physical and human features” (NGS 1994, 108), “analyze the locations of places and suggest why particular locations are used for certain activities” (NGS 1994, 112) .

Meeting all these criteria in a small set of questions is challenging, though good examples can be found in the State of Oregon Department of Education's Social Science Benchmark 3 sample test. On the test, two questions are paired with a single map showing early agricultural sites in Europe. The neatly labeled map shows only outlines of the continent, rivers, and agricultural locations. The first question asks about proximity of agricultural sites to types of landforms, and the second about the movement of population based on the age and location of agricultural sites. These questions address the National Geography Standards 1 and 2 using a single map.

My test included multiple choice questions that were paired with a map. Questions 1 through 5 used the same precipitation layer as the basis for the questions, and Questions 6 and 7 used agricultural product layers as the basis for the questions. The questions asked students to identify a place on the map (Questions 3 and 4), find a 
location on the map and identify how much precipitation occurs at that location (Questions 1, 2, 3, and 4), pick a location on the map that is conducive to a certain agricultural activity based on a certain amount of precipitation (relationship between two thematic layers, Question 5), identify a county based on the amount of a certain agricultural activity (Question 6 and 7), and make a comparison of two different thematic layers (Questions 8 and 9).

Three questions (7, 8 and 9) had a short written follow up. Several biographical questions were asked to record any differences between age, gender, or computer exposure. I have included an example of the map interface and several questions in Appendix D.

\section{User Testing}

This research requires that students answer questions similar to what they would encounter in a normal classroom activity using maps with a variety of thematic layers. For each question, students were given a single map. The number of layers on each map varied by student. Accuracy (score) and response time were recorded for comparison to the number of layers on the map used while answering the questions. The intent is to compare student performance to the number of layers on the map being used. Static maps on a web page replaced dynamic layer maps for simplicity and to limit the influence of other interactive map features on the results.

I found several teachers willing to participate through the Oregon Geographic Alliance and word of mouth. An informational flyer used to recruit potential volunteers can be found in Appendix C. 
Access to a computer lab was necessary so that all students could participate at the same time, thereby minimizing disruption to the classroom. The size and availability of lab computers determined how many separate classes or teachers I needed to involve, since I hoped to collect at least 80 responses. Each computer was prepared ahead of time to display the test (i.e. I pre-loaded the browser with the correct website) to reduce the amount of effort on the students’ part and reduce the amount of idle time.

On the day of testing, the map was introduced to the whole classroom simultaneously in order to present all students with the same instructions. The introduction included a brief tour of a sample map and its elements, such as the key, and how to save answers to the questions. The introduction was presented on an overhead LCD projector so all students could see the same map. If students had questions, all students had the benefit of the same response. Students were told that there was no time limit and no grade. Students were then led through three warm-up questions to help them get acquainted with the map. A sample script of the introduction can be found in Appendix B.

Students were next instructed to use the map to answer roughly eight questions that rely on a map and an additional six questions for biographical information. The time it took to respond to multiple choice questions was recorded by the map interface and stored along with the students' answers and layer selections. Free-response and biographical questions were not timed. Student responses, the map layer information and response times were all stored on a web server in a database for later comparison and analysis. 
The test drew from a large pool of potential questions and maps (called a question set) that gave each student a different set of questions. This allowed for the random assignment of maps with differing layers to students. This reduced the duration and repetitiveness of the test for individual students while providing enough data from each map.

\section{Pilot Testing}

One teacher allowed me to test my proposed methodology in his classroom. It was important to test the script, the timing of the test, the testing apparatus and questions in a classroom setting. The classroom was a combined $4^{\text {th }}$ and $5^{\text {th }}$ grade class, and on the day of the test, there were 26 participants. Unfortunately, a scheduling conflict came up that prevented us from using the computer lab. Instead, we used a laptop cart that was wheeled into the classroom. The situation was less than ideal, but I proceeded anyway so that I could get feedback about the testing apparatus and questions. The laptops took a long time to set up, and by the time I was ready to introduce my project and demonstrate how to use the map, 30 minutes of class time had passed. There were a number of issues that the pilot identified. Issues with venue:

- Smaller laptops (13” screen) were not optimal for the map.

- Setup took 30 minutes; students lost interest and momentum.

- Wireless Internet bottlenecks resulted in slowed computer performance during test.

- Some software quirkiness that was likely related to network bottleneck. 
Issues with map and testing

- $4^{\text {th }}$ grade students did poorly compared to $5^{\text {th }}$ graders

- Redundant questions (even when the map differed) confused students

- Some students were fatigued (bored)

- Many students did not complete the test

- Testing took 30 minutes, which was too long for most students

Demonstration proved problematic because:

- Projector in the classroom only displayed at a resolution of $640 x 480$, which was too small for the map

- I could not dim the room enough for adequate display of the map

- I accidently referred to the map as "quiz tool” which alarmed students

- I had trouble sticking to the script with the setup chaos.

Based on the feedback I received from the pilot, from the teacher, and from the data collected, I made the following changes to my methodology:

- I shortened the test by removing redundant questions

- I set up computers before students arrived

- I made sure labs had 15” or larger screens

- I selected $5^{\text {th }}-7^{\text {th }}$ grade classrooms

I widened the scope of the research to middle school students at the recommendation of my committee to increase the likelihood of soliciting enough teachers willing to volunteer their class time. 


\section{Data Collection}

I was able to identify three classrooms in the Portland area by posting a request on the Oregon Geographic Alliance e-mail listserv. I was also able to identify two other classrooms through personal contacts. I visited each of the classrooms between May $18^{\text {th }}, 2010$ and June $7^{\text {th }}, 2010$. At each of the locations, I was able to access the computer lab and set up the testing sessions, often with assistance from the lab instructors or librarians. Setup took approximately 20 minutes at each location, and then students arrived in the lab. I was able to introduce the project and follow my script while introducing the map with greater success than in the pilot.

Students sat down at a computer of their choice which had already been logged in to Blackboard, the testing software. Some schools had seating arrangements, others did not. I asked students not to click anything on the screen until after I had given the introduction. At two of the schools, the teacher used their classroom management skills to calm and focus students so I could introduce the project. Students rarely asked questions about the purpose or reason for my visit, I think partly due to the direction given in the introduction. The introduction also included three sample problems that I demonstrated to the students to familiarize them with the map interface and Blackboard CE8 software.

After completing the introduction, I instructed the students to click the "Begin Quiz” button in Blackboard. The first question was displayed and students were presented with a map, a question, and several multiple-choice options. Once a student was done with the question, the student clicked a "Save” button and a "Next Question" 
button. Students worked through the questions at their own paces. The time it took to answer each question was automatically recorded when the answer was saved. When the student completed the last question, the student submitted the quiz. After completing the quiz, the student could either surf the internet or work on math problems depending on instructions given by the teacher. After visiting all five classrooms, I had a total of 95 usable student responses (Table 1).

Table 1: Summary of participants by school

\begin{tabular}{|l|c|l|c|}
\hline School & Count & Location & Grade \\
\hline SEI Academy & 13 & Portland, OR & $6^{\text {th }}$ \\
\hline Columbus Elementary & 23 & McMinnville, OR & $5^{\text {th }}$ \\
\hline Newby Elementary & 21 & McMinnville, OR & $5^{\text {th }}$ \\
\hline Sunset Elementary & 25 & West Linn, OR & $5^{\text {th }}$ \\
\hline Tualatin Valley Academy & 13 & Hillsboro, OR & $7^{\text {th }}$ \\
\hline Total & 95 & & \\
\hline
\end{tabular}

I also collected some basic demographic information about the students. Of the 95 responses, 40 boys and 46 girls responded with gender information, ages from 10-14 (Figure 9). Some students were hesitant to answer questions about their gender and age and chose not to respond those questions; nine students did not respond with their gender, and fourteen did not respond (or responded humorously) about their age. 


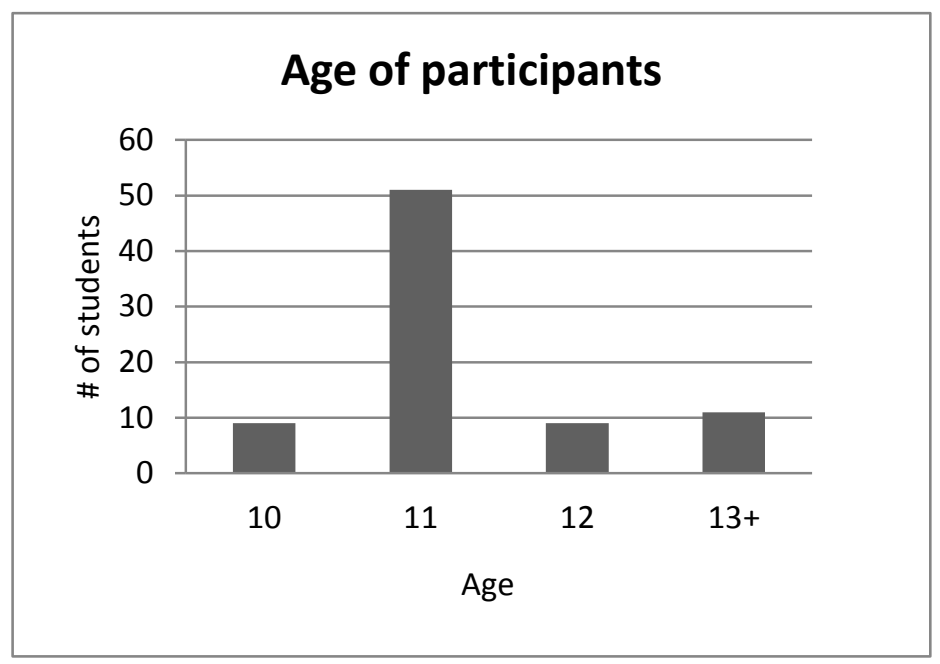

Figure 9: Age of participants. One student was 14 years old. Some students did not include their age in the responses.

\section{Exclusion of results}

I excluded individuals from data analysis if the majority of that individual's responses were incomplete. I kept responses when no more than two were incomplete, especially questions about gender or age. Two students’ results were removed completely because they failed to answer a majority of the questions. This reduced the total sample from 97 to 95 . When a student failed to respond to a single question, that individual's response was excluded from analysis on that question. There were instances where a question failed to save during the testing process. I attributed this either to coincidental technical problems related to the network where the test was occurring or to the Blackboard software. 


\section{Data Analysis}

After running the tests in all five classrooms, I downloaded the results from Blackboard into Microsoft Excel and manually entered the time recorded for each student response. I also assigned point values to the multiple-choice questions for correct and incorrect responses to measure accuracy. I assigned 1 point to student responses that were correct, and 0 points to responses that were incorrect.

The time was originally recorded in hours, minutes and seconds (e.g. 00:01:16), which I converted to seconds (e.g. 76) to simplify analysis. If a question was not answered, I entered a null value to exclude it from analysis.

I then performed statistical tests to determine if response times or scores for any of the questions differed significantly from naturally occurring differences in samples. I used nonparametric tests because my data did not meet all assumptions required for the use of parametric tests; the data were not normally distributed and the samples had different sizes and variances.

I used the Mann-Whitney U test when comparing two sample means, such as testing the response times for maps with and without hillshades. The Mann-Whitney U test is a nonparametric alternative to the t-test and helped determine if the two samples exhibited differences (McGrew and Monroe 2000, 133). If the result of this test is significant, it can be assumed that the two samples are different enough beyond what can be explained by chance.

I used the Kruskal-Wallis test to compare three or more sample ranked means to determine if the variability between samples was the result of differences between the 
sample populations (McGrew and Monroe 2000, 149). I used the Kruskal-Wallis test to evaluate response times for maps with differing numbers of layers. A significant result told me that the difference between the ranked means was significant beyond what might occur by chance.

I used Pearson’s Chi-Square test to compare observed response frequency to expected response frequency. This goodness-of-fit test helped determine if the observed responses were taken from an expected frequency distribution (McGrew and Monroe, $2000,155)$, or if the responses suggested that there was some difference in the samples taken. This test was most commonly used to compare correct and incorrect responses for maps with differing numbers of layers and maps with and without hillshades. A significant result indicates the observed results do not fit an expected pattern for the data.

I used the SPSS Exact test when the data did not meet the requirements for the Chi-Square test. The Exact test is a proprietary software package that works well on small datasets (IBM 2010). The results of the Exact test are reported as an addendum to the Pearson’s Chi-Square results and list a corrected significance level. The Exact results were helpful in avoiding Type II errors, which occur when incorrectly accepting the null hypothesis.

The purpose of these tests was to determine if there was a significant difference between my observations and what could simply be attributed to chance, including small differences in the samples that were a result of data collection. A significant result in any of these tests indicates that something in an individual question or map caused a 
difference in response that affected student performance. For consistency, I used a probability (p) value of 0.05 for all tests. 


\section{Chapter 4: Results}

This chapter presents and summarizes the data collected, and analyzes the results. The results are grouped by question. Each question used a different set of maps, and for each question, a different map was randomly distributed to the students. Figures 10 and 11 summarize the number of maps used for each question, as well as the number and type of layers in each map and the number of sampled users for each map.

Questions 8 and 9 are not included because those questions were not map reading tasks and did not evaluate response time and score.

The following null hypotheses were used when appropriate for each question when conducting statistical tests:

$H_{01}$ : There is no significant relationship between the number of layers on a map and student scores.

$H_{02}$ : There is no significant relationship between the number of layers on a map and student response time.

$H_{o 3}$ : There is no significant difference between scores for students who had a map with a hillshade and those who did not.

$H_{o 4}$ : There is no significant difference between response times for students who had a map with a hillshade and those who did not. 


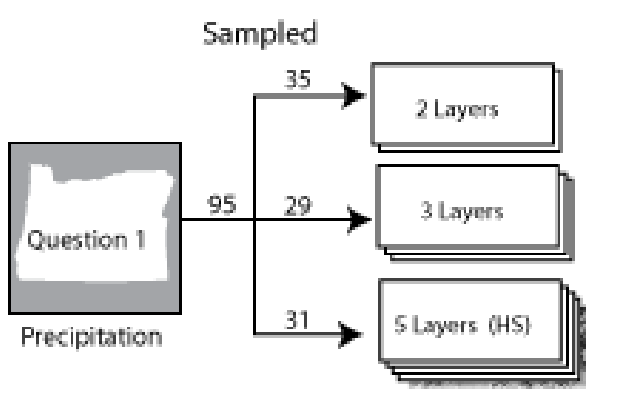

\author{
Layers Displayed \\ Precipitation, Eco-Regions \\ Precipitation, Eco-Regions, County Seats \\ Precipitation, Eco-Regions, County Seats, Rivers, Hillshade
}

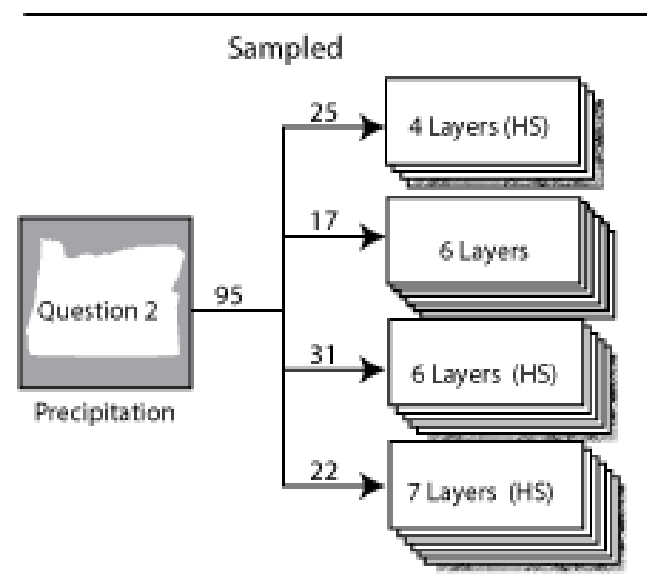

\title{
Layers Displayed
}

Precipitation, Eco-flegions, County Seats, Hillshade

Precipitation, Eco-fregions, County Seats, Fivers, Counties

Precipitation, Eco-fegions, County Seats, Fivers, Hillshade, Counties

Precipitation, Eco-Regions, County Seats, Rivers, Hillshade, Countios, Highways

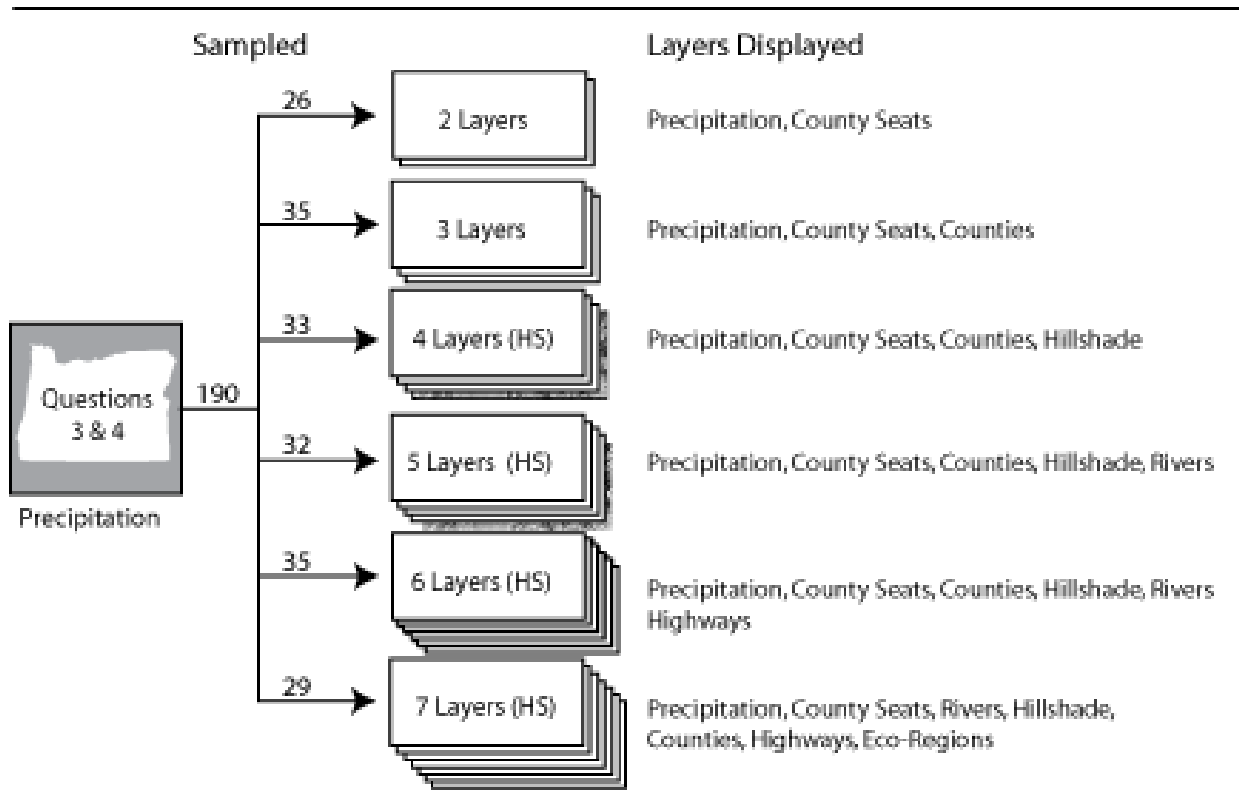

Figure 10: Map distribution summary. There were a total of 13 maps used in Questions 1-4, ranging from 2 to7 layers. The numbers above the arrows indicate the total sample size for each question as well as the number of samples for each individual map. The number of samples ranged from as little as 14 to as many as 50. A list of layers used in each map is listed to the right. 


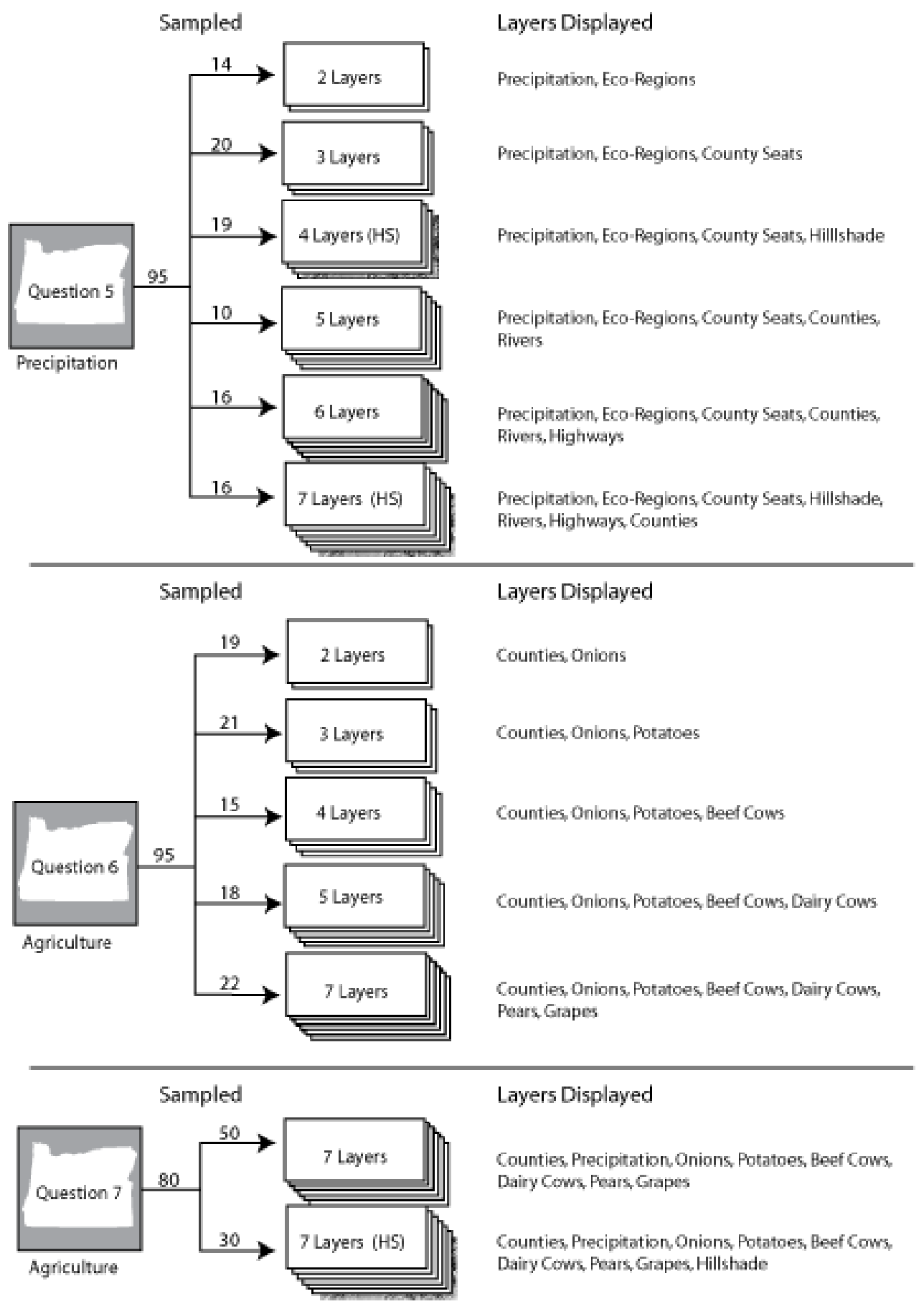

Figure 11: Map distribution summary continued. There were a total of 13 maps used in Questions 5-7, ranging from 2 to7 layers. The numbers above the arrows indicate the total sample size for each question as well as the number of samples for each individual map. The layers used in each map are labeled to the right of each map. 
In order to conduct any further analysis, I first evaluated the overall results, and explored how biographical factors may have influenced these results. In the data collection phase, students were asked about computer ownership, perceived difficulty of the exercise, and about their age and gender. I evaluated the overall score and response time for the questions that involved map reading (Questions 1-7) for differences based on age, gender, school, and computer screen size and listed the results in Table 2. I did not receive enough responses about computer access at home to perform any meaningful test.

Table 2: Analysis of biographical traits on overall time spent and score for the map-based questions.

\begin{tabular}{|l|l|l|l|l|}
\hline $\begin{array}{l}\text { Comparison (Population } \\
\text { variable and factor) }\end{array}$ & Test & Test Result & $\begin{array}{l}\text { Critical } \\
\text { Value } \\
(p=0.05)\end{array}$ & Significant \\
\hline Age and Score $(\mathrm{df}=3)$ & Kruskal-Wallis & $4.83(\mathrm{X} 2)$ & 7.82 & No \\
\hline $\begin{array}{l}\text { Age and Response Time } \\
(\mathrm{df}=3)\end{array}$ & Kruskal-Wallis & $14.58(\mathrm{X})$ & 7.82 & Yes \\
\hline Gender and Score & Mann-Whitney U & $-0.23(Z)$ & -1.65 & No \\
\hline Gender and Time & Mann-Whitney U & $-1.12(Z)$ & -1.65 & No \\
\hline School and Score (df=4) & Kruskal-Wallis & $1.38(X 2)$ & 9.49 & No \\
\hline $\begin{array}{l}\text { School and Response Time } \\
(\mathrm{df}=4)\end{array}$ & Kruskal-Wallis & $26.32(\mathrm{X} 2)$ & 9.49 & Yes \\
\hline Screen size and score & Mann-Whitney U & $-0.29(Z)$ & -1.65 & No \\
\hline Screen size and time & Mann-Whitney U & $-0.01(Z)$ & -1.65 & No \\
\hline
\end{tabular}

*The Question 13 ("Do you have a computer at home”) did not have enough responses to perform any meaningful statistical test.

The only biographical factors that showed any significant difference on the overall test results were age and school, and only with respect to response time. I suspect the two factors, age and classroom, may be related. However, since I had only 
one classroom of $7^{\text {th }}$ graders, I could not compare the results of 13 year olds from one class to another. And since these results correspond to a single classroom, the difference could be the result of site-specific factors like network latency or teacher. When I used the Kruskal-Wallis test to evaluate response times for just 10-12 year olds, there is no significant result, indicating that the response time for the 13 year olds is the significant factor. When I repeat the same test evaluating for schools and response time, but remove the $7^{\text {th }}$ grade classroom from the comparison, there is still a significant result. This may indicate that the significant factor is the classroom, but I did not have enough data to determine that. It was interesting to see that there was a significant difference in response time, but not in score. This result suggests that the $7^{\text {th }}$ grade students are faster readers than the $5^{\text {th }}$ and $6^{\text {th }}$ graders, but do not necessarily have any improved mastery of the maps.

These results suggest that age may have an impact on the overall results. However, since the maps were randomly delivered to students, any impact of a faster response time based on age were distributed among questions, reducing the overall impact of age on the remaining test results. In other words, the faster results of the older students were randomly distributed among the overall results and less likely to affect the results associated with any single map.

I have compiled a key to the results for each question in Table 3. The table identifies which independent variable (Layers, Hillshade) and which dependent variable (Score, Response Time) are being compared. Page numbers are listed for the test results and significant results are highlighted. 
Table 3: Summary of Statistical Findings. Page numbers are listed for corresponding test results. Highlighting indicates that the test results were significant.

\begin{tabular}{|c|c|c|c|c|c|c|c|c|c|c|c|c|c|}
\hline & & \multicolumn{2}{|c|}{ Q 1} & \multicolumn{2}{|c|}{ Q 2} & \multicolumn{2}{|c|}{ Q3 \& 4} & \multicolumn{2}{|c|}{ Q 5} & \multicolumn{2}{|c|}{ Q 6} & \multicolumn{2}{|r|}{ Q 7 } \\
\hline & & Layer & Hillshade & Layer & Hillshade & Layer & Hillshade & Layer & Hillshade & Layer & Hillshade & Layer & Hillshade \\
\hline \multirow[t]{2}{*}{ Q1 } & Score & p. 44 & p. 46 & $\mathrm{x}$ & $\mathrm{x}$ & $x$ & $\mathrm{x}$ & $\mathrm{x}$ & $\mathrm{x}$ & $\mathrm{x}$ & $\mathrm{x}$ & $\mathrm{x}$ & $\mathrm{x}$ \\
\hline & Time & p. 45 & p. 46 & $\mathrm{x}$ & $\mathrm{X}$ & $\mathrm{x}$ & $\mathrm{x}$ & $\mathrm{x}$ & $\mathrm{x}$ & $\mathrm{x}$ & $\mathrm{x}$ & $\mathrm{x}$ & $\mathrm{x}$ \\
\hline \multirow[t]{2}{*}{ Q2 } & Score & $\mathrm{x}$ & $\mathrm{x}$ & p. 47 & p. 48 & $\mathrm{x}$ & $\mathrm{x}$ & $\mathrm{x}$ & $\mathrm{x}$ & $\mathrm{x}$ & $\mathrm{x}$ & $\mathrm{x}$ & $\mathrm{x}$ \\
\hline & Time & $\mathrm{x}$ & $\mathrm{x}$ & p. 47 & p. 49 & $\mathrm{x}$ & $\mathrm{x}$ & $\mathrm{x}$ & $\mathrm{x}$ & $\mathrm{x}$ & $\mathrm{x}$ & $\mathrm{x}$ & $\mathrm{x}$ \\
\hline \multirow[t]{2}{*}{ Q3\&4 } & Score & $\mathrm{x}$ & $\mathrm{x}$ & $\mathrm{x}$ & $\mathrm{x}$ & p. 51 & p. 52 & $\mathrm{x}$ & $\mathrm{x}$ & $\mathrm{x}$ & $\mathrm{x}$ & $\mathrm{x}$ & $\mathrm{x}$ \\
\hline & Time & $\mathrm{x}$ & $\mathrm{x}$ & $\mathrm{x}$ & $\mathrm{x}$ & p. 51 & p. 53 & $\mathrm{x}$ & $\mathrm{X}$ & $\mathrm{x}$ & $\mathrm{x}$ & $\mathrm{x}$ & $\mathrm{x}$ \\
\hline \multirow[t]{2}{*}{ Q5 } & Score & $\mathrm{x}$ & $\mathrm{x}$ & $\mathrm{x}$ & $\mathrm{x}$ & $\mathrm{x}$ & $\mathrm{x}$ & p. 55 & p. 56 & $\mathrm{x}$ & $\mathrm{x}$ & $\mathrm{x}$ & $\mathrm{x}$ \\
\hline & Time & $\mathrm{x}$ & $\mathrm{x}$ & $\mathrm{x}$ & $\mathrm{x}$ & $\mathrm{x}$ & $\mathrm{x}$ & p. 55 & p. 56 & $\mathrm{x}$ & $\mathrm{x}$ & $\mathrm{x}$ & $\mathrm{x}$ \\
\hline \multirow[t]{2}{*}{ Q6 } & Score & $\mathrm{x}$ & $\mathrm{x}$ & $\mathrm{x}$ & $\mathrm{x}$ & $\mathrm{x}$ & $\mathrm{x}$ & $\mathrm{x}$ & $\mathrm{X}$ & p. 58 & $\mathrm{x}$ & $\mathrm{x}$ & $\mathrm{x}$ \\
\hline & Time & $\mathrm{x}$ & $\mathrm{x}$ & $\mathrm{x}$ & $\mathrm{x}$ & $\mathrm{x}$ & $\mathrm{x}$ & $\mathrm{x}$ & $\mathrm{x}$ & p. 59 & $\mathrm{x}$ & $\mathrm{x}$ & $\mathrm{x}$ \\
\hline \multirow[t]{2}{*}{ Q7 } & Score & $\mathrm{x}$ & $\mathrm{x}$ & $\mathrm{x}$ & $\mathrm{x}$ & $\mathrm{x}$ & $\mathrm{x}$ & $\mathrm{x}$ & $\mathrm{x}$ & $\mathrm{x}$ & $\mathrm{x}$ & $\mathrm{x}$ & p. 61 \\
\hline & Time & $\mathrm{x}$ & $\mathrm{x}$ & $\mathrm{x}$ & $\mathrm{x}$ & $\mathrm{x}$ & $\mathrm{x}$ & $\mathrm{x}$ & $\mathrm{x}$ & $\mathrm{x}$ & $\mathrm{x}$ & $\mathrm{x}$ & p. 61 \\
\hline
\end{tabular}




\section{Question 1 Results}

Question 1 (Figure 12) was intended as a warm-up that would introduce students to interacting with the map. This was the first question where students actually interacted with the map and were asked to respond to a question using the map on their own.

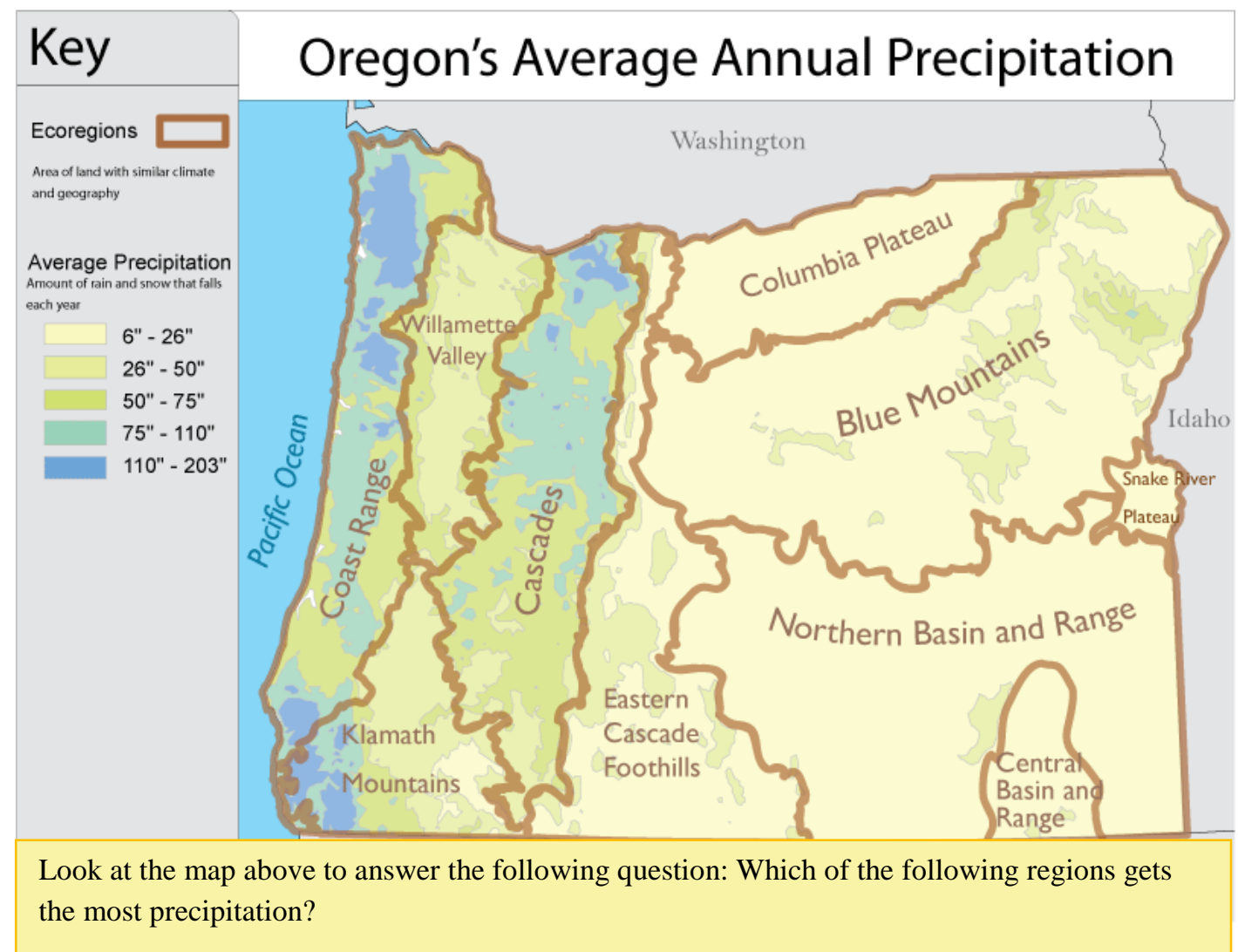

Figure 12: Question 1 and a sample map. Students were randomly given one of three maps, each with a differing number of layers.

Question 1 required that students use the key to make comparisons about relative regional precipitation using potential multiple-choice answers, the map, and key. There were three alternate questions offered: one with two layers, one with three layers, and one with five layers. The map with five layers included a hillshade as one of the layers. 
I first examined the relationship between the number of layers on a map and the students' score. The descriptive statistics are presented in Table 4, and indicate little variation between the number of layers presented on the map and the mean score.

Table 4: Descriptive Statistics for Question 1, layer evaluation

\begin{tabular}{|c|c|c|c|}
\hline Layers & Count & Percent Correct & Median Time \\
\hline 2 & 35 & 83 & 44 \\
\hline 3 & 29 & 93 & 81 \\
\hline 5 & 31 & 94 & 95 \\
\hline
\end{tabular}

The Pearson's Chi-Square test would have been preferable to determine if a significant relationship existed between expected and observed results. However, the test requires that each expected category have a count of five or more, or less than $20 \%$ of the categories have a count less than five and all must have a count greater than one (McGrew and Monroe 2000, 156), and my results did not. I used SPSS’s Exact test, which is a proprietary method for conducting analysis on small data sets that do not meet the requirements of the Pearson's Chi-Square test (IBM 2010). The results of the Exact test indicated no significance so I accepted the null hypothesis.

Referring back to Table 4, the descriptive statistics for the response time for each map indicate some differences between the mean response times. Figure 13 illustrates the response times for each map, showing an increasing mean response time as the number of layers increase. I used the Kruskal-Wallis test to see if the mean response times for each map varied enough to indicate some influence on the response time beyond what could be expected by chance. 


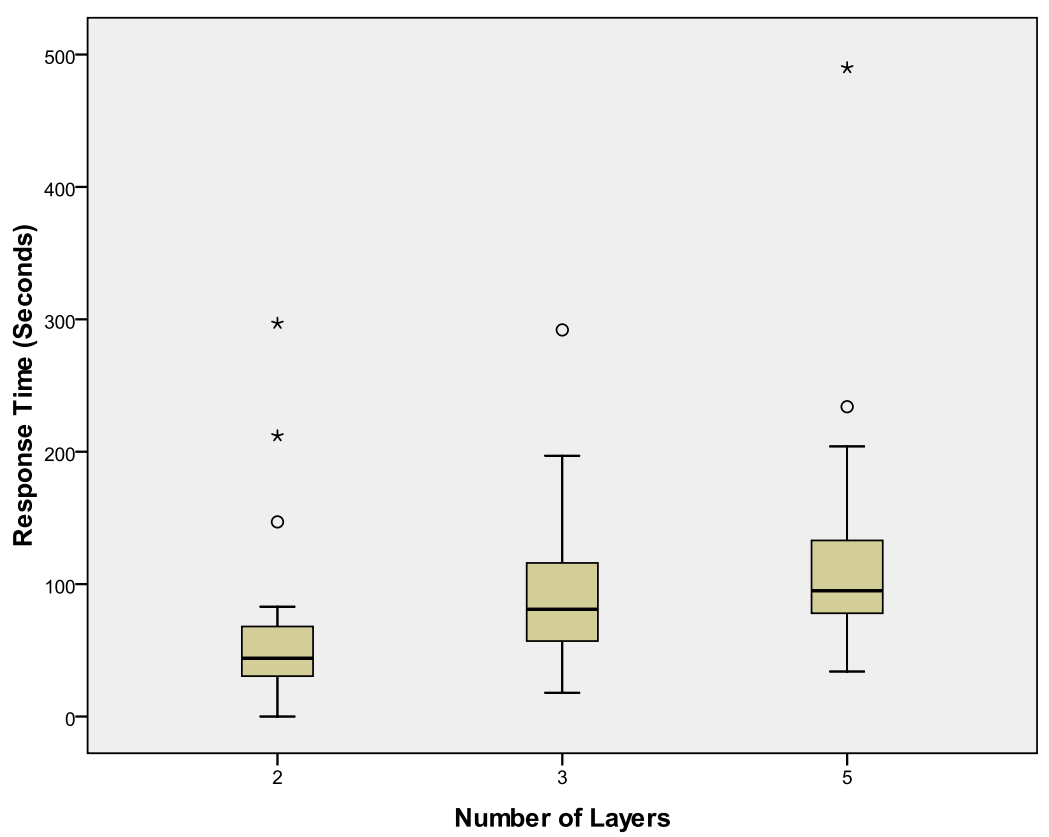

Figure 13: Response times for each map in Question 1.

Using the Kruskal-Wallis test, I received a Chi-Square result of 26.50. The critical value at $\mathrm{p}=0.05$ and two degrees of freedom is 5.99, so I rejected the null hypothesis and accepted the alternate, which states there is a significant relationship between the number of layers on a map and the student response time.

Next I investigated the effect that a hillshade has on student response time and score. I collected the descriptive statistics for the second part of this question in Table 5.

Table 5: Descriptive Statistics for Question 1, hillshade evaluation

\begin{tabular}{|c|c|c|c|}
\hline Map & Count & Percent Correct & Median Time \\
\hline Hillshade & 31 & 94 & 95 \\
\hline No Hillshade & 64 & 87 & 5 \\
\hline
\end{tabular}

I used the Exact test to evaluate the differences between the scores on maps with and without hillshades because the requirements for the Pearson's Chi-Square test were 
not met. The Exact test results did not indicate any significance, so I accepted the null hypothesis.

I used the Mann-Whitney U test to evaluate the relationship between presence of a hillshade on the map and student response time. The results for mean response time (Table 5) indicate difference between student response times with maps that contain a hillshade and those without. Figure 14 shows a box plot of response times for the map with and without a hillshade. There is a visible difference in the mean and ranges for the results. The Mann-Whitney $\mathrm{U}$ test results in a Z score of -3.85 . The critical value at $\mathrm{p}=$ 0.05 is 1.96 , so I rejected the null hypothesis which states that there is no relationship between the presence of a hillshade and response time.

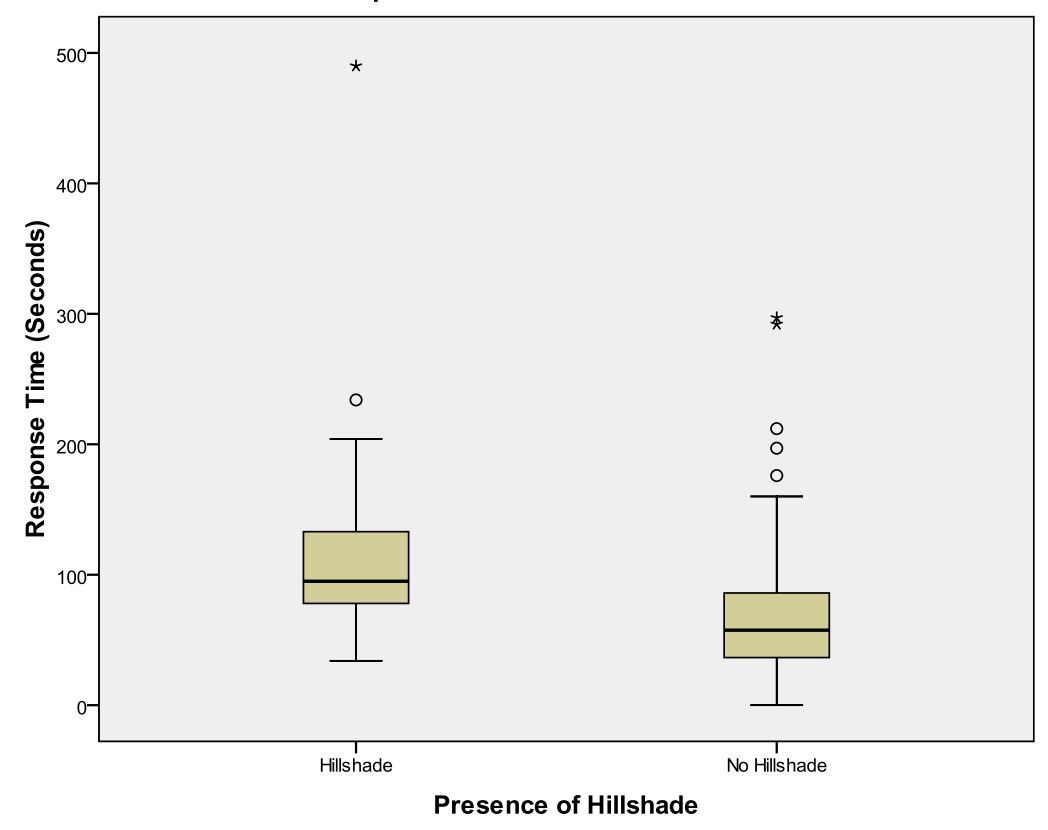

Figure 14: Response times for the maps with and without hillshades for Question 1.

\section{Question 2}

Question 2 is nearly identical to the first except that it uses maps with four, six, and seven layers. Students were presented one of the four maps and again asked to 
identify which of the listed regions received the most precipitation. There were two maps with six layers though each had a different set of layers; one included a hillshade and the other did not. I compiled a table of descriptive statistics for the first section (Table 6).

Table 6: Descriptive Statistics for Question 2, Layer evaluation

\begin{tabular}{|c|c|c|c|}
\hline Layers & Count & Percent Correct & Median Time \\
\hline 4 & 25 & 72 & 71 \\
\hline $6(\mathrm{HS})$ & 31 & 94 & 50 \\
\hline $6($ no HS) & 17 & 94 & 56 \\
\hline 7 & 22 & 77 & 47 \\
\hline
\end{tabular}

The data did not meet the requirements of the Pearson Chi-Square test, so I used the Exact analysis in SPSS, which did not yield significant results. I accepted the null hypothesis.

Figure 15 shows the distribution of response times grouped by the number of layers present on the map. I used the Kruskal-Wallis test to compare response times for each map. The test yields a Chi-Square result of 8.65 at two degrees of freedom with $\mathrm{p}$ $=0.05$, which is a significant result. Since there were two different maps with six layers each, I ran the test again treating those two different maps as different categories. The results of the test still give a significant Chi-Square value of 9.15 with degrees of freedom $=3$ and $p=0.05$. I rejected the null hypothesis and concluded there is a significant relationship between the number of layers on a map and student response time. 


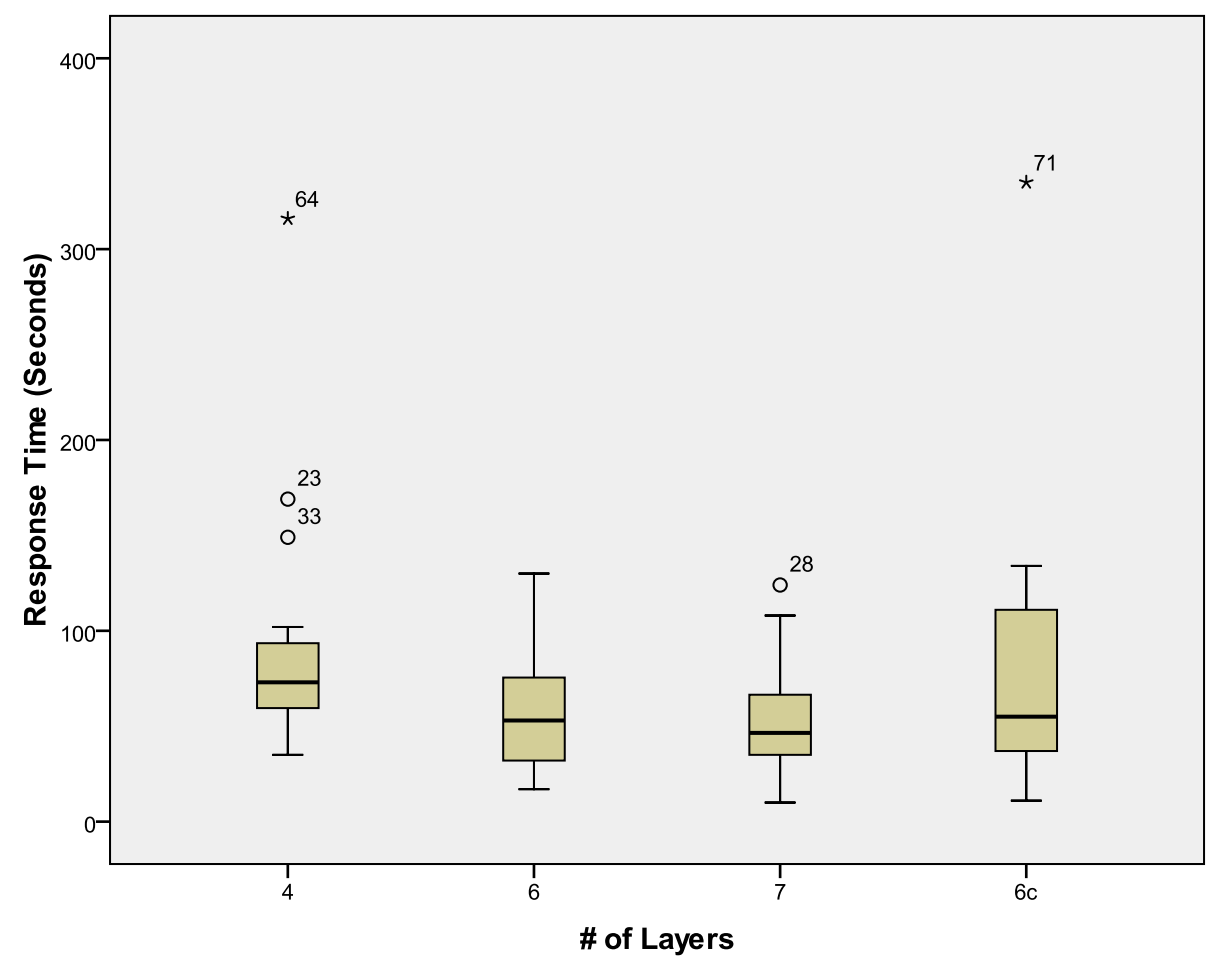

Figure 15: Response times for different maps in Question 2. The map labeled 6C did not include a hillshade as one of the layers.

I investigated the effect of a hillshade on student response time and score. I used the Exact test to evaluate the relationship between student scores and presence of a hillshade since the data did not meet the requirements of the Pearson Chi-Square test. I found no significant result and accepted the null hypothesis.

A visual comparison of the relationship between response times and presence of hillshade (Figure 16) does not reveal any obvious difference. 


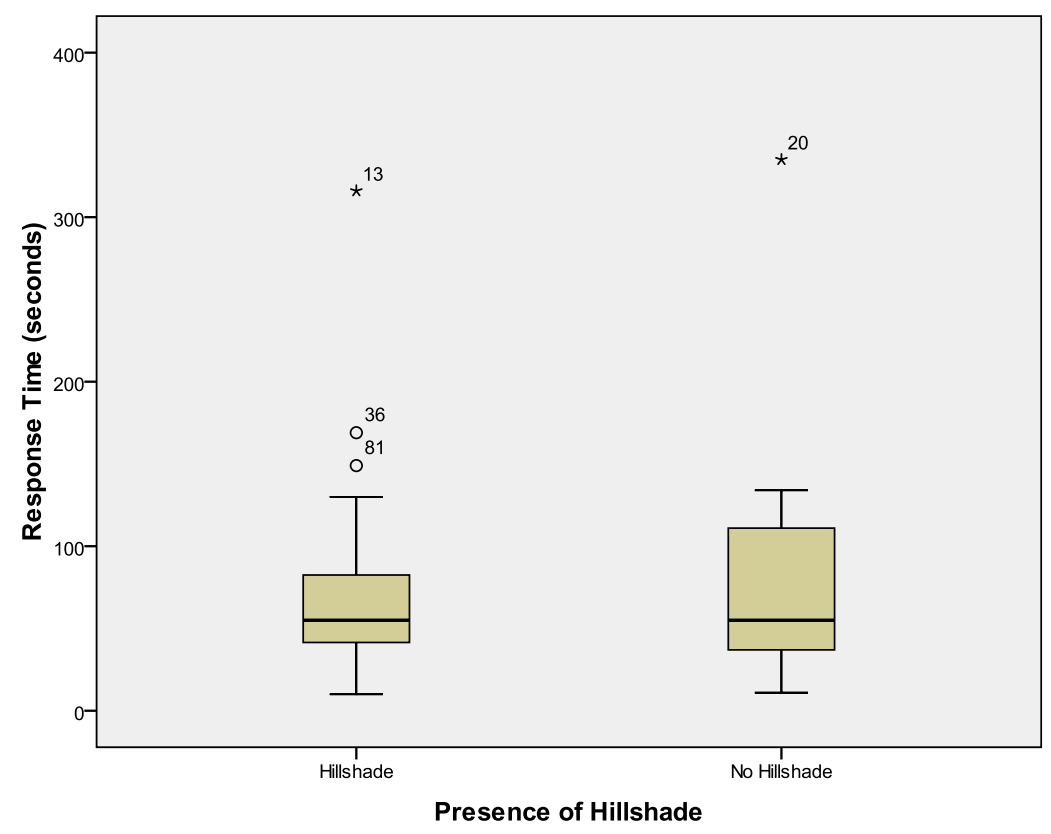

Figure 16: Response times for maps with and without hillshades in Question 2.

To evaluate the relationship between the presence of a hillshade and response time, I used the Mann-Whitney $\mathrm{U}$ test. The result is a $\mathrm{Z}$ score of -0.12 , which is not significant at $\mathrm{p}=0.05$; therefore I accepted the null hypothesis.

\section{Questions 3 and 4}

Questions 3 and 4 were drawn from the same question pool. Students were randomly assigned two questions from the pool. The intent of drawing from a pool was to collect a large sample using the same type of question while ensuring that each individual map had enough responses to perform statistical tests. It successfully provided me with my largest sample.

Questions 3 and 4 asked students to locate a specific city in Oregon and report the amount of precipitation expected at that location. Figure 17 shows the map with two layers displayed. The two layers were the county seats and the precipitation 
information, which was all that was needed to answer the question. The map with seven layers contained the most competing visual elements, including a hillshade.

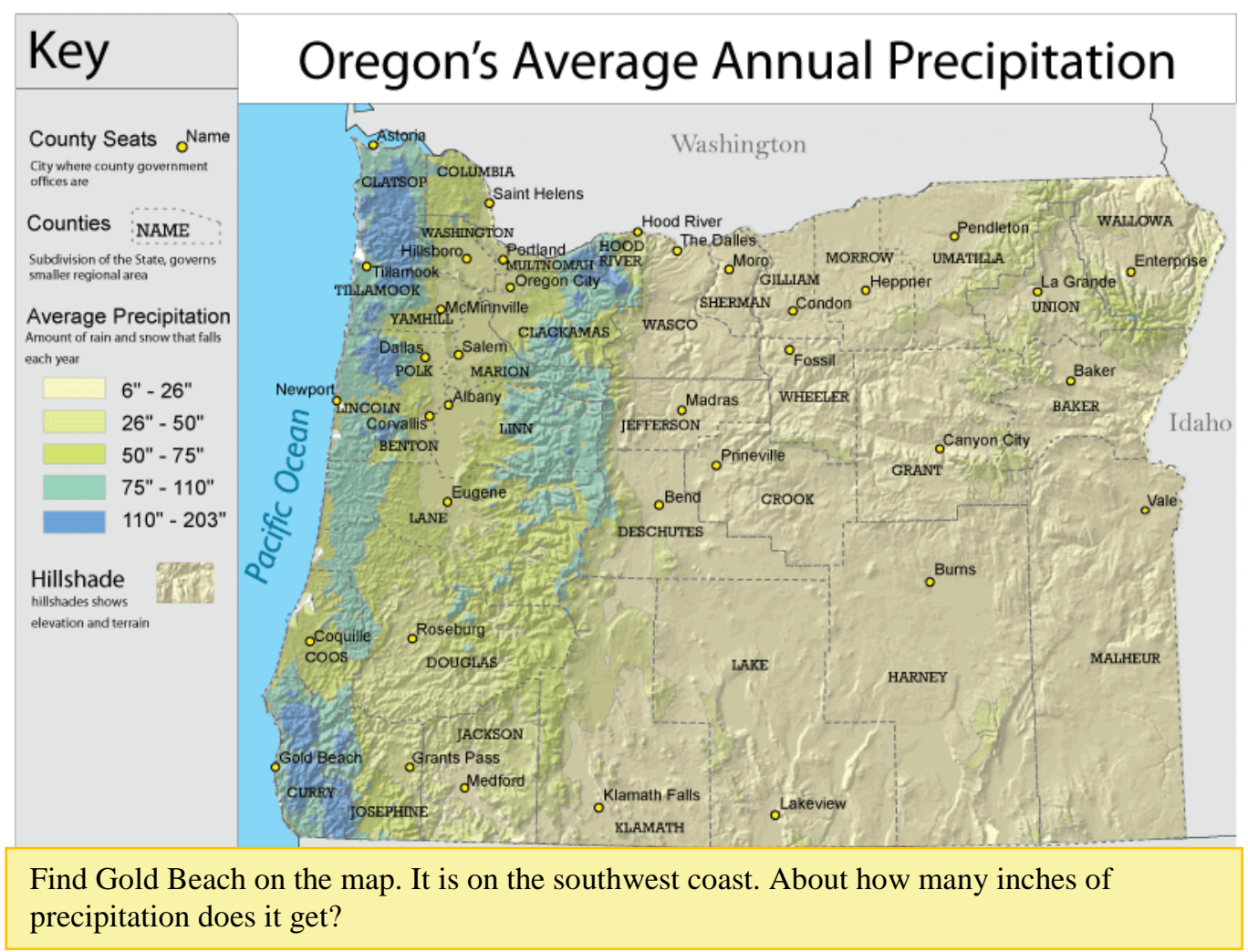

Figure 17: Sample question and map used in Questions 3 and 4 on the test.

I expected an increase in response time and a decrease in mean score as the number of layers increased on the maps that students were given. I summarized descriptive statistics for the results to Questions 3 and 4 together in Table 7.

Table 7: Summary statistics for Questions 3 and 4

\begin{tabular}{|c|c|c|c|}
\hline Layers & Count & Percent Correct & Median Time \\
\hline 2 & 25 & 36 & 35 \\
\hline 3 & 35 & 89 & 54 \\
\hline 4 & 33 & 55 & 51 \\
\hline 5 & 32 & 50 & 41 \\
\hline 6 & 34 & 56 & 57 \\
\hline 7 & 29 & 72 & 62 \\
\hline
\end{tabular}


I used the Pearson's Chi-Square test to determine if there was any relationship between the number of layers and student scores. Unlike Questions 1 and 2, there were enough responses to this question set that my data meet the requirements for the test. The resulting Chi-Square value of 21.837 exceeded the critical value of 11.07 for $\mathrm{df}=5$ and $\mathrm{p}=0.05$. In this case I can reject the null hypothesis and accept the alternate, which states that there is a significant relationship between the number of layers and the students’ scores.

I evaluated the relationship between response time and the number of layers. The response times can be seen in Figure 18. I used the Kruskal-Wallis test to evaluate the relationship between the number of layers and response time. The critical value for $\mathrm{df}=5$ and $\mathrm{p}=0.05$ is 11.07 . The test result of 10.68 is not significant so I accepted the null hypothesis.

I investigated the relationship between the presence of a hillshade and response time and score. The descriptive statistics for the results of the hillshade tests (Table 8) indicate a small difference between the mean score for maps with and without a hillshade.

Table 8: Descriptive Statistics for Question 3, Hillshade evaluation

\begin{tabular}{|c|c|c|c|}
\hline Map & Count & Percent Correct & Median Time \\
\hline Hillshade & 128 & 58 & 54 \\
\hline No Hillshade & 60 & 67 & 48 \\
\hline
\end{tabular}




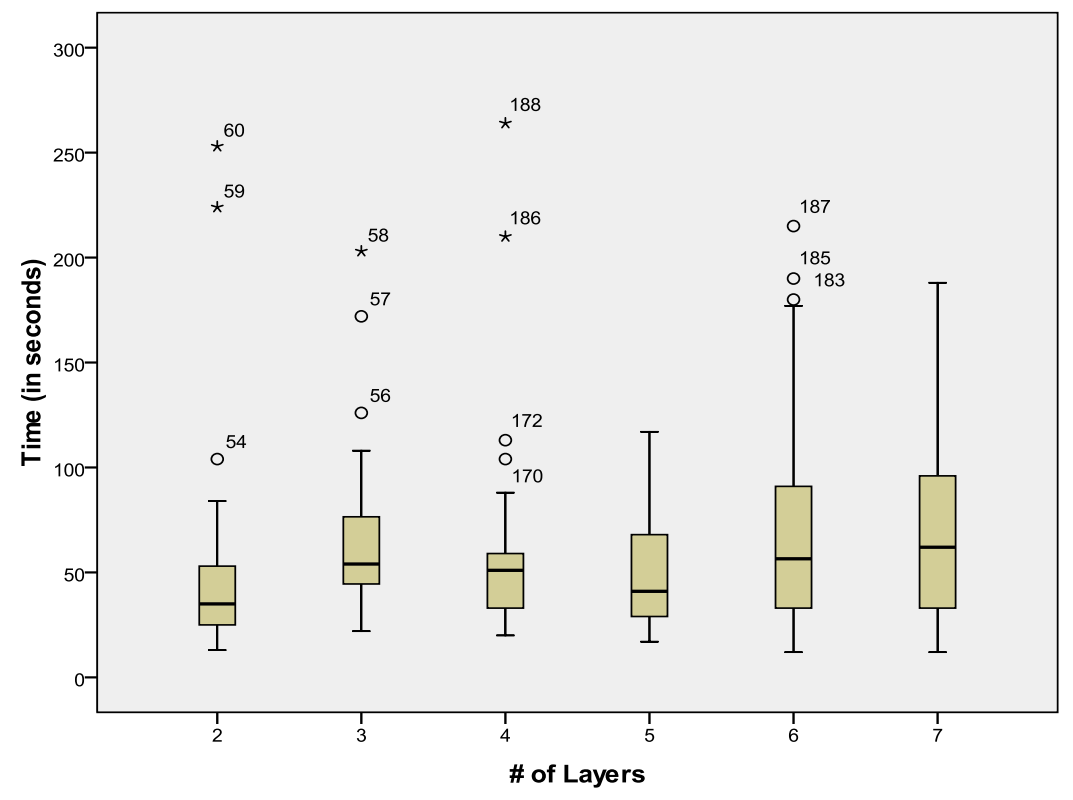

Figure 18: Response times for each map in Questions 3 and 4.

I used the Pearson Chi-Square test to evaluate the relationship between the score and the presence of a hillshade. The resulting Chi-Square value of 1.34 was insignificant with degrees of freedom $=3$ and a $\mathrm{p}=0.05$. I accepted the null hypothesis.

I used the Kruskal-Wallis test to evaluate the relationship between response times for students who had a map with a hillshade and those without (Figure 19). Like Question 2, there is no visual difference between the response times for the maps with and without hillshades. 


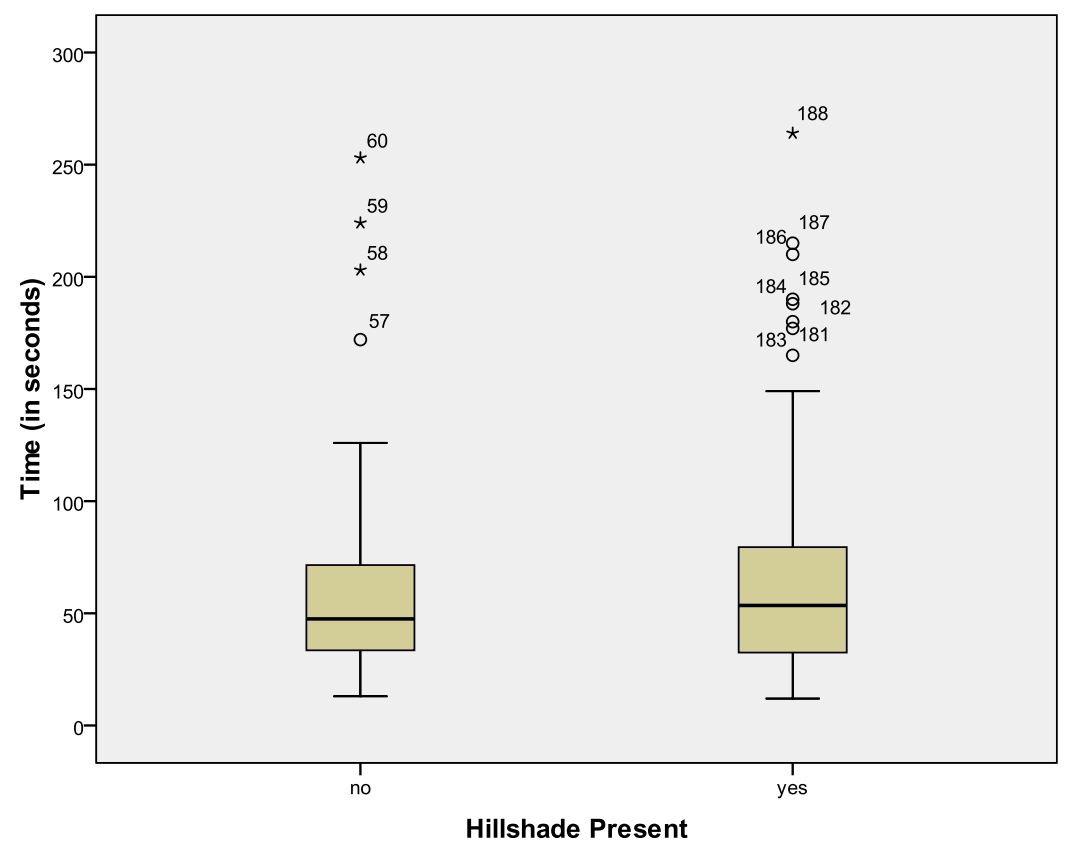

Figure 19: Response times for maps with and without a hillshade in Questions 3 and 4 . The results are nearly identical.

The results of the Kruskal-Wallis test gave a Chi-Square value of 0.421 , which is insignificant with $\mathrm{df}=1$ and $\mathrm{p}=0.05$ so $\mathrm{I}$ accepted the null hypothesis.

\section{Question 5}

Question 5 was a story problem that asked students to choose from a list of regions for the most appropriate location to grow wheat. Figure 20 shows one of six different maps; students were randomly presented with one of them. 


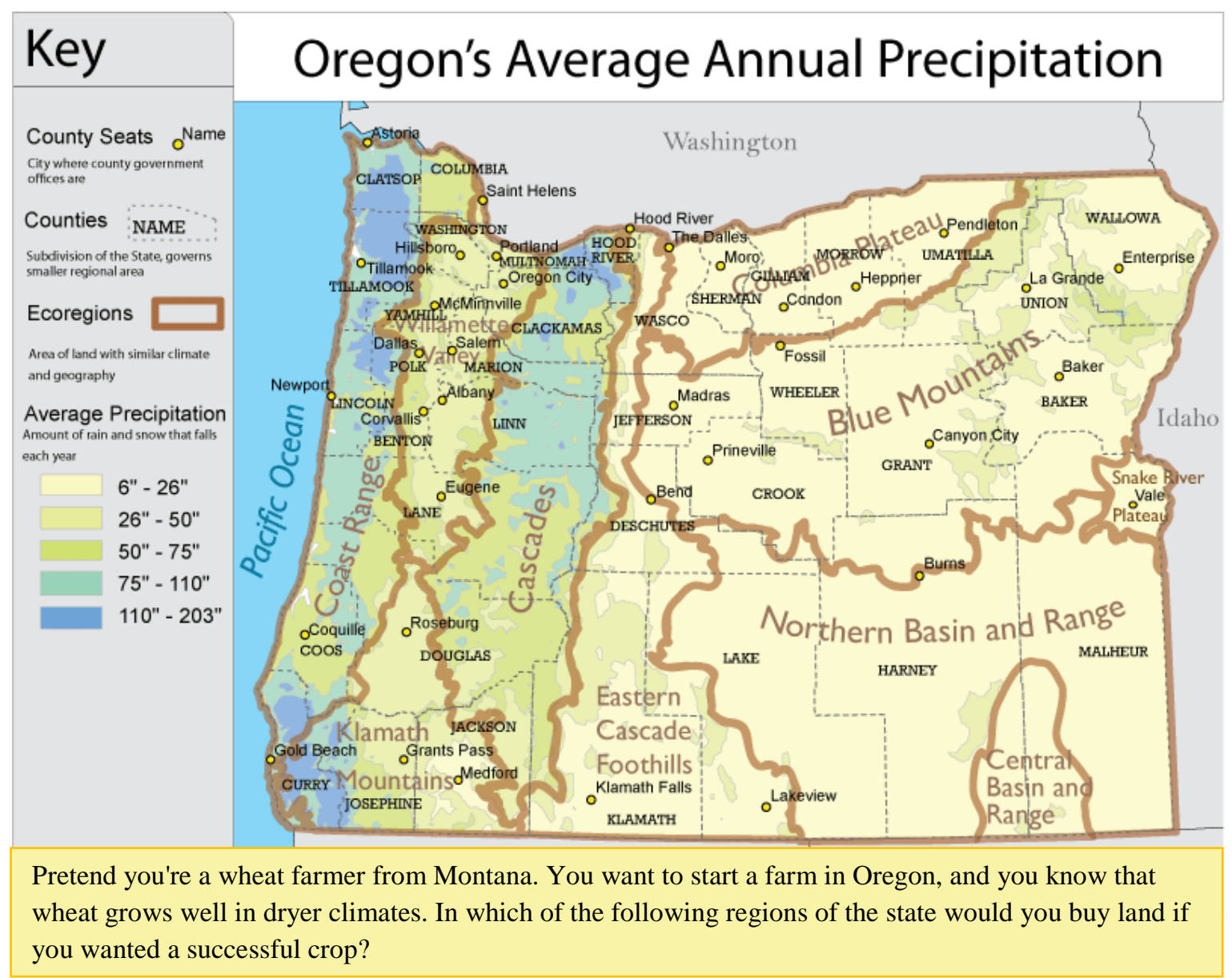

Figure 20: Question 5 asked students to choose the best region to start a wheat farm.

Because there was more than one right answer in some of the cases, I awarded a full point for any region that could be considered relatively drier than the alternative choices. For example, one combination of answers included both "Northern Basin and Range” and "Blue Mountains." Given only the information about the precipitation, both are considerably drier than the alternatives, “Cascades” and “Coast Range,” so both were awarded a full point.

I investigated the relationship between the number of layers on the map and both the student scores and response times. Table 9 shows the descriptive statistics for the results for each map identified by the number of layers. 
Table 9: Descriptive Statistics for Question 5, Layer evaluation

\begin{tabular}{|c|c|c|c|}
\hline Layers & Count & Percent Correct & Median Time \\
\hline 2 & 14 & 100 & 58 \\
\hline 3 & 20 & 80 & 60 \\
\hline 4 & 19 & 100 & 72 \\
\hline 5 & 10 & 100 & 61 \\
\hline 6 & 16 & 87 & 70 \\
\hline 7 & 16 & 87 & 64 \\
\hline
\end{tabular}

I used Pearson’s Chi-Square test to determine if there was any relationship between the number of layers and score. Unfortunately, there were not enough responses in each category to satisfy the requirements of the test so I accepted the null hypothesis.

The second test evaluated the relationship between the number of layers and response time. I used the Kruskal-Wallis test for the analysis. The results of the test were a Chi-Square value of 2.25 with $\mathrm{df}=5$ and $\mathrm{p}=0.05$. This result was insignificant so I accepted the null hypothesis.

I investigated the effect of a hillshade on student response time and score. Table 10 presents the descriptive statistics for the mean score and response time for the two maps.

Table 10: Descriptive Statistics for Question 5, Hillshade evaluation

\begin{tabular}{|c|c|c|c|}
\hline Map & Count & Percent Correct & Median Time \\
\hline Hillshade & 34 & 94 & 71 \\
\hline No Hillshade & 59 & 95 & 63 \\
\hline
\end{tabular}


I used the Pearson's Chi-Square test to evaluate the relationship between the presence of a hillshade and student score. The Chi-Square test yielded a value of 0.526 for $\mathrm{df}=1$ and $\mathrm{p}=0.05$ which was insignificant so I accepted the null hypothesis.

There was a very small difference in mean response times (Table 10), and using the Mann-Whitney U test, I confirmed that the difference between response times for maps with and without hillshades was insignificant. The $\mathrm{Z}$ score for the test was -0.57 , far below the critical value of 1.96 so I accepted the null hypothesis.

\section{Question 6}

Question 6 asked students to use a dot density map to answer a question about which county had the most of a certain type of agricultural activity. Each student was randomly assigned a question with between two and seven layers, asking the students which county had the most of a specific agricultural activity. Figure 21 shows an example of the map used in Question 6 with four layers displayed. 


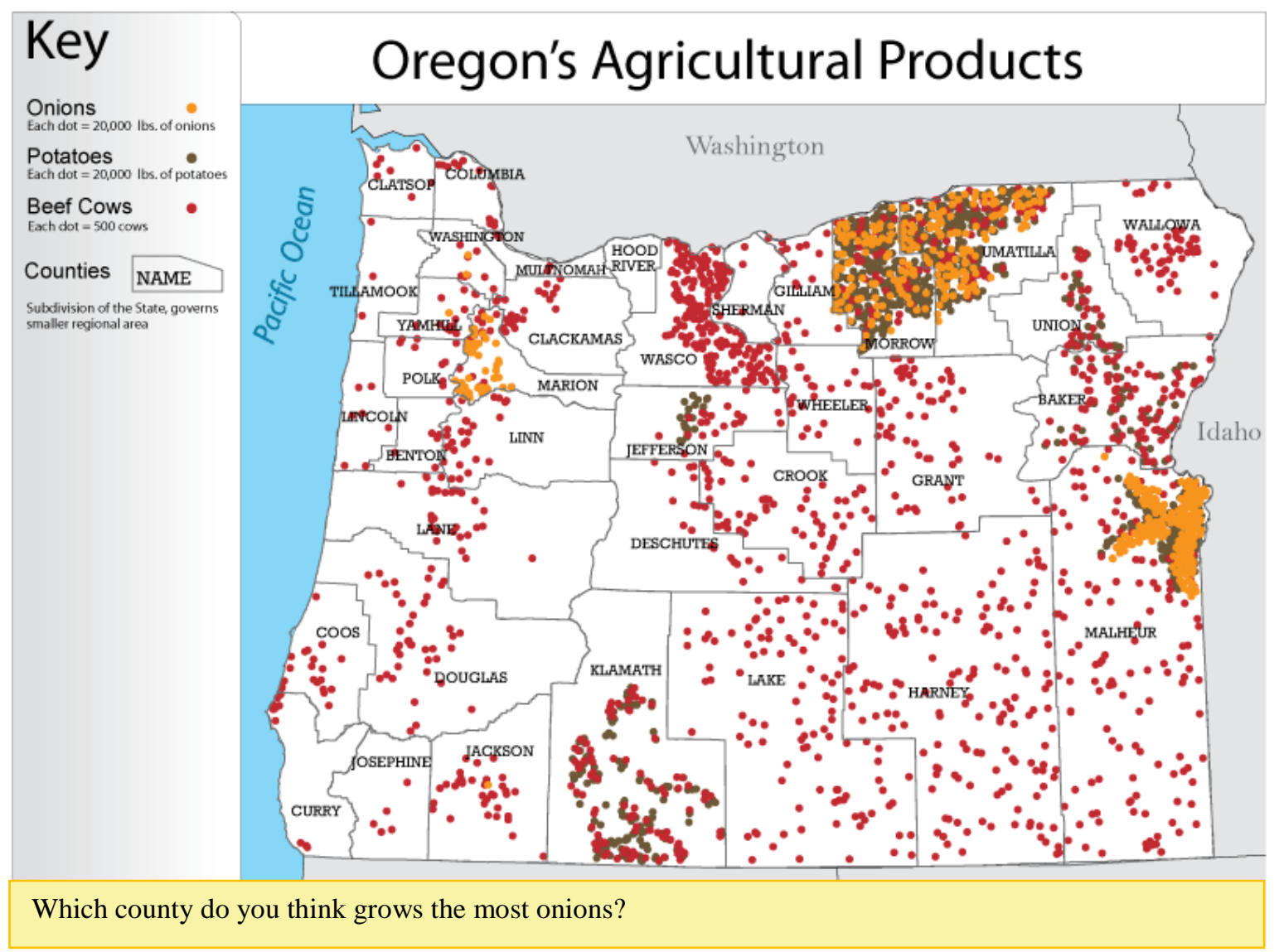

Figure 21: Question 6 used dot density maps to symbolize quantitative information.

The question was used to evaluate the effect of multiple layers on student response time and accuracy when a different type of symbolization was used. There were no maps with hillshades in this question, so there were only two tests conducted.

Table 11 contains the descriptive statistics for score and response times for the question.

Table 11: Descriptive Statistics for Question 6, Layer evaluation

\begin{tabular}{|c|c|c|c|}
\hline Layers & Count & Percent Correct & Median Time \\
\hline 2 & 19 & 84 & 49 \\
\hline 3 & 21 & 86 & 46 \\
\hline 4 & 15 & 100 & 52 \\
\hline 5 & 18 & 72 & 38 \\
\hline 7 & 22 & 95 & 36 \\
\hline
\end{tabular}


The first relationship I investigated was between the number of layers on the map and the student scores. The question might have been too easy for students because there were not enough expected "wrong” answers to use the Pearson Chi-Square test. I relied on the results of the EXACT analysis, which indicated no significant result, so I accepted the null hypothesis.

I investigated the relationship between the number of layers and student response time. Surprisingly, there was a decrease in the mean response times as the number of layers increased (Figure 22).

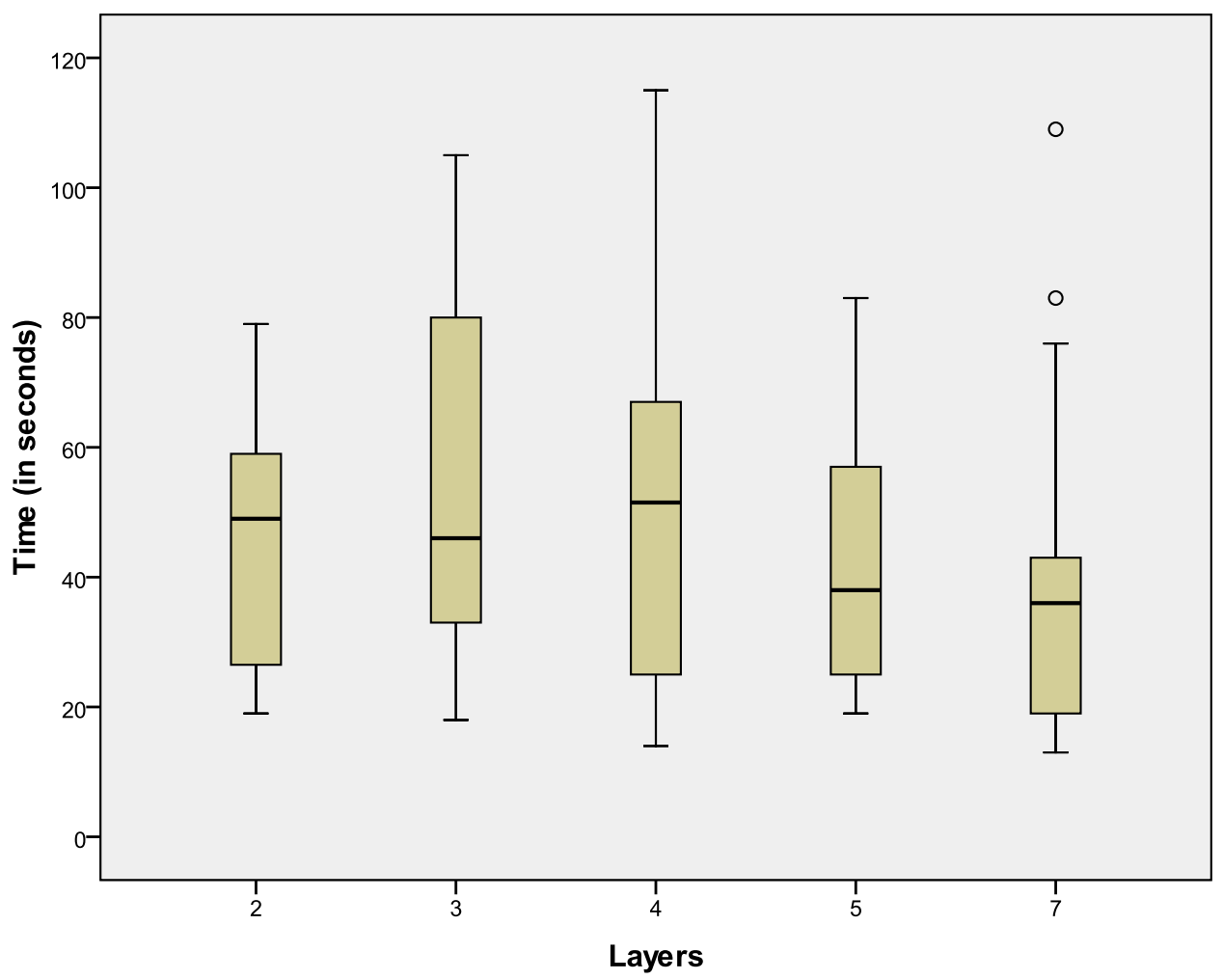

Figure 22: Question 6 response times per map. There appears to be a decrease in response time as the number of layers increases. 
I compared the time it took to respond to the question to the number of layers on the map using Kruskal-Wallis test. The critical F value for $\mathrm{df}=4$ at $\mathrm{p}=0.05$ is 9.49 , which was not a significant result. This meant that the variability between groups could be explained by chance, so I accepted the null hypothesis.

\section{Question 7}

Question 7 presented students with a multi-layered dot density map and asked them to make a decision about which agricultural activity they thought was least dependent on precipitation. The difference between the maps (Figure 23) was that some students were given a map with a hillshade and others without. This question specifically sought to evaluate the specific effects of a hillshade on the use of a multilayered thematic map.

There were only eighty responses for this question because one of the maps failed to display during the first tests in McMinnville. Those results were excluded and the map was fixed for later tests. I was able to collect fifty responses from students who were given the map without a hillshade, and thirty from students who received the map with the hillshade. The descriptive statistics for response time and score are listed in Table 12.

Table 12: Descriptive Statistics for Question 7, Hillshade evaluation

\begin{tabular}{|c|c|c|c|}
\hline Map & Count & Percent Correct & Median Time \\
\hline Hillshade & 30 & 57 & 40 \\
\hline No Hillshade & 50 & 66 & 42 \\
\hline
\end{tabular}




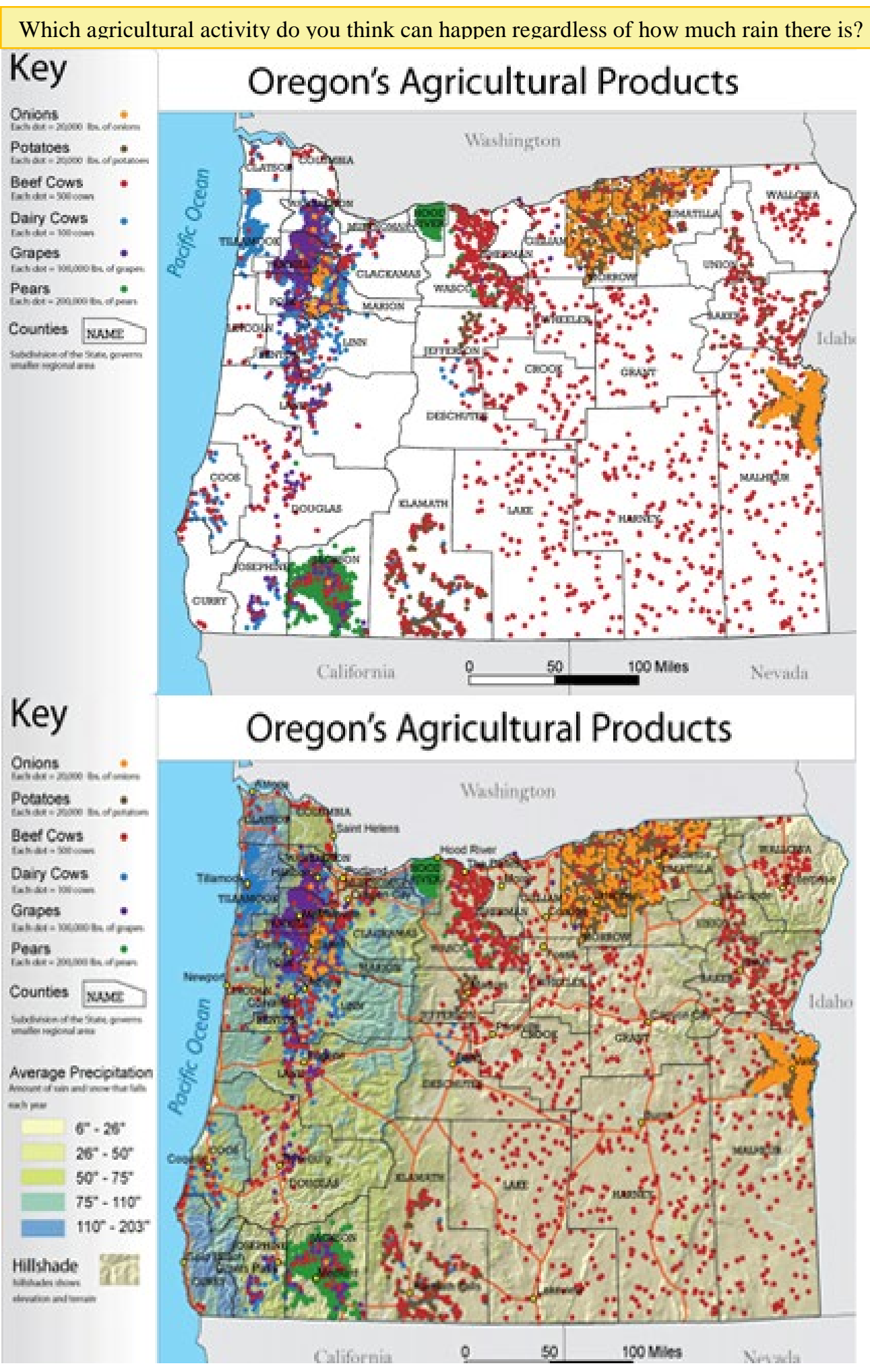

Figure 23: Question 7 compared the effect of hillshade on the use of a multi-layered dot-density map. 
I evaluated the relationship between presence of a hillshade and student response time. The response times for the map with a hillshade and without a hillshade are nearly identical (Figure 24).

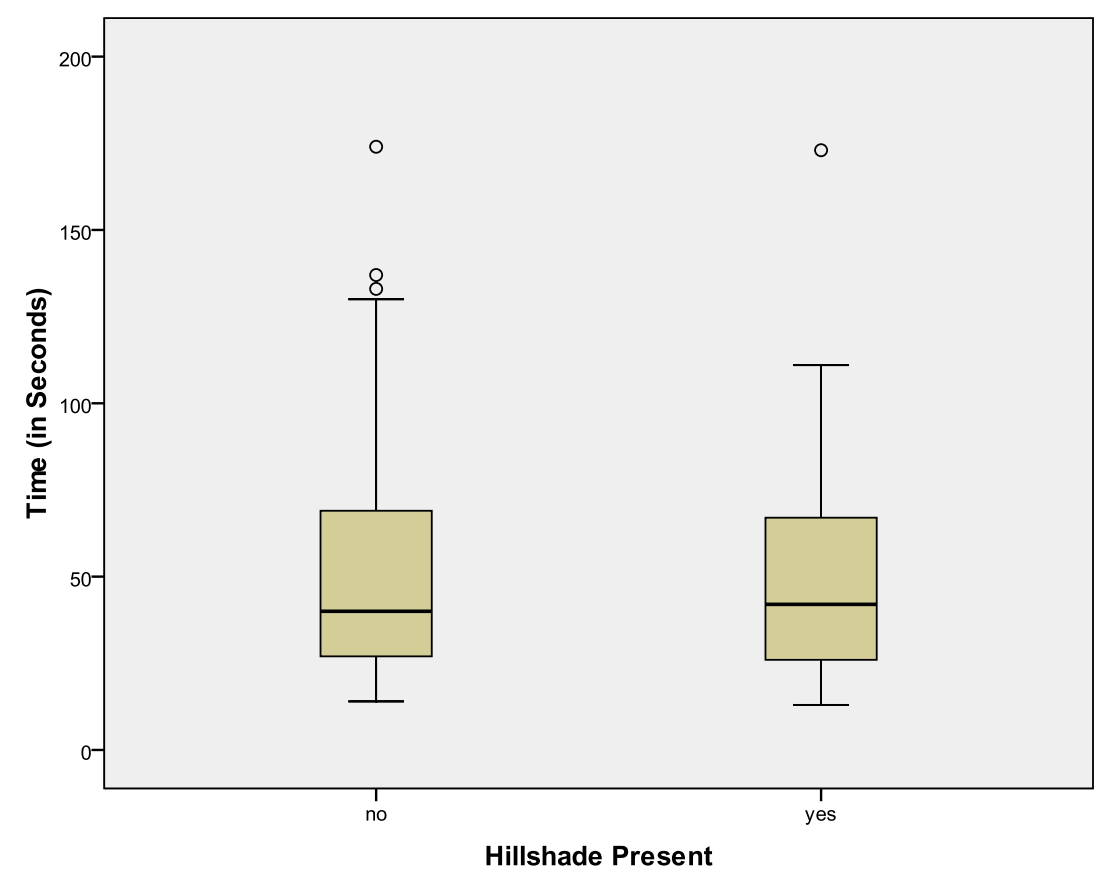

Figure 24: Response times for map with and without a hillshade for Question 7.

I used the Mann-Whitney U test to investigate any relationship between the response times for maps with and without a hillshade present. The test result was a Z score of -0.33 , which at $\mathrm{p}=0.05$ is an insignificant result so I accepted the null hypothesis.

I used a Chi Square test to evaluate any relationship between the presence of a hillshade and the score. The Chi-Square value was 0.697, and the critical F-score for $\mathrm{df}$ $=1$ and $\mathrm{p}=0.05$ is 3.84 . Because the results were insignificant, I accepted the null hypothesis. 


\section{Question 8}

Question 8 was markedly different than the previous questions. It asked students to consider two maps and pick the one they would choose to use when answering a question about precipitation and counties (Figure 25).

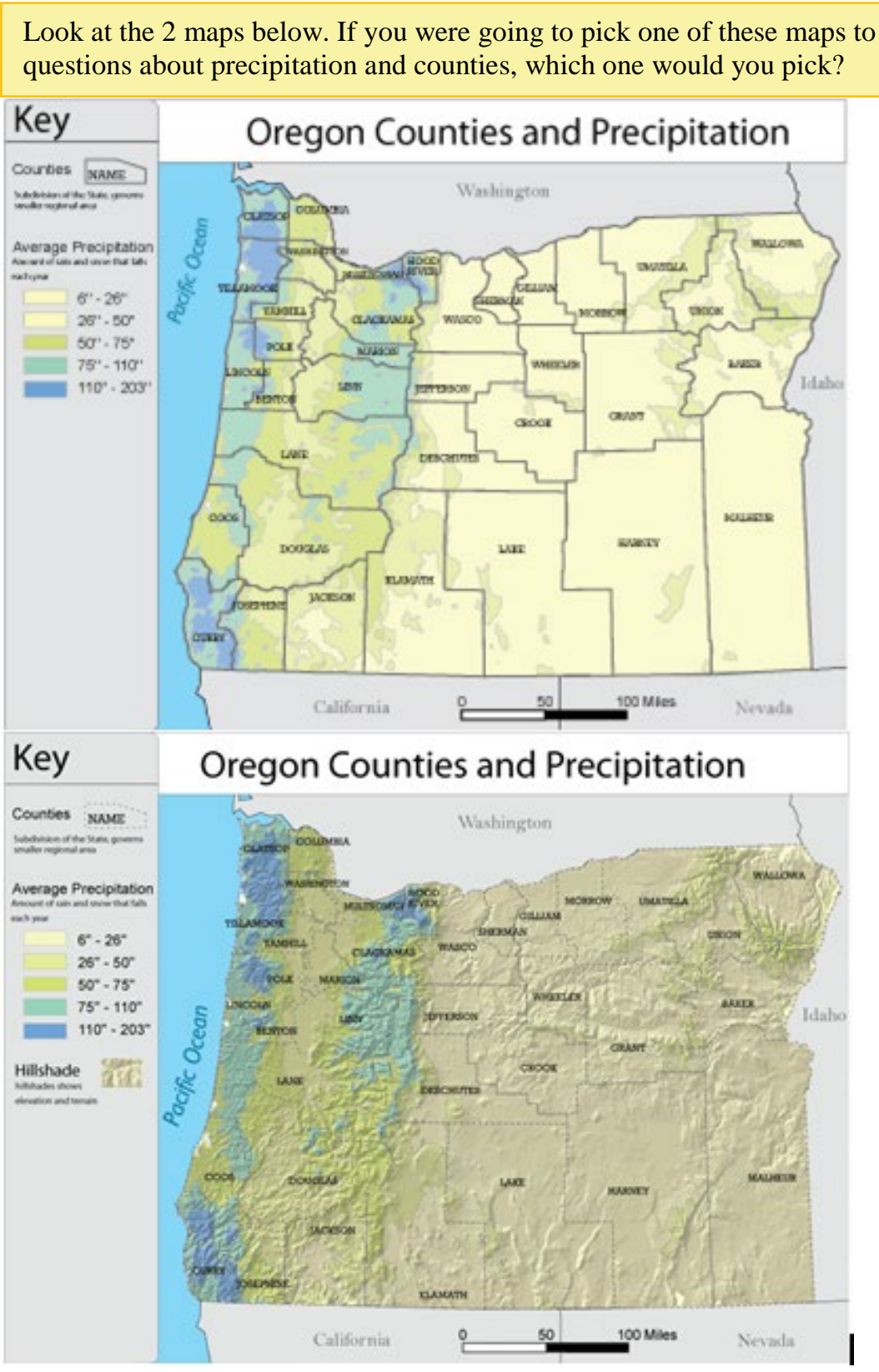

Figure 25: Question 8 presented students with two maps to choose from. One with only the necessary layers to answer the question, and one with an extraneous hillshade 
This question was an attempt to see if there was any preference among students to pick a map with a hillshade when that information was not pertinent to the question. The two maps were shown at a smaller screen size than the previous maps because the students were not expected to do any tasks using the maps. Overall, most students selected the map without a hillshade (Figure 26).

\section{Map Preference}

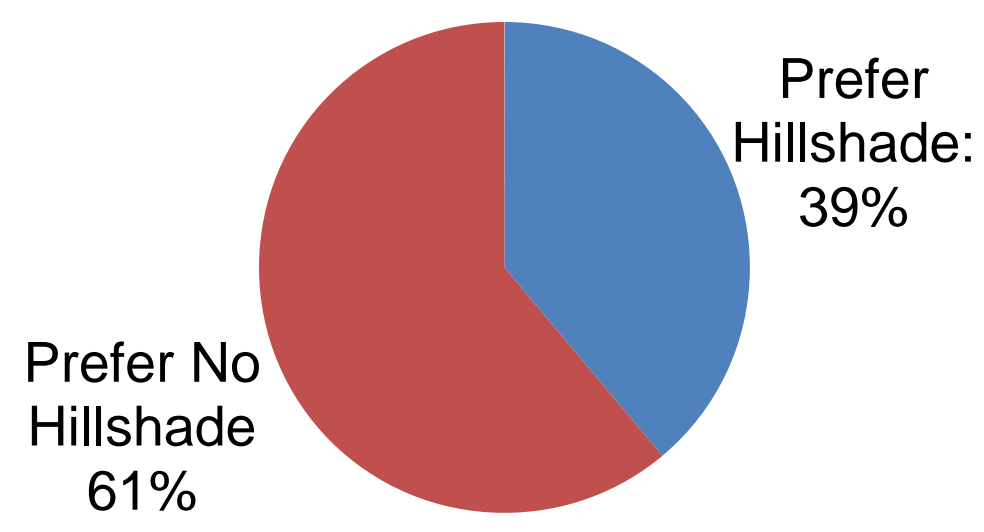

Figure 26: Map preference among students in Question 8

This question was asked to test my assumption that students would more often select a map with a hillshade because it makes the map look more "realistic" or more like reference maps that are commonly used by the public. The students were also asked to explain why they picked the map. I have grouped the student responses into the following categories:

- Visual Preference

- Legibility

- Assumed it was the right answer

- Comment not applicable (e. g. "Because my cousin Ryan sucks.”) 
Among students who picked the map with the hillshade, 17 (49\%) indicated a visual preference, and nine (26\%) felt it was more legible. Four (11\%) assumed it was right, and five (14\%) of the comments were not applicable (Figure 27).

\section{Reason for picking map with hillshade}

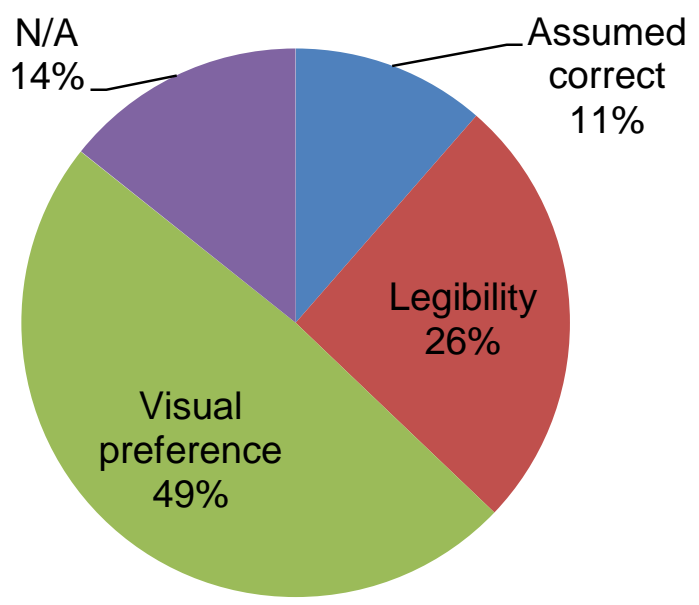

Figure 27: Reason given for picking the hillshade in Question 8

Among students who picked the map without the hillshade, 42 (75\%) felt it was more legible, four (7\%) thought it was the correct answer, and only two indicated that it was because of a visual preference (Figure 28). 


\section{Reason given for picking map without hillshade}

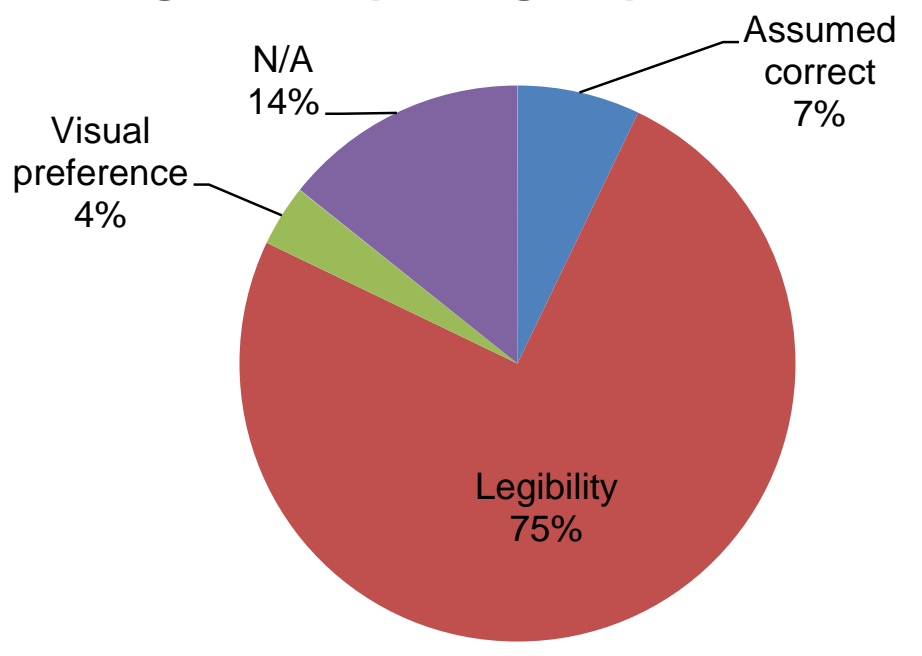

Figure 28: Reason student gave for picking map without hillshade in Question 8

Overall, 56\% of students listed legibility for the reason they picked one of the maps over the other; $21 \%$ listed a visual preference.

\section{Question 9}

Question 9 asked students to select a map to answer a question about onion production and counties (Figure 29). They were presented with two maps, one with only counties and onions, and one with counties, onions, precipitation and a hillshade layer. 
Look at the 2 maps below. If you were going to pick one of these maps to use when answering questions about counties and growing onions, which one would you pick?

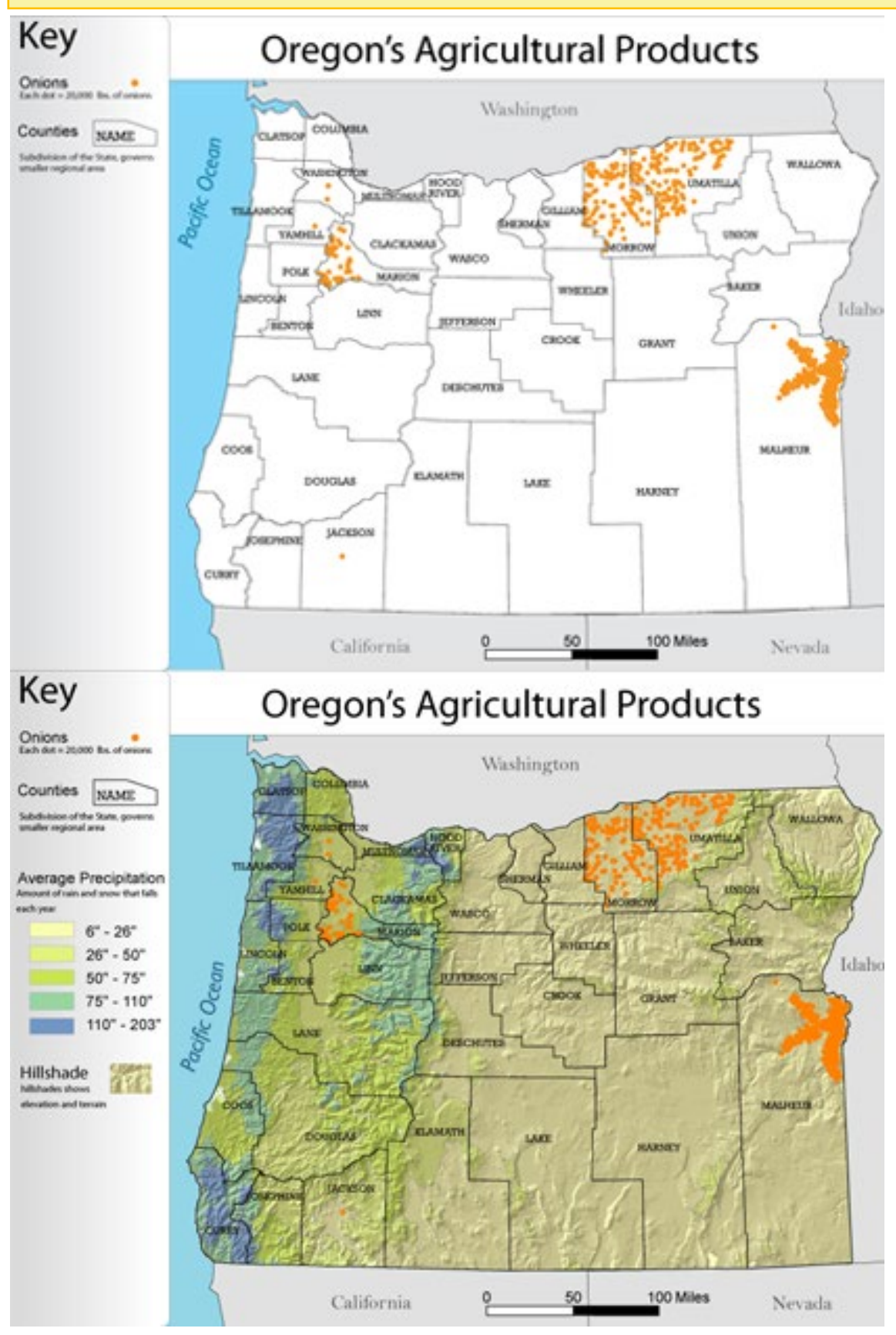

Figure 29: Question 9 asks students to select a map to answer questions about growing onions and counties 
The map with two layers had all the pertinent information for answering the question. Students' selections can be seen in Figure 30. A majority of students selected the map without the hillshade, but over $40 \%$ still chose the map with extraneous information on it.

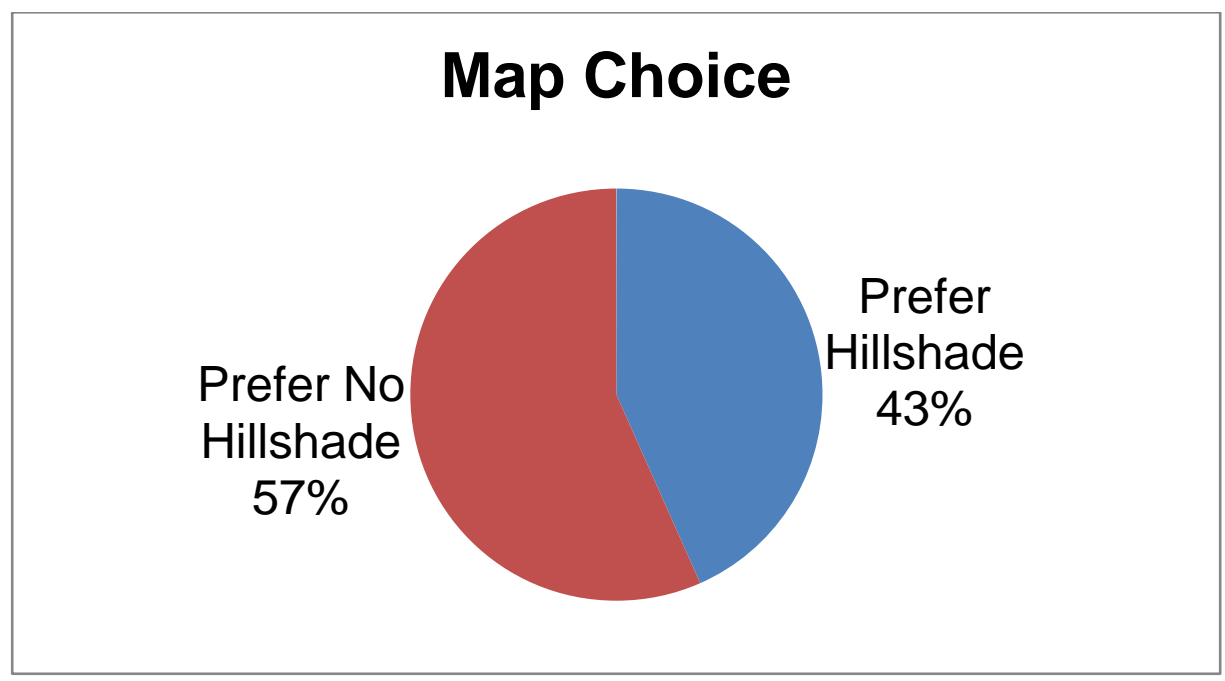

Figure 30: Map Choices for Question 9

I also asked students a follow-up question about their choice. I evaluated the responses and assigned the responses to the following categories:

- Visual Preference

- Legibility

- N/A

- Assumed it was right

Again, a majority of students indicated through comments that they picked the map without a hillshade because it was more legible (Figure 31). Students who picked the map with a hillshade indicated visual preference (Figure 32). 


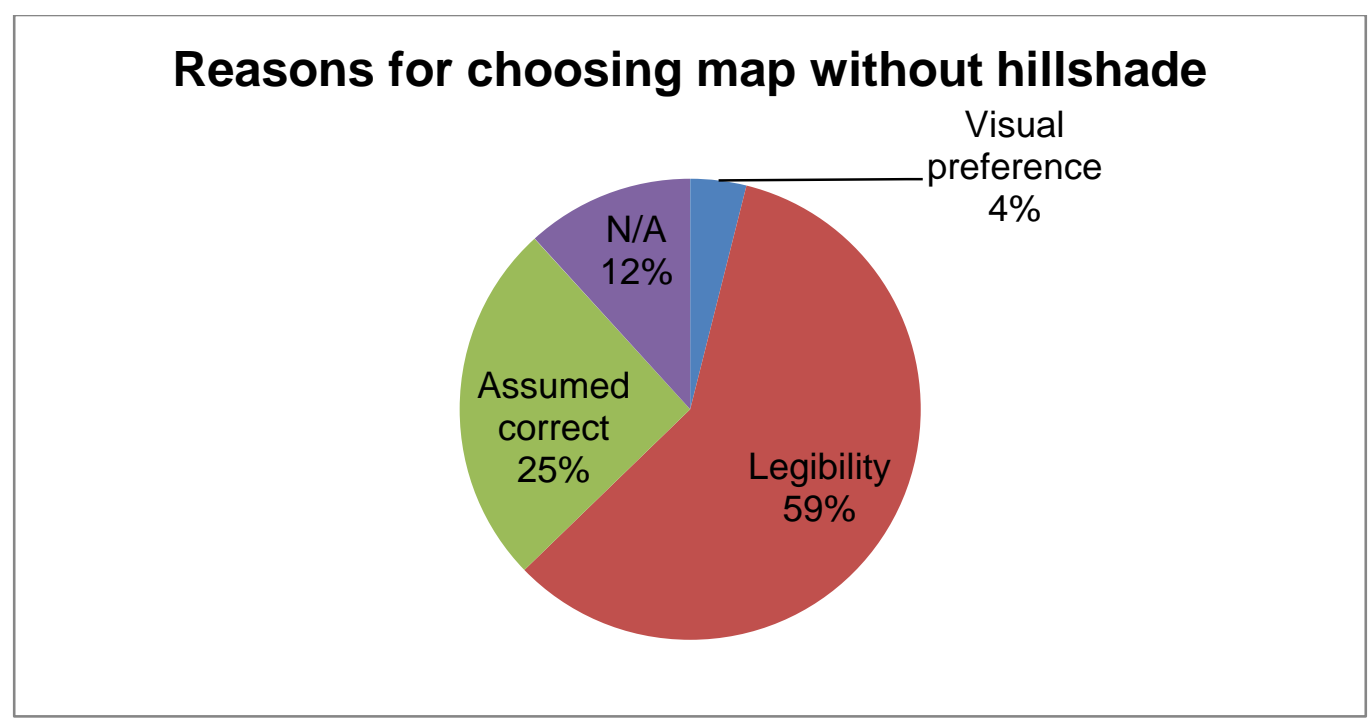

Figure 31: Reason given for choosing map without the hillshade.

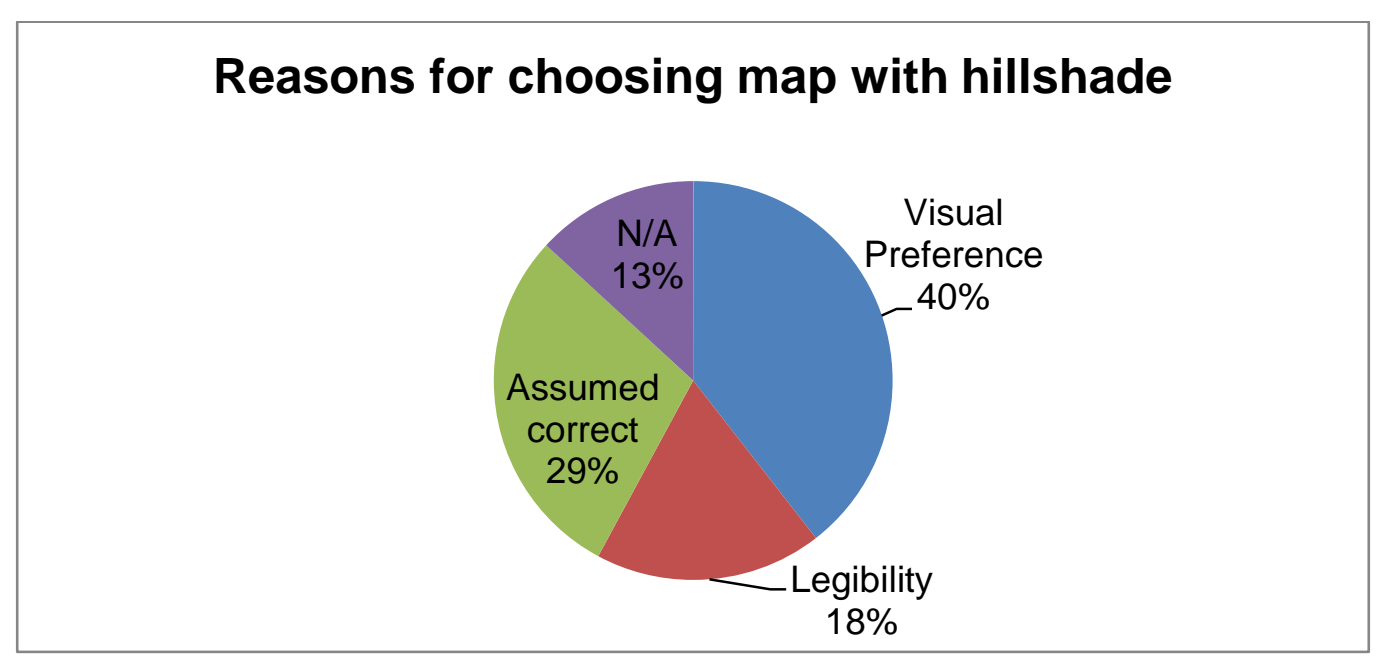

Figure 32: Reason given for choosing map with hillshade present

I did a Pearson's Chi-Square test to compare map selection to stated reason and for choice and found a significant relationship between map choice and reason for choosing the map. 


\section{Chapter 5: Analysis and Discussion}

My results indicate that there was often a significant relationship between the number of layers and students' response time while answering questions. This chapter evaluates the results of each question and discusses what each test result indicates about student use of web-based layer maps. Some of the results created further questions, and others indicated problems with the individual design of some questions.

\section{Discussion for Question 1}

Question 1 asked students to indentify which region received the most precipitation. Students were presented with a map and four regions to pick from. One of three possible maps was given to each student, and each map had a differing number of layers. The results from Question 1 indicate that the number of layers on a map affects student response time while answering the question (Table 13). The KruskalWallis test results reveal that there were significant differences in response times for users of maps with differing numbers of layers.

Table 13: Summary of Findings for Question 1

\begin{tabular}{|l|l|c|c|c|}
\hline \multicolumn{1}{|c|}{$\begin{array}{c}\text { Factors } \\
\text { Compared }\end{array}$} & \multicolumn{1}{|c|}{ Test used } & Test result & $\begin{array}{c}\text { Critical } \\
\text { Value }\end{array}$ & $\begin{array}{c}\text { Significant at } \mathbf{p}= \\
\mathbf{0 . 0 5} \boldsymbol{?}\end{array}$ \\
\hline Layers \& Score & SPSS Exact & .313 & .05 & No \\
\hline Layers \& Time & Kruskal-Wallis & $\mathrm{X} 2=26.50$ & $\mathrm{df}=2,5.99$ & Yes \\
\hline $\begin{array}{l}\text { Hillshade \& } \\
\text { Score }\end{array}$ & SPSS Exact & .490 & .05 & No \\
\hline $\begin{array}{l}\text { Hillshade \& } \\
\text { Time }\end{array}$ & Mann-Whitney U & $\mathrm{Z}=-3.85$ & $\mathrm{Z}=1.96$ & Yes \\
\hline
\end{tabular}

This supports my research hypothesis that the effect of layers on response time, but there was no significant finding regarding the effect of layers upon student scores. 
The mean score for the first question was 0.89 , which indicates a high success rate among students. However, there was no significant difference in mean scores for students using the maps with two, three or five layers present.

There was also evidence that suggests that the presence of a hillshade affects response time. While this would also support one of my research hypotheses, the results of the hillshade test are likely a byproduct of the same effect measured by the layers test. Since the map with five layers also included a hillshade, and that map was identified as having a significantly greater response time in the layers test, the hillshade/response time result could be attributed to the number of layers, however, there was not enough evidence from this question alone to make that assertion. Therefore, the lack of a significant relationship between the presence of a hillshade and response times in the results from the remaining questions indicates that the number of layers was more likely the cause for the significant result in the hillshade/response time test.

There was no significant difference in mean scores for students who received a map with a hillshade and those who did not.

It is worth noting that the relative simplicity of this question meant that there were not enough incorrect responses to perform the Pearson Chi-Square test for the score-based comparisons. The SPSS Exact test was used and confirmed that the null hypothesis should be accepted.

Question 1 was the only multi-layer map test that indicated a positive relationship between the number of layers and the response time. That is, as the number 
of layers increased, so did the response time. Subsequent results for the remaining questions do not indicate a similar pattern. I suspect that this result may have to do with this question coming first in the exercise. This was students' first opportunity to try out the map and answer a question themselves. Subsequent questions may have differed, but the students gained familiarity with the map in this question. However, I do not have any data to support this assumption.

\section{Discussion for Question 2}

Question 2 required students to repeat the same task from Question 1 but the maps students were given had different layers present. There were four maps used in Question 2; one with four layers, two with six layers, and one with seven layers. The results for the Question 2 (Table 14) indicate a significant relationship between the number of layers present on a map and the students' response times, which confirms one of my research hypothesis there is a significant relationship between the number of layers and response time.

Table 14: Summary of Findings for Question 2

\begin{tabular}{|l|l|l|l|l|}
\hline Factors Compared & Test used & Test result & $\begin{array}{l}\text { Critical } \\
\text { Value }\end{array}$ & $\begin{array}{l}\text { Significant } \\
\text { at } \mathbf{p = 0 . 0 5 ?}\end{array}$ \\
\hline Layers \& Score & EXACT & 0.073 & 0.05 & No \\
\hline $\begin{array}{l}\text { Layers \& Time (6 layer } \\
\text { results combined) }\end{array}$ & Kruskal-Wallis & $\mathrm{X} 2=8.65$ & $\mathrm{df}=2,5.99$ & Yes \\
\hline $\begin{array}{l}\text { Layers \& Time (6 layer } \\
\text { results separated) }\end{array}$ & Kruskal-Wallis & $\mathrm{X} 2=9.15$ & $\mathrm{df}=3,7.82$ & Yes \\
\hline Hillshade \& Score & EXACT & 0.29 & 0.05 & No \\
\hline Hillshade \& Time & $\begin{array}{l}\text { Mann- } \\
\text { Whitney U }\end{array}$ & $\mathrm{Z}=-0.12$ & $\mathrm{Z}=1.96$ & No \\
\hline
\end{tabular}


The results from Question 2 do not indicate any relationship between the number of layers and score, nor is there evidence of a relationship between the presence of a hillshade and score or response time. I intentionally placed two different maps with six layers in this question: one with a hillshade and one without. My intention was to determine if a map with a hillshade corresponded to different scores or response times when the number of layers remained the same. The two six-layer maps had identical mean scores (0.94) and while the mean response times differed; the difference was not significant ( $\mathrm{Z}$ score of 0.76 ).

Unlike Question 1, there was not a positive relationship between the number of layers and response time (Figure 33), and the map with the fewest layers had the highest median response time.

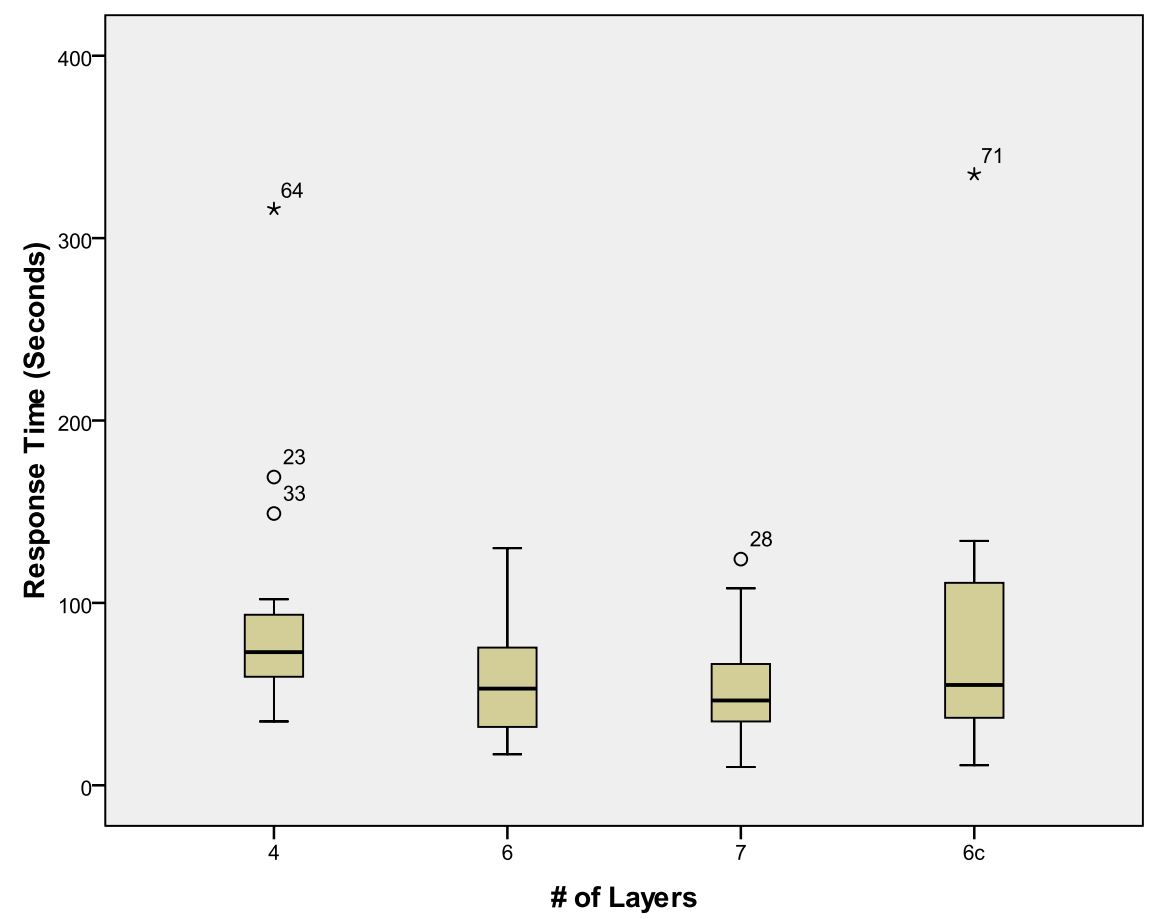

Figure 33: Response times for each map in Question 2. The map labeled 6C did not include a hillshade as one of the layers. 
I reviewed the map with four layers to see if there was anything in the map or questions that might have caused this result. I could not find any reason for the higher mean response time. In fact, the only difference between the maps provided was the number of layers present. The map with seven layers included the same four layers as the four layer map and had additional competing visual elements. I cannot explain this result, though it may suggest that in some cases, the type of layers present may assist the map reader by adding context to the theme being evaluated. The map with seven layers added rivers, highways, and County borders, which may have provided the students with additional information that was useful to them in answering the question.

\section{Discussion for Questions 3 and 4}

Questions 3 and 4 asked students to locate a specific county seat on the map and identify the amount of precipitation from the four multiple-choice options. Each question included a short description of the location (Southwest corner of the state) for each county seat. The descriptions were intended to reduce the potential effect on response time that a student's prior knowledge, or lack thereof, might have on locating the individual county seats.

The results of this question indicate a significant relationship between the number of layers on the map and student score. However, there was not any significant relationship between the number of layers and the students' response time. This result surprised me because it was the opposite of my results from Questions 1 and 2. The Chi-Square result for the evaluating the relationship between the number of layers and response time were just beyond my threshold for significance (Table 15). 
Table 15: Summary of Findings for Questions 3 \& 4

\begin{tabular}{|l|l|c|c|c|}
\hline \multicolumn{1}{|c|}{$\begin{array}{c}\text { Factors } \\
\text { Compared }\end{array}$} & \multicolumn{1}{|c|}{ Test used } & Test result & $\begin{array}{c}\text { Critical } \\
\text { Value }\end{array}$ & $\begin{array}{c}\text { Significant at } \mathbf{p}= \\
\mathbf{0 . 0 5} \text { ? }\end{array}$ \\
\hline Layers \& Score & $\begin{array}{l}\text { Pearson Chi- } \\
\text { Square }\end{array}$ & $\mathrm{X} 2=21.8$ & $\mathrm{df}=5,11.07$ & Yes \\
\hline Layers \& Time & Kruskal-Wallis & $\mathrm{X} 2=10.68$ & $\mathrm{df}=5,11.07$ & No \\
\hline $\begin{array}{l}\text { Hillshade \& } \\
\text { Score }\end{array}$ & SPSS Exact & .490 & .05 & No \\
\hline $\begin{array}{l}\text { Hillshade \& } \\
\text { Time }\end{array}$ & Mann-Whitney U & $\mathrm{Z}=-3.85$ & $\mathrm{Z}=1.96$ & No \\
\hline
\end{tabular}

Surprisingly, the map with the fewest layers had the lowest median score. The question associated with the 2-layer map referenced McMinnville, Oregon, which was where two of the schools I visited were located. In fact, $46 \%$ of my sample came from McMinnville. The low median score was surprising because the map associated with it had the fewest layers, and only included the necessary layers to answer the question. Every other map in this question included these same two layers. I looked at the individual results for this map and found 12 of the 24 students who used the two layer map were from McMinnville, yet the mean score for just the McMinnville students was not significantly higher than the other students'. This result is counterintuitive and I cannot explain it with the information I collected.

There was no significant relationship between the presence of a hillshade and student score or response time from the data collected with Questions 3 and 4, so neither of my research hypotheses regarding hillshades is supported.

It is worth sharing my experience using the randomization of questions for this question in case it may aid future research using the Blackboard software. Blackboard's ability to randomize delivery of maps in Questions 3 and 4 helped assign two maps 
from a potential of seven, making it possible to collect enough samples using each map without having to test students using all seven maps. However, it resulted in a significant chore matching student response times to question choices. I would not recommend using randomized question pools for distributing questions in similar research because of the additional effort and increased likelihood for error while manually collating the results.

\section{Discussion for Question 5}

Question 5 asked students where they would choose to start a wheat farm knowing that wheat tends to prefer dryer climates. Students were then given a list of potential regions to select from and a map that contained layers with regions, precipitation, and a differing number of other layers that were not needed to answer the question. However, since many of the layers were equally appropriate if only using the precipitation data, any of the regions on the eastern side of the state qualified as a "dry" region compared to those on the west. If students had both Blue Mountains and Columbia Plateau as options, both were appropriate choices given only the map to decide with.

I did not find any significant relationship between the number of layers and score, number of layers and response time, presence of a hillshade and score, or presences of a hillshade and response time.

\section{Discussion for Question 6}

Question 6 presented students with a dot density map displaying one or more agricultural activities. Students were asked to determine which county they thought had 
the most of a specific agricultural activity using the map. The maps ranged from having two layers (counties and onions) to seven layers (counties, onions, potatoes, beef cows, dairy cows, grapes, and pears) and the associated question varied between maps.

The results for response time in Question 6 were surprising. There was an overall decrease in the mean response time as number of layers increased (Figure 34)

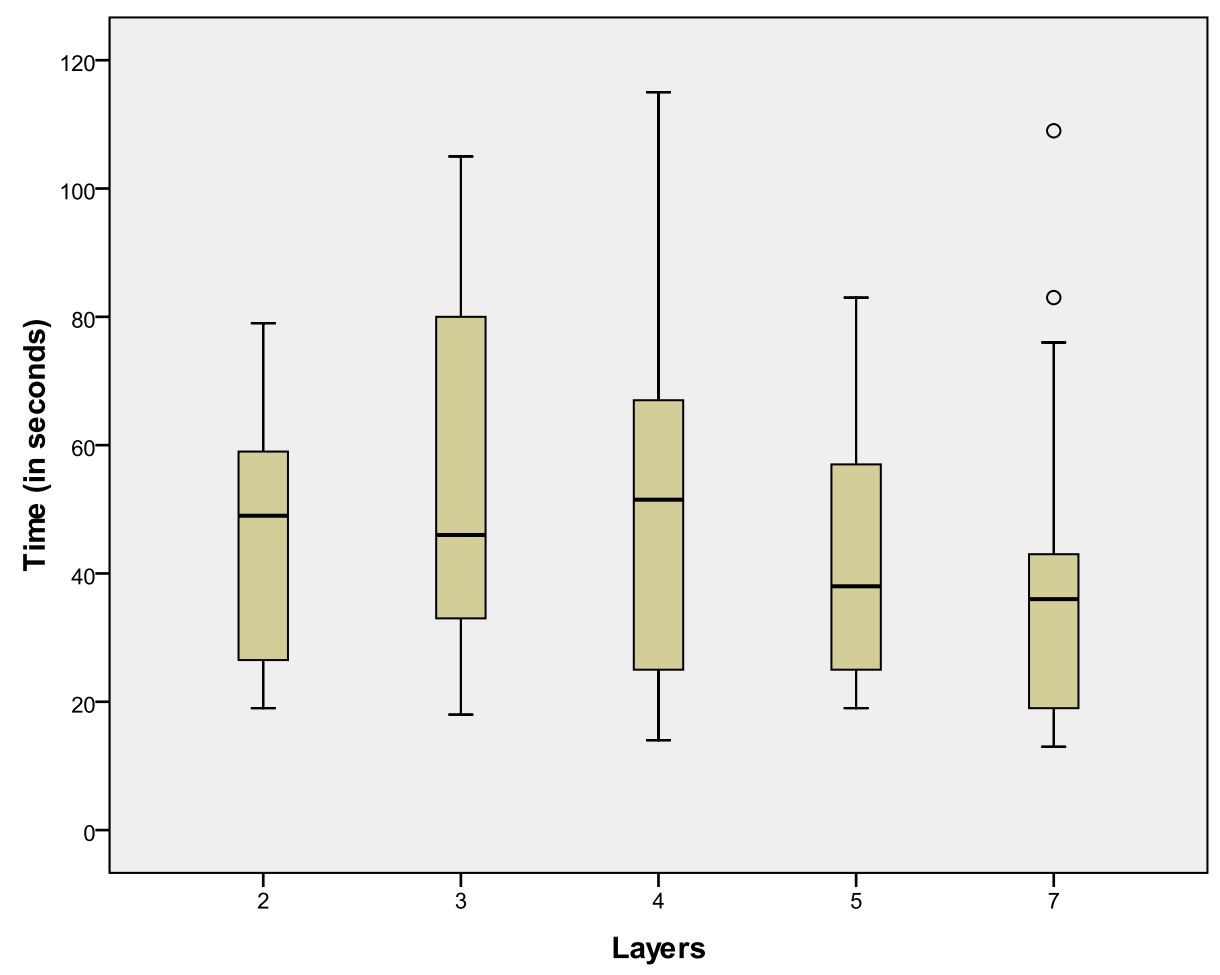

Figure 34: Response times for each map in Question 6. There appears to be a decrease in response time as the number of layers increases. Puzzling.

This was not only contrary to what I had expected prior to the data collection, but it was the opposite of the relationship indicated in Question 1. I suspect the decrease in mean response time as the number of layers increased was a result of the question asked, not a result of map complexity. The map and question varied for each user, and the type of attribute being evaluated varied between maps. The test was initially 
designed to give students two questions from a pool so students would not be given the same question twice. However, after the pilot revealed the test was too long, I shortened the test by delivering only one question from the pool. I failed to remove questions from the pool that asked about different agricultural activities.

Specifically, the question listed with the four-layer map was about the locations of beef cows, which has a more dispersed distribution on the map and less obvious clusters than the agricultural activities referred to in maps with two, three, five, and seven layers (Figure 35).

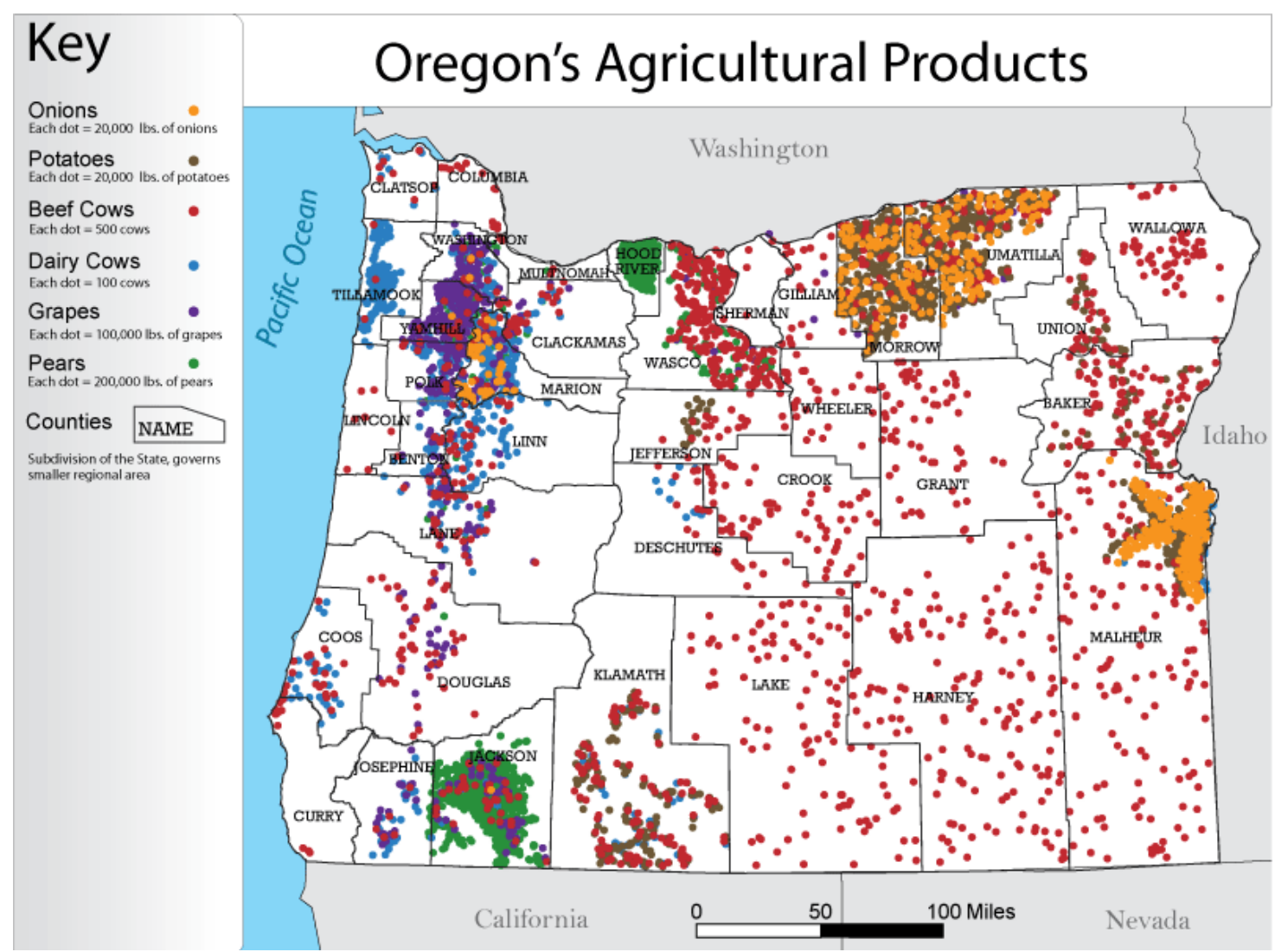

Figure 35: Notice the dispersion of beef cows (red) compared to onions (orange) which was used in the layers two and three maps, or pears or dairy cattle in the five and seven layer maps.

The question given to students with the seven-layer map required them to locate the county that grows the most pears. Despite the overall complexity of the seven-layer 
map, it resulted in the shortest mean response time. I believe the shorter response time was related to the clustering of pears in two specific regions, Jackson and Hood River counties. Even with the competing layers, the densely clustered dots in only two locations meant that there was very little search time and visual analysis needed for a simple pairwise comparison. Compare this to the question asking about beef cows, which required students to compare multiple counties spread across the state with fewer large clusters.

The unexpected results could also have been the result of poor symbolization on the maps. While Stephanie Gaspers found that $6^{\text {th }}$ graders were successful in using dot density maps (2007), her maps and test subjects only evaluated one phenomenon (e.g. population) at a time. It is possible that the clustering of potatoes, beef cattle and onions in some counties made it difficult to compare agricultural activities because of similar symbol size and color used for activities with overlapping geographic locations. The similarity in color is especially problematic in counties like Klamath (Southwest Oregon) and Morrow (Northeast Oregon), where the red and brown might have been confused.

I think it would be best to exclude this question from the overall analysis because the differences in response time and score are more likely influenced by problems with the question design. For example, during the question development phase, I had some concern that students would answer this question using prior knowledge and familiarity of the Tillamook brand, as Tillamook County was the correct answer. Oddly enough, the lowest mean score occurred with the five-layer map (mean 
score 0.72 ), which asked students which county they thought had the most dairy cows.

The median score was 0.87 for the question across all maps.

\section{Discussion for Question 7}

Question 7 presented students with a multi-layered dot density map with several agricultural activities displayed. Some students received a map with a hillshade, others without. The purposes of the question was to see if a hillshade had a specific noticeable impact on response time when that was the only difference between maps. The question also asked students to compare agricultural activities and determine which seemed least dependent on precipitation.

I expected a significant difference in the amount of time it took students to respond when a hillshade was present, and for more incorrect responses. The results did not indicate any significant difference in response time or score. Response times were nearly identical for both maps (Figure 36).

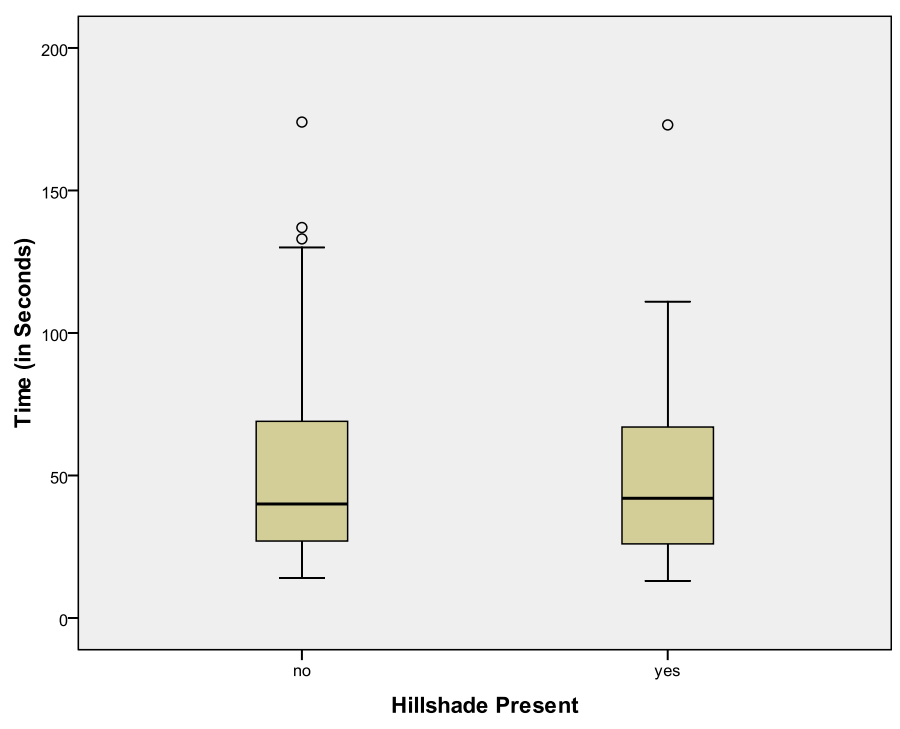

Figure 36: Response times for map with and without a hillshade in Question 7. 
It is possible that students could have answered this question using their understanding of agriculture rather than by analyzing the map. However, I suspect that students did use the map in most cases. Since most of the agricultural activities exhibit a clustered nature, the beef cows stand out as dispersed with dots in areas with different precipitation. I asked a follow-up question and provided students with a free-response form to submit their answer. There were a lot of silly responses, but among the students who got the question correct, there were several thoughtful responses:

- "Because the red dots meant they were raising beef cows in that area. The red dots were everywhere on the map, not just in one place."

- "because beef cattle was everywhere in the north south west and east"

- "Because there were beef cattle in all different climates"

- "because cows don't need as much water as fruit trees"

- "I picked beef cattle because they it grass and do not need a lot of water or sunlight." "

- "Because you don't need rain or sunshine to grow cattle. You don't even grow cattle, you raise them."

- "there was more red dots on the map"

- "Because there is a lot of red"

While the responses are not universally accurate, the answers do indicate two different thought processes. One was evaluating the location of the red dots, which symbolize the cows, and the second was an understanding about animal husbandry. It is interesting that many used the word "cattle" when the key refers to cows. I interpret this choice of vocabulary as reflecting some understanding of the animals among some students, but their answers also refer to the placement of the beef cow symbols on the map. It is not clear if the results indicate a decision based on prior knowledge, or if the map itself led students to a conclusion about beef cattle. 
It is worth noting that among students who got the answer incorrect, many selected "growing grapes" for their answer. The follow-up responses for those who selected grapes indicated that these students misunderstood the question and picked which activity that they expected required the most precipitation. For example:

- "Because there was a lot of purple dots where it showed there was a lot of precipitation, and purple meant grapes."

- "There were a lot of grapes grown were there was high precipitation"

- "Because grapes need water"

The selection of grapes had no correlation to schools, so it is unlikely that students from McMinville, located in vineyard-laden Yamhill County, were simply rooting for the home team.

\section{Discussion for Question 8}

Question 8 presented students with a hypothetical question and two maps from which they were to choose one to answer the hypothetical question. The question asked which map they would use to answer a question about precipitation and counties. One map had only those two layers present, and the other had those same layers plus a hillshade.

This question tried to evaluate one of my concerns about using interactive layer maps in the classroom. While the previous questions investigated the specific effect of layers and hillshades on student response time and accuracy, this question investigated the likelihood that a student might add additional non-essential information to a map when answering questions. In this case, the first map contains all the information 
needed to answer the question. However, nearly $40 \%$ of the students indicated that they would prefer the map with a superfluous hillshade.

I asked students a follow-up question about why they selected the map and put the responses into categories. Visual preference was indicated as the primary reason for picking the map with the hillshade. Here are some example student responses:

- "Because it looks more like the shape of the land"

- "because it shows hillshade. that means it shows WHY there is that precipitation"

- "because it had something else other then precipitation that could be a factor in rain fall”

- "Because it looks more real"

- "because it looked more realistic. and it seemed more convenient."

These responses indicate that some students believe that the map with the hillshade is more realistic. One of my research hypotheses was that students would prefer maps with hillshades. While it was a minority that picked the map with the hillshade, the responses confirmed my assumption. Some of the responses indicate that they chose the map with a hillshade because it provided better insight to why precipitation occurs in those places.

Most notably, the results from the previous questions show that the presence of a hillshade does not negatively impact student learning or hinder geographic thought. My results do not indicate any significant relationship between the presence of a hillshade and accuracy of student response or their response time.

\section{Discussion for Question 9}

This question, like Question 8, attempts to understand map preference among middle school students. The question presented students with a hypothetical question 
and a pair of maps to choose from to use in answering the hypothetical question. In Question 9, the phenomena being investigated was an agricultural activity, which was symbolized using a dot density map. One map included only the two necessary layers and the other contained two additional layers; a hillshade and precipitation layer. Again, $43 \%$ of the students picked the map with the superfluous layers.

Among students who picked the map without a hillshade, the specific comments about why they chose it are quite illuminating. Responses included:

- "because it only showed where they grow onions"

- "This map showed me only the two things I needed to see the other one showed me average precipitation and hillshade."

- "i picked that map because it shows me only about onions and where they grow”

- "Because it was easier to tell what was onions because there was no other colors to get onions confused with."

- "its easer to see the orange dots"

- "you don't need to see the amount of rainfall and physical features."

These responses indicate that the students understood that the additional layers were not necessary to answer the question. Among students who picked the map with the hillshade, many indicated that they had interest in the additional information available on that map:

- "Because it shows where the mountains are for more information."

- "Because it would be good to know the precipitation if you needed to grow something."

- "because it included the rainfall and if your growing something that would be important"

- “because it show more information”

This again reaffirms my concern that students will use a map with extraneous information that could negatively impact their ability to extract information from the 
map. While I appreciate some of the students’ forward-thinking in selecting a map with additional information, I was concerned that it may impact the indicated task given DeLucia (1972) and Michaelidou et al.’s (2004) research showing that the presence of terrain information hindered extraction of non-terrain info. In this case, I was concerned it would slow down or confuse students when trying to locate information about onion production by county.

As I indicated in the discussion for Question 8, there was no evidence in my research to show that a superfluous hillshade has any negative impact on response time or accuracy when using that map to answer questions. Some of the student feedback indicates that they made an association between terrain and precipitation, which demonstrates that some of the students are making connections between different phenomena.

There was a strong correlation between the students' choice of map in both Question 8 and 9 and the reason stated for selecting that map. This is not surprising, but students who picked the map with the hillshade largely cited visual preference, and students who picked the map without largely cited legibility.

\section{Summary of Discussion}

I was pleased to see that students were successful in completing this test and were successful in answer the questions using the maps. To summarize, I reviewed each of my research hypotheses and discuss what the results indicate: 


\section{The number of layers on a map will have a strong negative correlation with the accuracy of student responses to questions.}

I must reject this hypothesis. My results, with the exception of Questions 3 and 4 do not indicate any significant relationship between the number of layers present on a map and the student's score. Questions 3 and 4 did indicate a significant relationship between the number of layers and score, however, there was an unusual result where the map with the fewest layers resulted in the lowest mean score. I cannot explain the result and therefore would not submit the result as evidence supporting this hypothesis.

\section{The number of layers on a map will have a strong negative correlation with the speed of students' response to questions.}

The only significant relationship that appeared in more than one of the questions was the effect of multiple layers on response time. However, this relationship was not significant in every question, so I hesitate to make a statement to that effect.

Additionally, I found that age and class did have a significant relationship with response time in evaluating potential influence of demographic factors on the results.

\section{Students will answer questions more accurately when using maps without a hillshade layer present}

I found no evidence in any of the questions to support this hypothesis and must reject it. 


\section{Students will answer questions more quickly when using maps without a hillshade layer present}

The results of Question 1 may support this statement, however, I attribute the results in Question 1 to the effect of the number of layers rather than the presence of a hillshade. This is confirmed by the results from the remaining questions, which do not indicate any significant relationship between response time and presence of a hillshade. I must reject this hypothesis.

\section{Students will prefer maps with a hill shade layer.}

Questions 8 and 9 indicated that 40\% of students selected maps with hillshades to answer questions where the terrain information was unnecessary. The primary reason students gave for picking the maps with a hillshade was visual preference. While the majority of students chose the map without a hillshade, it is still important to understand that a large percentage of students will pick a map with unnecessary information on it. 


\section{Chapter 6: Concluding Remarks}

This research evaluated how multiple layers on web maps affect middle school students' ability to answer questions while using those maps. My first hypothesis was that as the number of thematic layers present on a map increased, the accuracy of student responses would decrease. The results do not support my first hypothesis, so I reject it. Questions 3 and 4 did show some potential for a significant relationship between the number of layers present and student scores, but the results did not reflect a decrease in score as the number of layers increased. The lowest scoring map for that question had the fewest layers.

These results do not suggest that thematic maps should be made with more layers; this would be counter to the standard cartographic practice of limiting the information present on a thematic map to as little as needed for geographic context (Dent 1996). But it does suggest that having additional thematic layers on a map is not deleterious to student's using the map to answer questions. In many ways, this result should encourage teachers to explore the use of multiple layer web maps in support of course curriculum.

My second hypothesis stated that there was a significant relationship between the number of layers present on the map and student response time while answering questions. The results indicated that in at least two of the tests, this was true. However, the results differed between questions. More importantly, there was not a positive relationship between the number of layers and response time. Students using maps with more layers did not have a significantly higher response time. 
My second hypothesis and the results were not intended to make a judgment about the importance of time in educational map use. There are situations where efficient use of a map is desirable, but that is not necessarily how students learn. It is important to consider that while the response time differences in some of my results were statistically significant, they were not practically significant. A difference of a few seconds may not have any bearing on classroom use. I used response time as a method to measure the complexity of the maps, not as an indication of student learning. However, there was some indication that the number of layers on a thematic map has a significant effect on student response time. This result begs further investigation, and would encourage future evaluation of how specific types of layers affect map use.

My study did not evaluate how certain types of layers and methods of symbolization affected response time. It is possible that some types of layers like roads may benefit the map user while others might slow the map user in extracting information. It is also possible that certain combinations of symbology, such as several layers with point symbols may exhibit a different effect on response times than maps with layers that use different types of symbology.

Bausmith and Leinhardt indicated that, at least while making maps, $7^{\text {th }}$ grade students learned more from the interconnections of geographic phenomena when there were multiple layers present on the map (1998). The feedback I collected from students in Questions 8 and 9 indicate that students did make some connections between two phenomena when recognizing the similarities between the terrain and precipitation. 
I was interested to see if the presence of an extraneous hillshade would complicate students' use of web maps. My third hypothesis was that students would prefer to use a map with a superfluous hillshade instead of a map without a hillshade. The results from Questions 8 and 9 suggest that most students will choose a map without a hillshade if none is needed. The wording of Questions 8 and 9 intentionally directed students to pick a map to answer a question about two themes, and both questions offered as a choice a map that had only those two themes present. $60 \%$ of students in Question 8 and 57\% in Question 9 recognized the intent of the question and selected the map without the hillshade. However, that left approximately $40 \%$ of the students selecting a map with irrelevant hillshade layer. Some of the student responses indicated that they picked the map with the hillshade because it looked more realistic. The result was concerning because previous research indicated that hillshades impair map readers from extracting non-landform information (DeLucia 1972). That concern led me to my fourth and fifth hypotheses, which measured the effect of hillshade presence on student accuracy and response time when answering questions using a map.

My fourth hypothesis stated that students would answer questions more accurately when using maps without a hillshade. However, the results indicated no significant difference in student scores when using maps with or without a hillshade present. This result may be attributable to the subject of the first four questions, which involved evaluating precipitation on a map. It is possible that students recognized a strong correlation between precipitation and the terrain represented by the hillshade layer. It is possible therefore, that the hillshade actually reinforced the precipitation 
information rather than obscuring it in these questions. In one sense, the hillshade served as an appropriate base layer rather than an additional thematic layer depending on the combination of other thematic layers, and on the map use required by the question the students were given. If the hillshade was functioning as a base layer rather than a thematic layer, it may have not have been an impediment to students. It is possible that the students were actually able to ignore the hillshade as a background layer and concentrate on the other thematic layers.

But what if the terrain information had not been, as some students identified it, realistic looking? Would neon colors for the hillshade dissuade the students from picking the map with terrain information? Would the garish colors have reduced any capacity the students may have had to "tune out" the hillshade?

Although I excluded Question 6 from the analysis due to problems related to question design and the results on how layers effect response time, the results potentially provide some insight regarding hillshade. Question 6 used dot density maps and did not require any terrain or precipitation information yet there was no significant difference between scores on those maps when a hillshade was or was not present.

The fifth hypothesis stated that students would answer questions more quickly when using maps without a hillshade than those maps with a hillshade. The results do not confirm this. There was no significant difference in response time for students using maps with or without a hillshade present. In most cases, the mean response time using maps with and without a hillshade were nearly identical. Again, this result surprised me. I cannot determine from my results whether students grew accustomed to the hillshade 
over the course of the test, or if the students were able to tune out the visual noise added by the hillshade layer by mentally placing it in the background, or if the hillshade simply did not complicate the map enough to affect student use. I feel there is ample room for further investigation of this topic, especially since approximately $40 \%$ of the students showed a preference for using maps with hillshades.

Since I rejected my fourth and fifth hypotheses, I am less concerned about the implications of my third hypothesis. If the presence of a hillshade does not negatively impact student scores or response times, and students were able to make an association between spatial phenomena like precipitation and terrain, including a hillshade layer in a web map may be beneficial to student learning. At the very least, I would encourage those making web maps for middle school students with multiple layers, or educators using tools like Google Earth, to include a hillshade layer for terrain portrayal.

This recommendation compliments that made by Gaspers (2007) that middle school students should be presented with more thematic maps, both in quantity and complexity, in their coursework. Her research showed that students were more capable of using thematic maps than expected. A similar recommendation was made by Michaelidou et al. (2004) that map makers should not be simplifying or removing layers from elementary textbook maps because it limits students’ ability to learn.

There has been speculation that children today are more technically savvy than previous generations and may be more successful at using information presented on computers. My research confirmed that middle school students were capable of using multi-layered thematic maps presented as part of web pages, but Michaelidou et al.'s 
research also confirmed students of the same age group as being capable of working with multi-layered maps as well (2004). Are today's students more adept at using complex maps? Are they more adept at absorbing information presented on a screen? A comparison of different age groups using multi-layered maps could be an excellent topic for further research.

I should note that the layers I used were not that complex and were not dense with features for the scale of the map. This was intentional on my part following the recommendations I collected in Appendix A. It would be interesting to see how a change in scale, an increase in the number of displayed features, or a change in location might change students' ability to deal with the noise caused by a hillshade.

I have several recommendations for changes that I would make after using and evaluating my methodology. I would like to have performed the research using truly interactive maps, where students selected which layers were displayed. While the process of measuring use of an interactive map is somewhat daunting, it would have given me a better indication of hillshade preference as well as information on how students would have interacted with the map. It would also have allowed me to see how students used different layer combinations to answer questions. I think these would be promising areas for future investigation. The results could help form recommendations on interactive map design using data collected from real interactive map use. Still, I think that my results and design recommendations (Appendix A) can inform others making layer maps for middle school students. 
I initially selected Oregon because it complimented the $5^{\text {th }}$ grade curriculum, and therefore I anticipated that schoolteachers might be more willing to participate and give up valuable class time. Using a location that was not familiar to students would avoid the bias that students' prior knowledge might have on the results. I had originally avoided using any Portland-centric questions because I expected to conduct all my tests in the Portland area. However, I ended up visiting two classrooms in McMinnville, Oregon, which was the subject of one of the questions. To determine if any bias was introduced, I compared the results from the McMinnville students to the others and found no significant differences.

This research would have benefitted from some pre-tests to get an understanding of what prior knowledge students had of the study area. The pre-testing could have helped establish a baseline of geographic information for individual students, and would have helped determine if students had learned during the process of the testing. The pretests would have been challenging given the difficulty finding enough volunteers for a single visit, but could have been valuable.

Future studies like this would benefit from a new methodology for evaluating map use. For over 50 years, the literature has largely relied on having children use maps to answer questions (Bartz 1965, Miller 1984, Michaelidou et al. 2004, Gaspers 2007). Even in this study, there were many different variables that could not be isolated. I was not able to determine from my results if certain combinations of layers had an effect on the results. There are often many inter-related processes that could have an effect on an individual's map use that could manifest in ways that affect the results of what is being 
tested. It is possible that one student's color-blindness (identified or not) may have resulted in a wrong answer but was interpreted as an effect of the combination of layers. Relying on the question and answer method of testing has limitations, but there are not currently any better options that scale well and limit the interruptions that research like this had on class time.

I am surprised by the findings of my research. I expected there to be a significant difference in student scores and response times when maps included multiple layers. I also expected hillshades to have a negative impact on student score and response times. Since students used similar maps of Oregon during the testing, it is possible that they became more familiar with the region, and therefore biasing the results. I tried to prevent this potential bias by limiting the number of overall questions, and by changing the type of map and the nature of the questions asked during the testing process.

It is important to note that while my results indicated no significant negative effect on students, adding multiple thematic layers to a map goes against convention, and it does change the complexity and readability of the maps. More research should be done in this area.

Lastly, I postulate that if this test were repeated using a tool like Google Earth instead of a non-interactive web map that was specifically designed for children, the results would be different. The map and layers used in this test were designed to complement each other when combined. In a tool like Google Earth, the individual data layers come from a variety of sources and are not prepared with combinations in mind. I 
predict that maps in Google Earth would become more challenging to use, and response times would increase as more layers were added. I suspect that this would be the case for adult map-users as well. Since there is currently no cartographer or designer curating the use of maps in tools like Google Earth, the combination of layers, the haphazard symbology, changes in scale, the differences in data quality, the poorly designed key, the mish-mash collection of data provider logos and the awkward feature labeling done by auto-label placement often result in the map equivalent of Frankenstein's monster. The confusion created by the output dilutes the effectiveness of the map, hindering its use as a learning and exploration tool. 


\section{References}

Anonymous. Oregon Department of Education. In Oregon Department of Education [database online]. Salem, OR, 2008 Available from http://www.ode.state.or.us/search/results/?id=24 (last accessed 2/23/2008 2008).

Academic Content Standards 2006. Salem,OR: Oregon Department of Education, Report Number 2.

Grade-Level Map Benchmark 2 Grade 5. 2003. Salem, OR: Oregon Department of Education.

Subject Area Endorsement Resource Manual. 2005. Salem, OR: Oregon Department of Education.

Andrienko, N., G. Andrienko, H. Voss, F. Bernardo, J. Hipolito, and U. Kretchmer. 2002. Testing the Usability of Interactive Maps in commonGIS. Cartography and Geographic Information Science 29:325-342.

Audet, R. and J. Paris. 1997. GIS Implementation Model for Schools: Assessing the Critical Concerns. Journal of Geography 96:6, 293-300.

Baker, T. R. 2005. Internet-Based GIS Mapping in Support of K-12 Education. Professional Geographer 57:44-50.

Banis, D. 2008. Atlas Survey. E-mail communication with atlas coordinator, including summary of survey on faculty preferences for on-line atlas:1-6.

Bartz, B. S., and Field Enterprises Educational Corporation. 1965. Map Design for Children. Field Enterprises Educational Corporation.

Bausmith, J. M., and G. Leinhardt. 1998. Middle-School Students' Map Construction: Understanding Complex Spatial Displays. Journal of Geography 97:93-107.

Borchert, J. R. 1987. Maps, Geography, and Geographers. Professional Geographer 39:387389.

Buckley, A. 2003. Atlas Mapping in the 21st Century. Cartography and Geographic Information Science 30:149-158.

Collier, P. 2003. The Representation of Topographic Information on Maps: The Depiction of Relief. Cartographic Journal 40:17-26.

De Lucia, A. 1972. The Effect of Shaded Relief on Map Information Accessibility. Cartographic Journal 9:4-10.

Dent, B. 1996. Cartography: Thematic Map Design (4th ed.). Dubuque, IA: Wm. C Brown Publishers. 
Dragićević, S. 2004. The Potential of Web-based GIS. Journal of Geographical Systems 6:7981.

Egbert, S. L., and T. A. Slocum. 1992. EXPLOREMAP: An Exploration System for Choropleth Maps. Annals of the Association of American Geographers 82:275-288.

Gaspers, S. L. 2007. "Questions about stuff you don't normally see on a map" A study of sixthgraders' abilities to understand quantitative thematic maps. Portland, OR: Unpublished Master’s Thesis, Portland State University Geography Department. 129 pp.

Geography Education Standards Project. 1994. Geography for Life: National Geography Standards 1994. Washington, DC: National Geographic Research and Exploration.

Harrower, M. 2004. A Look at the History and Future of Animated Maps. Cartographica 39:3342.

Kraak, M. 2004. The Role of the Map in a Web-GIS Environment. Journal of Geographical Systems 6:83-93.

-1996. Integrating Multimedia in Geographical Information Systems. IEEE Multimedia 3:59-65.

Leinhardt, G., C. Stainton, and J. M. Bausmith. 1998. Constructing Maps Collaboratively. Journal of Geography 97:19-30.

Linn, S. E. 1997. The Effectiveness of Interactive Maps in the Classroom: A Selected Example in Studying Africa. Journal of Geography 96:164-170.

Lobben, A. K., and D. K. Patton. 2003. Design Guidelines for Digital Atlases. Cartographic Perspectives 44:51-64.

MacEachren, A. M. 1995. How Maps Work: Representation, Visualization, and Design. New York : Guilford Press.

McCoy, J. 2003. Using Maps to Assess Middle School Learning. Ph.D. dissertation, University of Oregon, College of Education.

Meyer, J. W., and J. Butterick. 1999. GIS in the K-12 Curriculum: A Cautionary Note. Professional Geographer 51:571-579.

Michaelidou, E. C., B. P. Nakos, and V. P. Filippakopoulou. 2004. The Ability of Elementary School Children to Analyse General Reference and Thematic Maps. Cartographica 39:65-88.

Miller, J. W. 1982. Improving the Design of Classroom Maps: Experimental Comparison of Alternative Formats. Journal of geography (Houston) 81:51-55. 
Morgan, A. 2008. Grade-Level Benchmarks. E-mail communication with documentation contact on Grade-Level Benchmark and Content Standards site:1.

Muir, S. P. 1985. Understanding and Improving Students' Map Reading Skills. The Elementary School Journal 86:206-216.

Patterson, T. C. 2007. Google Earth as a (Not Just) Geography Education Tool. Journal of geography (Houston) 106:145-152.

Pedersen, P., P. Farrell, and E. McPhee. 2005. Paper Versus Pixel: Effectiveness of Paper Versus Electronic Maps to Teach Map Reading Skills in an Introductory Physical Geography Course. Journal of Geography 104:195-202.

Peterson, M. P. 2006. The Internet and Multimedia Cartography. In Multimedia Cartography, Second Edition, ed. Cartwright,W.E., Peterson, M.P., Gartner, G., 35-50. Berlin: Springer.

Roth, R. E., and M. Harrower. 2008. Addressing Map Interface Usability: Learning from the Lakeshore Nature Preserve Interactive Map. Cartographic Perspectives 60:46-66.

Springer, N. 1999. Designing Dynamic Maps. Cartographic Perspectives 33:60-63.

Trifonoff, K. M. 1995. Going beyond location: Thematic Maps in the Early Elementary Grades. Journal of geography (Houston) 94:368-374.

1994. The Role of Interactive Technology in Cartography Instruction. Pennsylvania Geographer 32:26-36.

Waters, N. M., and De Leeuw, G. J. A. 1987. Computer Atlases to Complement Printed Atlases. Cartographica 24:118-133.

Weinman, L. Non-Dithering Colors in Browsers. Available from http://www.lynda.com/hex.asp (last accessed 3/16/2008 2008).

Wiegand, P. 2006. Learning and Teaching with Maps. London: Routledge. 2003. School Students' Understanding of Choropleth Maps: Evidence from Collaborative Mapmaking Using GIS. Journal of Geography 102:234-242.

Williams, D., D. O’Brien, and E. Kramers. 2003. The Atlas of Canada Web Mapping: The User counts. Cartographic Perspectives 44:8-28.

Wonders, L. J. 1980. The Junior Atlas of Alberta: Introducing New Mapping Techniques to Young Students. Canadian Geographer 24:306-311. 


\section{Appendix A: Design Considerations for Thematic Maps Based on Audience}

Compiled by author from multiple sources

This appendix combines cartographic design guidelines compiled from multiple sources. I have compiled this list because there is no set list of recommendations for web-based maps for children. These guidelines were used to inform design choices made while making maps for use in this project. In many cases, the suggestions are the same for more than one category such as number of typefaces used and type placement to reinforce feature location. In others, the recommendations are in disagreement, as with the use of pictorial symbols or color saturation.

I used my own judgment to select which design guideline to apply when there was conflict. In the case of color saturation, children prefer saturated colors (Buckingham and Harrower 2007), though it is recommended to avoid saturated when working with web maps (Springer 1999). I applied a non-saturated color scheme for representing precipitation in the Average Annual Precipitation map largely for aesthetic reasons. The chosen color scheme works well both when the map is viewed with a hillshade and without. Conversely, in the Agricultural Products map, I used saturated colors for the point symbols to increase visibility.

The overall layout was selected to compliment a 1024 by 768 pixel display. 


\begin{tabular}{|c|c|c|c|}
\hline $\begin{array}{l}\text { Design } \\
\text { Considerations }\end{array}$ & General Recommendations & Design Choices for Children & Design Choices for Web Maps \\
\hline $\begin{array}{l}\text { Visual } \\
\text { Hierarchy }\end{array}$ & $\begin{array}{l}\text { Use visual differences to highlight } \\
\text { important information } \\
\text { Reduce peripheral detail to highlight } \\
\text { important information } \\
\text { Important information is easier to } \\
\text { highlight when map has clear purpose } \\
\text { (Dent 1996) } \\
\text { Use of texture is great way to accentuate } \\
\text { difference in land/water difference }\end{array}$ & & $\begin{array}{l}\text { Important symbols should be designed to } \\
\text { give "maximum visibility" (Miller 1999) } \\
\text { Interactive flourishes like rollovers, and } \\
\text { (shudder) blinking to give visual } \\
\text { significance to important elements. }\end{array}$ \\
\hline Generalization & $\begin{array}{l}\text { Systematic reduction of detail to enhance } \\
\text { point of map (Krygier and Wood 2005) } \\
\text { Simplification can enhance visibility, } \\
\text { reduce clutter, reduce the size of the map } \\
\text { file (digital) (Krygier and Wood 2005) } \\
\text { Selection of important elements, } \\
\text { exclusion of unimportant (Krygier and } \\
\text { Wood 2005) } \\
\text { Smoothing reduces angularity, enforces } \\
\text { natural features like rivers (Krygier and } \\
\text { Wood 2005) } \\
\text { Displacement increases visual clarity at } \\
\text { the cost of accuracy (Krygier and Wood } \\
\text { 2005) } \\
\text { Enhancement adds detail to communicate } \\
\text { more about a feature that is not apparent } \\
\text { from the map (Krygier and Wood 2005) } \\
\text { Changing dimension from area to point } \\
\text { symbols can improve legibility (Krygier } \\
\text { and Wood 2005) }\end{array}$ & $\begin{array}{l}\text { Generalization often leads to great } \\
\text { misunderstandings about physical features. } \\
\text { Understand that your omissions will } \\
\text { communicate things you don't intend. } \\
\text { Generalize in a way that benefits the } \\
\text { relationship you're trying to illustrate. } \\
\text { (Wiegand 2006) } \\
\text { Children have an easier time locating items } \\
\text { when there is low information density, but } \\
\text { develop better understanding of a place's } \\
\text { surroundings when more information is } \\
\text { included. (Wiegand 2006) }\end{array}$ & $\begin{array}{l}\text { Dynamic zooming allows for multiple } \\
\text { scales in single map. Select scales } \\
\text { appropriate to data source so information } \\
\text { is accurate } \\
\text { Less graphical complexity makes digital } \\
\text { maps easier to use (Springer 1999, } \\
\text { Lobben 2003) } \\
\text { Zooming allows selection of data based } \\
\text { on scale (Springer 1999, Lobben 2003) } \\
\text { Cartographer must be involved in } \\
\text { selecting appropriate data for various } \\
\text { levels of "zoom" (van den Worm 2001) } \\
\text { Rely on vector data when possible to } \\
\text { keep download sizes appropriate (van den } \\
\text { Worm 2001) }\end{array}$ \\
\hline
\end{tabular}




\begin{tabular}{|c|c|c|c|}
\hline $\begin{array}{l}\text { Design } \\
\text { Considerations }\end{array}$ & General Recommendations & Design Choices for Children & Design Choices for Web Maps \\
\hline Classification & $\begin{array}{l}\text { Reduce the number of classes to simplify } \\
\text { map (Krygier and Wood 2005) } \\
4 \text {-8 classes best for qualitative area maps } \\
\text { (Krygier and Wood 2005) }\end{array}$ & $\begin{array}{l}\text { Children perform better with qualitative } \\
\text { thematic maps (Gerber 1984) }\end{array}$ & \\
\hline Symbology & $\begin{array}{l}\text { Choice of symbology can be affected by } \\
\text { convention, scale data is displayed at, } \\
\text { nature of the data (qualitative vs. } \\
\text { quantitative), relationship between data } \\
\text { on the map (Krygier and Wood 2005) } \\
\text { Differences in qualitative data are best } \\
\text { expressed by using shape and color as the } \\
\text { visual variable (Krygier and Wood 2005) } \\
\text { Differences in quantitative data are best } \\
\text { expressed using size and color as the } \\
\text { visual variable (Krygier and Wood 2005) } \\
\text { Enhance figure-ground to give flat maps } \\
\text { "depth" (Krygier and Wood 2005) }\end{array}$ & $\begin{array}{l}\text { Some symbology such as blue for water and } \\
\text { black dots for cities are almost universally } \\
\text { understood, but others, such as the use of color } \\
\text { can confuse map readers (Wiegand 2006, } \\
\text { Michaelidou) } \\
\text { Students may have trouble matching symbols } \\
\text { on key and on map (Wiegand 2006) } \\
\text { Reading key and understanding key are very } \\
\text { different. Key should be descriptive in child's } \\
\text { vocabulary, and should describe each symbol in } \\
\text { detail (Miller 1982, Wiegand 2006) } \\
\text { Relief is difficult to communicate, though hill } \\
\text { shades seem best for helping students } \\
\text { understand relative rather than absolute changes } \\
\text { in relief. (Wiegand 2006) } \\
\text { Hill shades are best for communicating slope } \\
\text { and elevation (Michaelidou 2004) } \\
\text { Hypsometric coloring for elevation tends to } \\
\text { confuse terrain and elevation in children (Muir } \\
\text { 1985, Michaelidou 2004) } \\
\text { Single color backgrounds make it easier for } \\
\text { students to compare relationships between } \\
\text { locations (Michaelidou 2004) though Bartz } \\
\text { (1965) recommends against using solid } \\
\text { background if terrain information is important. }\end{array}$ & $\begin{array}{l}\text { Key should have "embedded, self- } \\
\text { describing symbols" which display more } \\
\text { information when interacted with. (Miller } \\
\text { 1999, Lobben 2003) } \\
\text { Key should be structured based on } \\
\text { hierarchy of symbols and sub-symbols } \\
\text { (Lobben 2003) } \\
\text { Use of drop-shadow effect on symbols } \\
\text { can induce interaction (Kraak 2004) } \\
\text { Symbols on static or dynamic web maps } \\
\text { should mimic those on print and follow } \\
\text { many of the same guidelines, but can } \\
\text { include click-to-interact abilities for } \\
\text { additional data (van den Worms 2001) } \\
\text { Avoid pop-up, movable, and static keys } \\
\text { that leave map frame when zoomed (van } \\
\text { den Worms 2001) } \\
\text { Point symbols are often easiest to } \\
\text { represent on web maps but often connote } \\
\text { some interactivity (van den Worms 2001) } \\
\text { Point symbols should be enlarged to } \\
\text { make them more easily noticed } \\
\text { Pictographic symbols must often be } \\
\text { oversized to make them visible on web } \\
\text { maps, which }\end{array}$ \\
\hline
\end{tabular}




\begin{tabular}{|c|c|c|c|}
\hline $\begin{array}{l}\text { Design } \\
\text { Considerations }\end{array}$ & General Recommendations & Design Choices for Children & Design Choices for Web Maps \\
\hline $\begin{array}{l}\text { Symbology } \\
\text { continued }\end{array}$ & & $\begin{array}{l}\text { Mimetic or pictographic symbols are useful } \\
\text { when symbol and item are familiar to students } \\
\text { (Wiegand 2006), and are preferred over abstract } \\
\text { geometric symbols (Michaelidou 2007) } \\
\text { Dot maps are useful in communicating quantity } \\
\text { (Wiegand 2006, Gaspers 2007), though } \\
\text { explaining the symbology can be complex. } \\
\text { (Wiegand 2006) } \\
\text { With choropleth maps, darker should mean } \\
\text { more. } \\
\text { Include “obvious" items like land and sea in } \\
\text { key, make key comprehensive. (Bartz 1965, } \\
\text { Wiegand 2006) } \\
\text { Children prefer vibrant color and high contrast } \\
\text { (Sorrell 1974) } \\
\text { Adding descriptive text to numeric labels in a } \\
\text { key can help students understand what that } \\
\text { number means in the real world (Wiegand } \\
\text { 2006) } \\
\text { Mark national and state boundaries clearly and } \\
\text { include them on the key (Miller 1982) } \\
\text { Symbol on key and map should be same } \\
\text { size (Bartz 1965) } \\
\text { Extend boundaries over water even when water } \\
\text { forms a political boundary (Bartz 1965) } \\
\text { Include boundaries in key (Bartz 1965) }\end{array}$ & $\begin{array}{l}\text { interferes with the map (van den Worms } \\
\text { 2001) } \\
\text { Use of interesting textures or fills for area } \\
\text { symbols can enhance the aesthetic and } \\
\text { figure-ground relationship on maps, but } \\
\text { can also increase files size and distract } \\
\text { from other important features (van den } \\
\text { Worm 2001) } \\
\text { Lines often render bolder than intended. } \\
\text { Lines can be softened by making line } \\
\text { color similar to background. (Springer } \\
\text { 1999) }\end{array}$ \\
\hline
\end{tabular}




\begin{tabular}{|c|c|c|c|}
\hline $\begin{array}{l}\text { Design } \\
\text { Considerations }\end{array}$ & General Recommendations & Design Choices for Children & Design Choices for Web Maps \\
\hline Type & $\begin{array}{l}\text { Legibility comes from appropriate } \\
\text { selection of type face, placement and } \\
\text { spacing (Dent 1996) } \\
\text { "Harmony" can come from a single font } \\
\text { by mixing roman and italic of same font } \\
\text { as well as changing weight. (Dent 1996) } \\
\text { Avoid using more than 4-6 different type } \\
\text { size (Dent 1996) } \\
\text { Use lowercase to label point symbols and } \\
\text { uppercase to represent area (Dent 1996) } \\
\text { Type placement should reinforce } \\
\text { geographic feature, but priority to } \\
\text { placement of type near a phenomena goes } \\
\text { to top-right corner, top-left corner, } \\
\text { bottom-right corner, etc.. (Dent 1996) }\end{array}$ & $\begin{array}{l}\text { There is a slight preference for sans-serif fonts } \\
\text { when working with students (Sandford 1978, } \\
\text { Gerber 1982) } \\
\text { Use less than } 4 \text { type sizes which have highest } \\
\text { clarity and contrast (Miller 1982) } \\
\text { Lowercase type is easier to read because the } \\
\text { descenders and ascenders make letters easier to } \\
\text { recognize (Wiegand 2006) } \\
\text { Type placement is especially important for } \\
\text { children and should reinforce location of object } \\
\text { (Bartz 1965, Wiegand 2006) } \\
\text { Using full caps for some items gives students a } \\
\text { visual clue about that feature and can help with } \\
\text { scanning and identifying (Wiegand 2006) } \\
\text { Place labels in compact, horizontal placement } \\
\text { next to features with exception of rivers and } \\
\text { mountain ranges (Bartz 1965, Miller 1982) } \\
\text { Exaggerate sizes between levels of type as } \\
\text { children often miss difference (Bartz 1965) }\end{array}$ & $\begin{array}{l}\text { Stick with standard font sets like Times, } \\
\text { Arial, and Helvetica since they are likely } \\
\text { installed on most workstations (Springer } \\
\text { 1999, van den Worms 2001, Lobben } \\
\text { 2003) } \\
\text { Reduce use of type by incorporating } \\
\text { graphic representations (Buziek 1999) but } \\
\text { complimented by clickable symbols } \\
\text { (Lobben 2003) } \\
\text { Capital lettering on web maps may } \\
\text { improve readability, especially with small } \\
\text { fonts? (van den Worms 2001) } \\
\text { Adding white outline to text can improve } \\
\text { figure-ground relationship (van den } \\
\text { Worms 2001) } \\
\text { Do not use type smaller than } 7 \text { points } \\
\text { (Feringa 2001) }\end{array}$ \\
\hline Color & & $\begin{array}{l}\text { Color is a source of problems for young map- } \\
\text { readers. } \\
\text { Color for relief or elevation is often confused } \\
\text { with vegetation cover. (Wiegand } 2006 \\
\text { Children prefer saturated colors, though use of } \\
\text { saturated colors has no impact on their map use } \\
\text { (Buckingham and Harrower 2007) }\end{array}$ & $\begin{array}{l}\text { Refer to Color Brewer for samples color } \\
\text { sets that render well on a variety of } \\
\text { screens. (Lobben 2003) } \\
\text { Adhering to the "web-safe" palette of } 216 \\
\text { colors ensures accurate rendering of } \\
\text { colors in any browser (Springer 1999) } \\
\text { and can help reduce file size (Feringa } \\
\text { 2001) } \\
\text { Avoid saturated colors (Springer 1999) }\end{array}$ \\
\hline
\end{tabular}




\begin{tabular}{|c|c|c|c|}
\hline $\begin{array}{l}\text { Design } \\
\text { Considerations }\end{array}$ & General Recommendations & Design Choices for Children & Design Choices for Web Maps \\
\hline Layout & $\begin{array}{l}\text { Focus follows normal reading direction } \\
\text { from top-left to center (Krygier and } \\
\text { Wood 2005) } \\
\text { Place items using a grid to enhance look, } \\
\text { reduce complexity (Krygier and Wood } \\
\text { 2005) } \\
\text { Balance map elements to enhance } \\
\text { understanding (Krygier and Wood 2005) } \\
\text { include title, legend, scale, description, } \\
\text { directional indicator, source, credits, } \\
\text { border, insets (Krygier and Wood 2005) }\end{array}$ & $\begin{array}{l}\text { Graphic scale bars with labeling above bar } \\
\text { allows for use of ruler to measure distances } \\
\text { without obscuring distance. (Wiegand 2006) } \\
\text { Textual scale statements are too confusing. } \\
\text { (Wiegand 2006) } \\
\text { Locator inset maps are very useful in tying map } \\
\text { to larger geographic region, though inset maps } \\
\text { can also add confusion when they place items } \\
\text { from out of the frame within the map. (Wiegand } \\
\text { 2006) } \\
\text { Concrete and explanatory titles are especially } \\
\text { useful when language is intended for age group. } \\
\text { (Wiegand 2006) } \\
\text { Include simple compass rose with all } 4 \\
\text { directions labeled (Bartz 1965, Miller 1982) } \\
\text { Include latitude and longitude grid labeled with } \\
\text { degrees (Bartz 1965, Miller 1982) } \\
\text { Scale should be conspicuous and differ visually } \\
\text { from the design of the map (Bartz 1965) } \\
\text { Always start scale with "0" (Bartz 1965)j } \\
\text { Describe, or "Un-code" the scale in text with } \\
\text { the graphic scale (Bartz 1965, 29) } \\
\text { Consider areal scales for maps showing density. } \\
\text { (Bartz 1965) }\end{array}$ & $\begin{array}{l}\text { Layout should compliment a variety of } \\
\text { display sizes and meet minimum display } \\
\text { standards (Lobben 2003) } \\
\text { Focus viewer attention on map and data } \\
\text { rather than on interface by keeping a } \\
\text { consistent, structured layout (Lobben } \\
\text { 2003) } \\
\text { Use of introduction or home button on } \\
\text { map will help users explore the map and } \\
\text { interface more comfortably (Lobben } \\
\text { 2003) } \\
\text { Expanding menus are too complex for } \\
\text { most users (Williams et al. 2003) } \\
\text { Web maps should have clear layout and } \\
\text { should avoid requiring the user to scroll } \\
\text { to view the entire map. (Richard 2000, } \\
\text { Feringa 2001) } \\
\text { Divide interface in to segments of } \\
\text { interaction or navigation, map, and } \\
\text { information, with the map constituting } \\
\text { the largest part of the interface. (Richard } \\
\text { 2000) } \\
\text { Avoid minimalistic tool icons as they are } \\
\text { often too simple for most users to } \\
\text { understand (Roth 2008) } \\
\text { Choose navigation methods most } \\
\text { appropriate to map task and size of map, } \\
\text { then consider adding alternate method for } \\
\text { backup (Roth 2008) } \\
\text { Use real map content when designing } \\
\text { interface, not Loren Ipsum content (Roth } \\
\text { 2008) }\end{array}$ \\
\hline
\end{tabular}




\begin{tabular}{|c|c|c|c|}
\hline $\begin{array}{l}\text { Design } \\
\text { Considerations }\end{array}$ & General Recommendations & Design Choices for Children & Design Choices for Web Maps \\
\hline Other & & $\begin{array}{l}\text { Unknown classroom environment may impact } \\
\text { students' understanding of and access to maps. }\end{array}$ & $\begin{array}{l}\text { Display situation unknown so design for } \\
\text { the minimum display expected. } \\
\text { "solving the resolution problem requires } \\
\text { that the cartographer implement design } \\
\text { guidelines for the digital map that may be } \\
\text { distinctly different than those adopted for } \\
\text { the printed map" (Lobben 2003) } \\
\text { Include ability to query map data for } \\
\text { better interactivity and exploration } \\
\text { (Lobben 2003) } \\
\text { Most preferred features are } \\
\text { Zoom in \& out, Print, View entire key, } \\
\text { Move about map } \\
\text { Get information on features (Williams et } \\
\text { al. 2003) } \\
\text { Get user input and do reiterative designs } \\
\text { (Williams et al. 2003) } \\
\text { Limit "levels of zoom" to a small set on } \\
\text { large format maps }\end{array}$ \\
\hline
\end{tabular}




\title{
Appendix B: Script for Map Introduction
}

\author{
Hi Everyone,
}

My name is Andy and I'm a student like all of you. I'm taking geography classes at Portland State University, and before I can finish, I have to do a big project. I'm hoping you can help me out with my project since you all have a fresh set of eyes and probably see things better than me.

My project is to make web based maps that students like you can use in your classrooms when you're studying about Oregon. The best way for you to help me is to answer some questions using these maps so I can see what I need to fix. You won't be graded on this, and I won't even know who picked which answers. Luckily, there aren't any wrong answers. I'm not testing you, you're testing the map, or in a way, testing me. And my teachers are going to grade me.

First I want to explain what is going to happen. I'm going to show you how the map works with an example, then you're going to answer a few questions yourselves to see how it works.

The map is part of a web page. You'll be using the mouse select answers and move to the next question. You will be using the keyboard to type some of your answers. You will see a map followed by a question. The maps may look alike and the questions may seem similar, but I want you to answer the question the best you can using only the map in front of you. When you pick your answer, you will click Save and Next Question to see the next map.

First, I'd like to show you an example on the screen up here. Here is the map. On the left side is a gray area called the key that shows what the stuff on the map represents. The far right side has a timer and shows you which questions you have answered, and which you have not. Remember, you are not being timed, that's just part of the software. Here below the are the questions. Here is the scale bar. An here is the button to save your answer. Once you save the answer, you cannot go back, so make sure you pick the answer you want before saving it.

Let's look at the map a little more closely. Notice how the symbols on the key match something in the map? That will help you identify what all the lines and points and colors on the map mean. There is also a description next to each layer in the key if you want to know what each symbol represents.

Here's what each layer means. County Seats are the city in each county that houses the county government. Highways are major roads. Counties are political subgroups of the State that have their own government powers and responsibilities. Average precipitation is roughly how much water falls at some place in a given year either as rain, snow, sleet or hail. Ecoregions are natural areas that have 
similar geography and climate, and the hillshade is used to show elevation, or how hilly a place is. You will also see some dots that show you where different agricultural products are from. Some dots will represent a certain number of, say onions, and some will represent a certain number of dairy cows.

Now, lets look at a sample question. The first question is "what color shows areas that get the most precipitation?" Does everyone know what precipitation is? Well, like the key says, it's the amount of water that falls in the form of snow and rain. If we look at the key, we see that the dark blue color is used to show places that get the most rain. The key says that it gets between 110 and 203 inches of rain each year! Lets move on to another sample. Does anyone have any questions?

"Which county gets the heaviest precipitation?” Ok, for this question we're going to need to look at the precipitation and the counties. Now, in our sample, it gives us four options: Harney, Crook, Jackson, or Clatsop. Lets look at each of those counties. First, let's find Harney County, then Crook and so on. Now, if we compare the precipitation colors for each county, I think we can see that Clatsop County is the wettest. Are there any questions?

Ok, now it's your turn to answer a few questions. When you're ready to start, click the begin button and you'll get your first question. Read the question and do your best to answer the question. Once you're done with the question, hit the save button and move on to the next question. In some questions, you get to type your response, such as why you picked a certain answer. After you've completed all the questions, you'll see a finish button, which means you're done.

Please sit patiently while everyone finishes. Thank you so much for all your help. 


\title{
Appendix C: Informational Flyer
}

\section{Layer map use by $5^{\text {th }}$ thru $7^{\text {th }}$ grade students}

\author{
Andy Freed, Masters Candidate in Geography at Portland State University
}

\section{Introduction}

The World Wide Web is an increasingly popular way to deliver maps for use in personal navigation, exploration, and in support of classroom activities and learning. One type of map, layer maps, are popular because they let the map user pick what kind of information to place on a map. You can toggle different thematic information to display on a map depending on what you're interested in looking at.

In this research, I'm examining how layer maps affect $5^{\text {th }}-7$ th graders ability to answer geographic questions in support of their course work. Layer maps can be powerful tools for exploring geographic relationships, but they can also make maps cluttered and difficult to read. I want to see how the number of layers on a map affects how well a student can answer questions, and how long it takes them to answer questions. I will also be able to see if there are certain types of layers, like a hillshade that shows topography either positively or negatively affect a student's ability to answer questions. The questions are based off the Oregon Department of Education's Curriculum Guidelines for $5^{\text {th }}$ graders.

\section{Your students' role}

In order to collect information about layer map usage, I need to have several classrooms of students participate in a quick exercise that will present students with a series of maps and ask them to answer questions using those maps. The

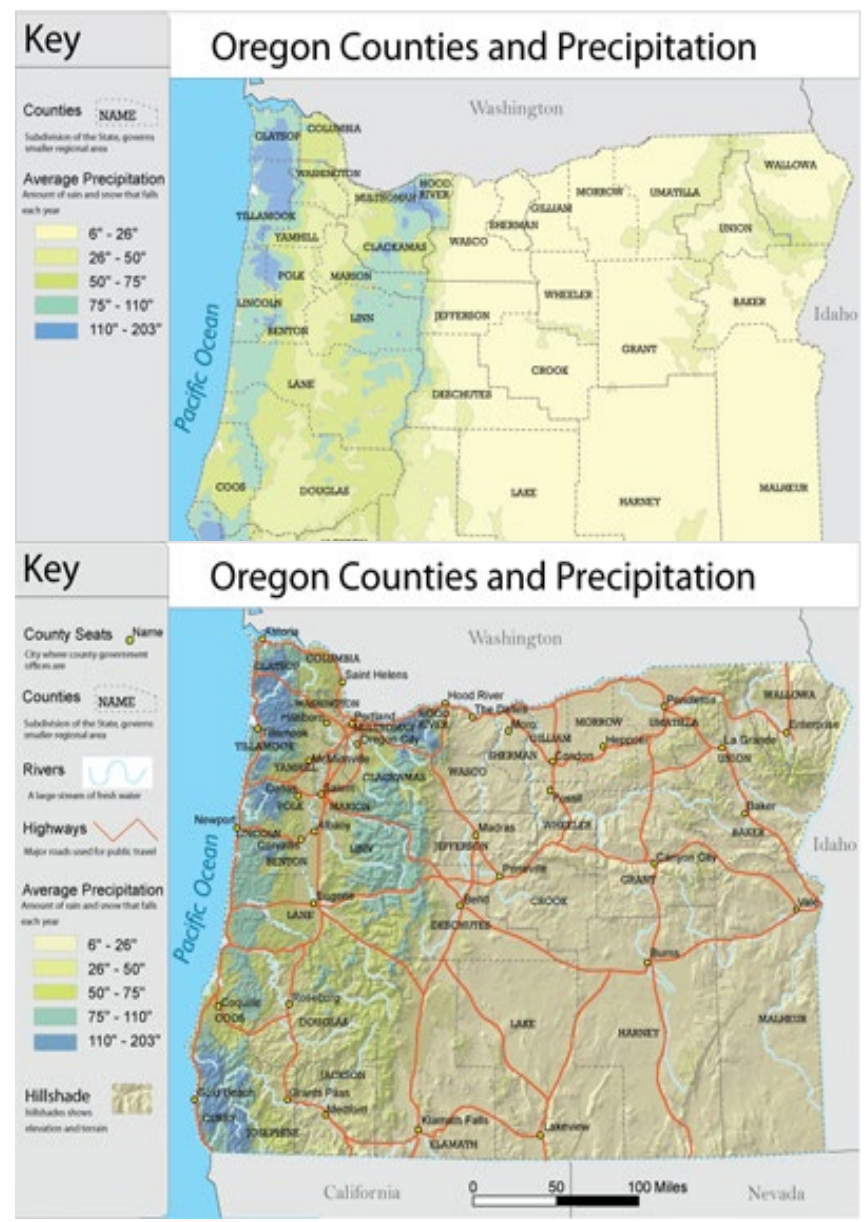
exercise is not graded, the information is anonymous, and no student names will be recorded. The exercise is a critique of the map design techniques, not the student's learning or prior education.

The exercise should take about 30 minutes, but will require access to a computer lab at your school. If you would be willing to share some of your class time for this exercise, I would love to hear from you.

Contact Andy Freed with questions. afreed@pdx.edu or 503-860-4173 


\section{Appendix D: Sample of Map Interface and Question}

A sample of the map interface and example question is shown below. The question reads, "Look at the map above the question. Which of the following regions gets the most precipitation.” This is an example of what Question 1 might look like for students who were assigned the map with only 2 layers.

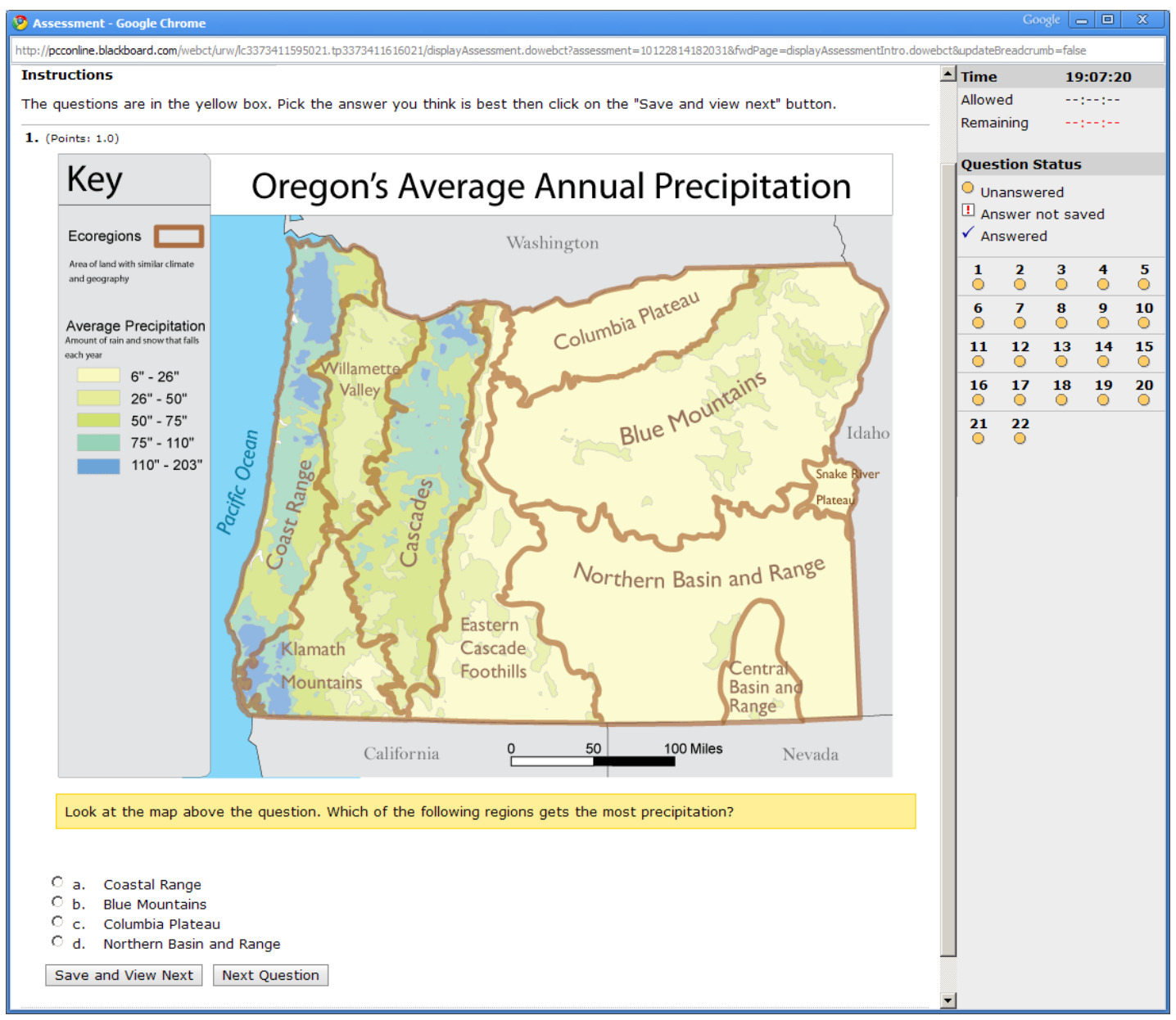

The multiple-choice options are:
a. Coastal Range
b. Blue Mountains
c. Columbia Plateau
d. Northern Basin and Range 
The correct answer is "Coastal Range."

Here is another sample question with seven layer map. The question reads, "Look at the map above the question. Which of the following regions gets the most precipitation.” (Size reduced to fit printed page.) It is an example of Question 2, and the map includes 7 layers.

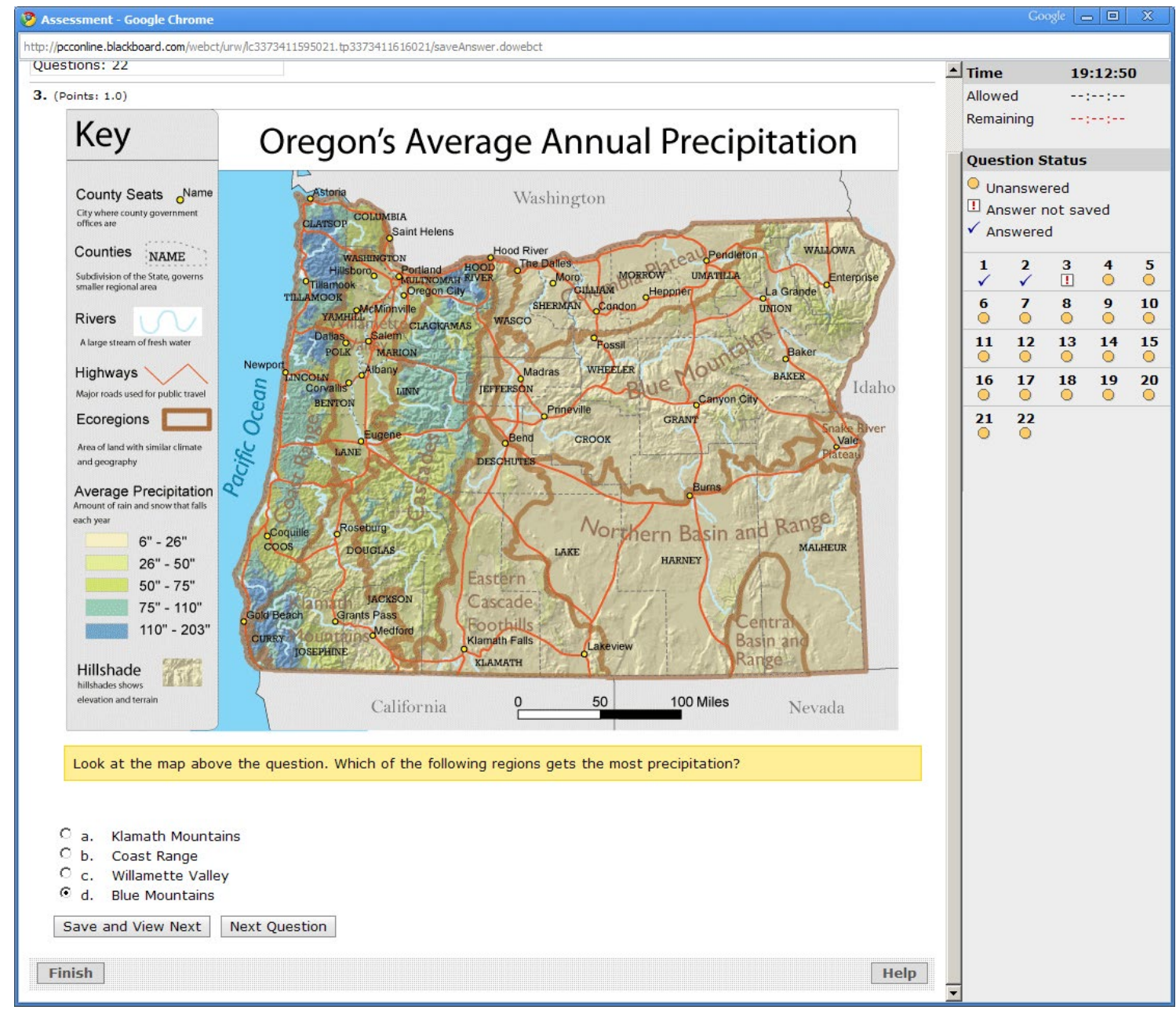

The multiple-choice options are:
a. Klamath Mountains
b. Coastal Range
c. Willamette Valley 


\section{d. Blue Mountains}

The correct answer is also “Coastal Range.”

Here is an example of Question 3 and 4. The question reads "Find Albany on the map. It is south of Portland. About how many inches of precipitation does it get?” and the student was presented a map with 6 layers; County Seats, Counties, Rivers, Highways, Average Precipitation and a hillshade.

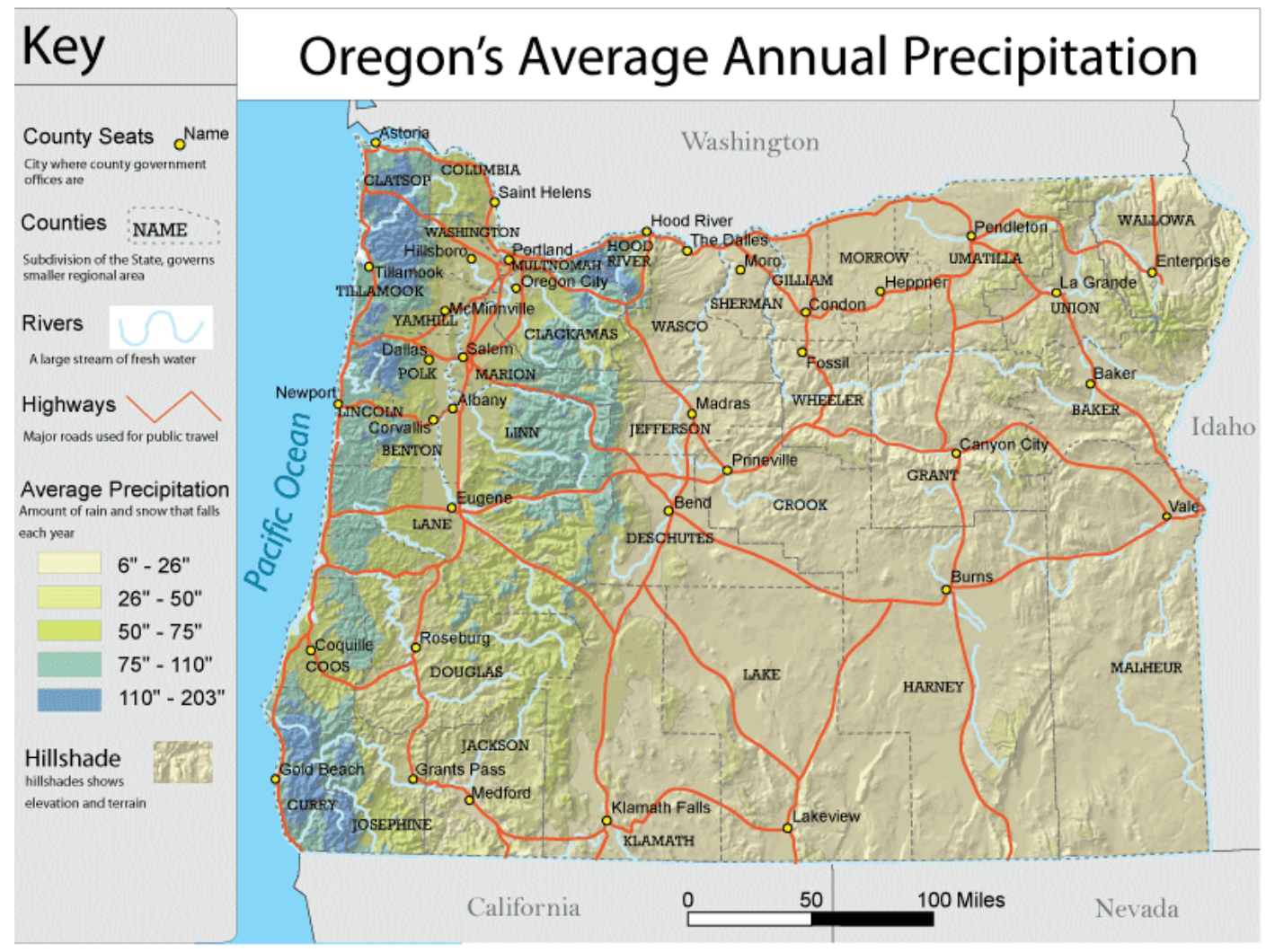

Find Albany on the map. It is south of Portland. About how many inches of precipitation does it get?

The correct answer is 50”-75” per year. 
Here is an example of question 6, where a student is presented with a map showing 7 layers and the following question: "Which county do you think grows the most pears?”

The layers include Onions, Potatoes, Beef Cows, Dairy Cows, Pears, and Counties.

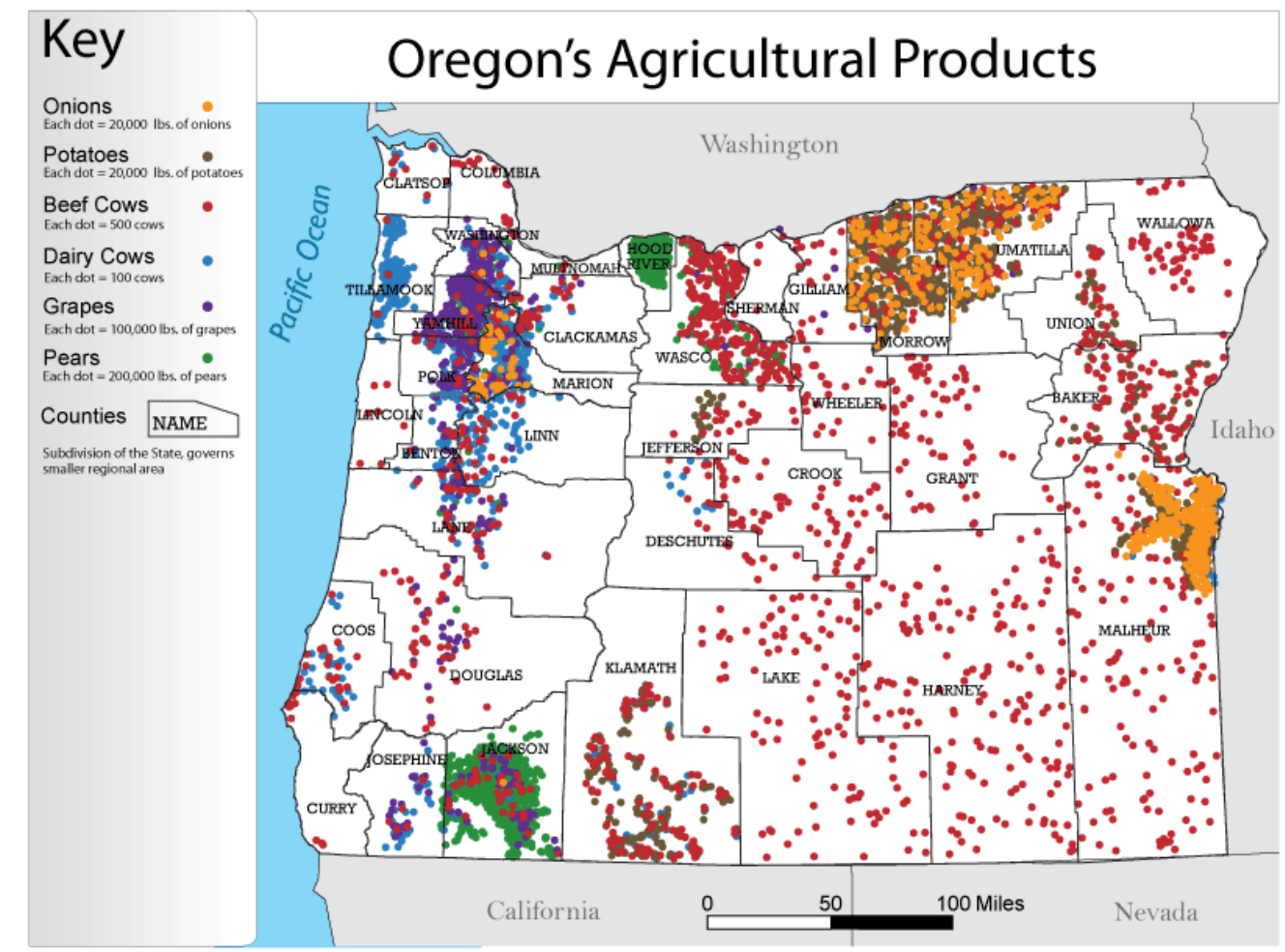

Nhich county do you think grows the most pears?

The correct answer is Jackson County. 


\title{
Appendix E: Human Subjects Research Review Committee Approval
}

\section{P Portland State}

\author{
Human Subjects Research Review Committee \\ Post Office Box $751 \quad 503-725-4288$ tel \\ Portland, Oregon 97207-0751 503-725-3416 fax \\ hsrre@lists.pdx.edu
}

November 16, 2009

To: Andrew Freed

From: Nancy Koroloff, HSRRC Chair

Re: Approval of your application titled, "Map Construction Using Layers" (HSRRC Proposal $\# 091113$ ).

Dear Andrew,

In accordance with your request, the Human Subjects Research Review Committee has reviewed your proposal referenced above for compliance with DHHS policies and regulations covering the protection of human subjects. The committee is satisfied that your provisions for protecting the rights and welfare of all subjects participating in the research are adequate, and your project is approved. Please note the following requirements:

Changes to Protocol: Any changes in the proposed study, whether to procedures, survey instruments, consent forms or cover letters, must be outlined and submitted to the Chair of the HSRRC immediately. The proposed changes cannot be implemented before they have been reviewed and approved by the Committee.

Continuing Review: This approval will expire on November 16,2010. It is the investigator's responsibility to ensure that a Continuing Review Report (available in ORSP) of the status of the project is submitted to the HSRRC two months before the expiration date, and that approval of the study is kept current.

Adverse Reactions: If any adverse reactions occur as a result of this study, you are required to notify the Chair of the HSRRC immediately. If the problem is serious, approval may be withdrawn pending an investigation by the Committee.

Completion of Study: Please notify the Chair of the Human Subjects Research Review Committee (campus mail code ORSP) as soon as your research has been completed. Study records, including protocols and signed consent forms for each participant, must be kept by the investigator in a secure location for three years following completion of the study.

If you have questions or concerns, please contact the HSRRC in the Office of Research and Sponsored Projects (ORSP), (503) 725-4288, 6th Floor, Unitus Building, 4th \& Lincoln.

Cc: Joseph Poracsky 


\section{P Portland St State}

Human Subjects Research Review Committee

Post Office Box 75

503-725-4288 te

Portland, Oregon 97207-0751 503-725-3416 fax

hsrre@lists.pdx.edu

October 1,2010

To: $\quad$ Andrew Freed

From: Mary Oschwald, HSRRC Chair

Re: $\quad$ HSRRC renewal of approval for your project titled, "Map Construction Using Layers" (HSRRC Proposal \# 091113).

As part of the Committee's continuing review, the Human Subjects Research Review Committee has reviewed your above referenced project for compliance with Department of Health and Human Services policies and regulations on the protection of human subjects.

The Committee is satisfied that your provisions for protecting the rights and welfare of all subjects participating in the research are adequate. Your project is renewed and this approval will expire on November 16,2011. Please note the following policies:

1. If the project continues beyond the expiration date, the investigator needs to submit a Continuing Review Report form two months before the expiration date. The form is available at www.rsp.pdx.edu/compliance_human.php and in the Office of Research \& Strategic Partnerships.

2. To add this project's continuing review to the HSRRC/IRB meeting agenda, please refer to the HSRRC/IRB meeting schedule. Submit the report, and the required number of copies, by the submission deadline that is approximately two months before the project's expiration date. The HSRRC/IRB needs two months to do a continuing review of the project, so it is extremely important that you meet the committee's submission deadline.

3. If this project finishes before the expiration date, please contact the HSRRC administrator so that the file can be closed and records updated. It is the investigator's responsibility to keep the approval status current. If the project's approval expires while the project is active, the investigator must complete a new application and submit it for a new HSRRC review. In addition, any data collected after the expiration date cannot be used in the research. Please don't let this happen!

If you have questions or concerns, please contact the HSRRC in the Office of Research and Strategic Partnerships (ORSP), 503-725-4288, Unitus Building, 6th Floor, 4th and Lincoln Streets.

Cc: Joseph Poracsky 